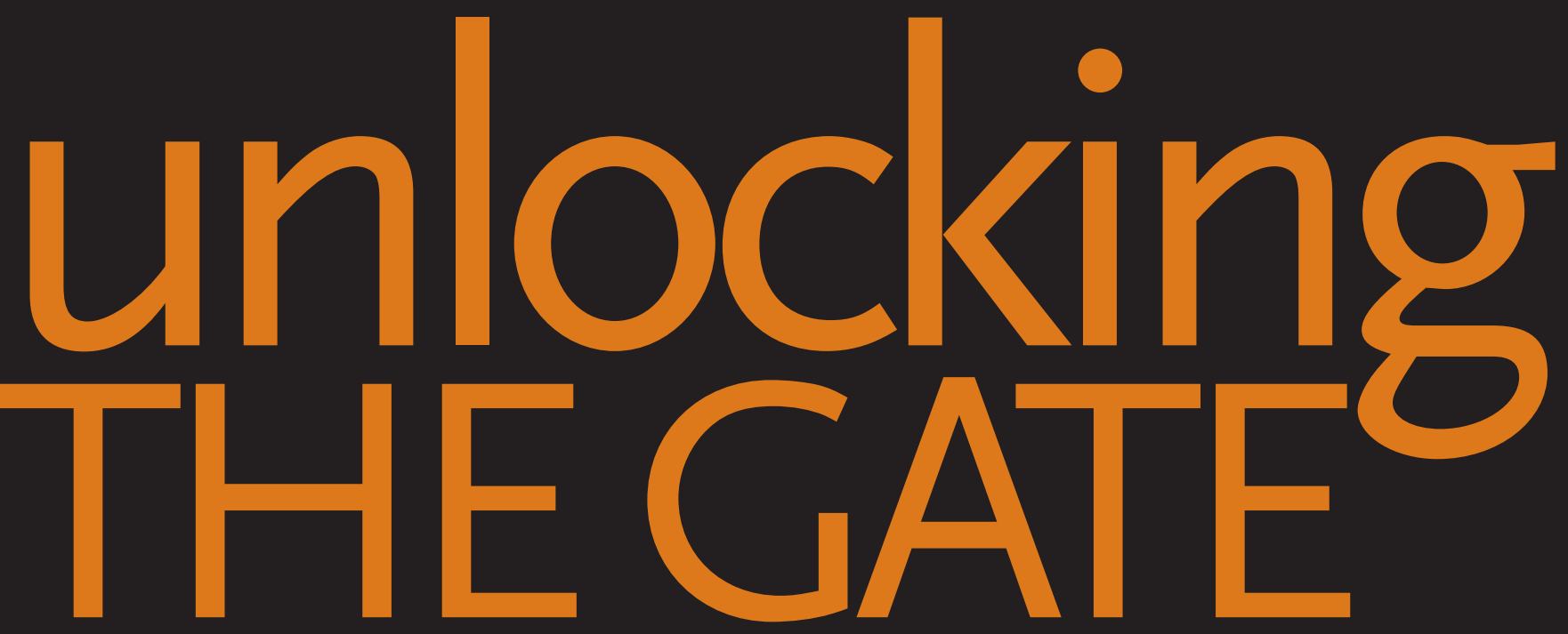

What We Know About

Improving Developmental Education

Elizabeth Zachry Rutschow

Emily Schneider

June 2011 



\section{Unlocking the Gate \\ What We Know About Improving Developmental Education}

Elizabeth Zachry Rutschow

Emily Schneider

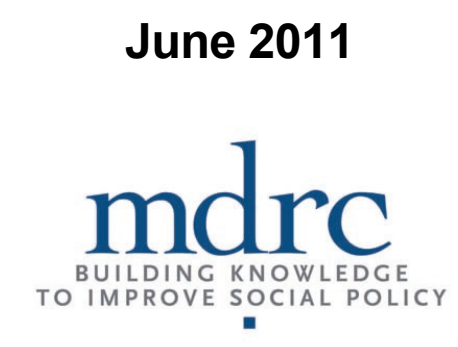


Funding for this report was provided by the National Center for Postsecondary Research (NCPR) and the Carnegie Corporation of New York. NCPR was established by a grant (R305A060010) from the Institute of Education Sciences of the U.S. Department of Education.

Dissemination of MDRC publications is supported by the following funders that help finance MDRC's public policy outreach and expanding efforts to communicate the results and implications of our work to policymakers, practitioners, and others: The Ambrose Monell Foundation, The Annie E. Casey Foundation, Carnegie Corporation of New York, The Kresge Foundation, Sandler Foundation, and The Starr Foundation.

In addition, earnings from the MDRC Endowment help sustain our dissemination efforts. Contributors to the MDRC Endowment include Alcoa Foundation, The Ambrose Monell Foundation, Anheuser-Busch Foundation, Bristol-Myers Squibb Foundation, Charles Stewart Mott Foundation, Ford Foundation, The George Gund Foundation, The Grable Foundation, The Lizabeth and Frank Newman Charitable Foundation, The New York Times Company Foundation, Jan Nicholson, Paul H. O’Neill Charitable Foundation, John S. Reed, Sandler Foundation, and The Stupski Family Fund, as well as other individual contributors.

The findings and conclusions in this report do not necessarily represent the official positions or policies of the funders.

For information about MDRC and copies of our publications, see our Web site: www.mdrc.org. Copyright (C) 2011 by MDRC. ${ }^{\circledR}$ All rights reserved. 


\section{Overview}

One of the greatest challenges that community colleges face in their efforts to increase graduation rates is improving the success of students in their developmental, or remedial, education programs - the courses that students without adequate academic preparation must take before they can enroll in courses for college credit. Emphasizing results from experimental and quasiexperimental studies, this literature review identifies the most promising approaches for revising the structure, curriculum, or delivery of developmental education and suggests areas for future innovations in developmental education practice and research. This analysis focuses on four different types of interventions for improving students' progress through remedial education and into college-level courses, including (1) strategies that help students avoid developmental education by shoring up their skills before they enter college; (2) interventions that accelerate students' progress through developmental education by shortening the timing or content of their courses; (3) programs that provide contextualized basic skills together with occupational or college-content coursework; and (4) programs that enhance the supports for developmentallevel learners, such as advising or tutoring.

While research on best practices in developmental education abounds, little rigorous research exists to demonstrate the effects of these reforms on students' achievement. Programs that show the greatest benefits with relatively rigorous documentation either mainstream developmental students into college-level courses with additional supports, provide modularized or compressed courses to allow remedial students to more quickly complete their developmental work, or offer contextualized remedial education within occupational and vocational programs. These strategies show the most promise for educators and policymakers who must act now, but they should also continue to receive attention from researchers. Many of the strategies have not yet been evaluated using more rigorous and reliable research methods, and/or early promising results have not been replicated in other settings.

This literature review also notes several promising reforms that merit further study: technologyaided approaches, improved alignment between secondary and postsecondary education, and curricular redesign that reconsiders the key skills that academically underprepared students will need in their careers. Finally, it flags two generic issues - placement assessments and faculty support — that will likely need to be addressed for community colleges to see large-scale changes in their developmental-level students' achievement. 



\section{Contents}

Overview $\quad$ iii

List of Exhibits vii

Preface $\quad$ ix

Acknowledgments $\quad$ xi

Executive Summary $\quad$ ES-1

\section{Chapter}

$1 \quad$ Introduction 1

Previous Research on Best Practices in Developmental Education 2

Rigorous Research in Developmental Education: The Next Step 11

Methods Used for This Literature Review $\quad 12$

Identification of Promising Intervention Models $\quad 13$

$2 \quad$ Interventions for Avoiding Developmental Education 15

Models for Avoiding Developmental Education $\quad 16$

$\begin{array}{ll}\text { Dual Enrollment Programs } & 16\end{array}$

Early Assessment Programs 20

Summer Bridge Programs $\quad 22$

Summary of Avoidance Models $\quad 24$

3 Accelerating Students' Progress Through Developmental Education 25

Models for Accelerating Students' Progress Through Developmental Education 26

Fast-Track Courses 26

Modularized Courses $\quad 29$

Mainstreaming into College-Level Courses $\quad 30$

Summary of Acceleration Models 33

$4 \quad$ Contextualized Instruction 35

Models for Contextualized Learning with Developmental Education Students $\quad 36$

Contextualized Learning in Vocational Programs 36

$\begin{array}{ll}\text { Learning Communities } & 39\end{array}$

Summary of Contextualized Learning Models 41

$5 \quad$ Supplemental Supports to Advance Students' Achievement 43

Models for Supplemental Supports with Developmental Education Students $\quad 43$

Tutoring and Supplemental Instruction $\quad 44$

$\begin{array}{ll}\text { Advising } & 48\end{array}$

$\begin{array}{lr}\text { Student Success Courses } & 50\end{array}$

Summary of Student Support Models 
6 Conclusion $\quad 53$

Improving the Quality of Evidence $\quad 55$

Promising Strategies for Improving Developmental Students' Success 56

Additional Considerations for Future Research and Practice 62

$\begin{array}{ll}\text { Conclusion } & 67\end{array}$

\section{Appendix}

A List of Journals Reviewed $\quad 69$

$\begin{array}{ll}\text { References } & 73\end{array}$ 


\section{List of Exhibits}

\section{Table}

1.1 Summary of Major Research Works on Developmental Education 4

1.2 Synthesis of Recommendations for Best Practices in Developmental Education 6

1.3 Standards of Evidence: How This Report Classifies Available Quantitative Research on Developmental Education

2.1 Summary of Research on Avoidance Strategies 19

3.1 Summary of Research on Acceleration Strategies 27

4.1 Summary of Research on Contextualized Instruction Strategies 37

5.1 Summary of Research on Student Support Services 45 



\section{Preface}

In recent years it has become clear that the United States must focus serious efforts on raising the graduation rates of community college students if we are to see higher levels of educational attainment nationally and improve the quality and competitiveness of our workforce. The challenge for community colleges is to pave the way to success for the tens of thousands of academically underprepared students who are enrolled in developmental, or remedial, courses. Building a strong research base that can inform educators and policymakers about effective developmental education strategies is of central importance in helping these struggling students.

In September 2010, the National Center for Postsecondary Research hosted a national conference to bring leaders in the field together to discuss "Developmental Education: What Policies and Practices Work for Students?" To complement presentations on current innovations, MDRC conducted a literature review to uncover the most promising reforms of the past 40 years and suggest future areas for research and practice.

This review emphasizes results of rigorous studies that compared outcomes for students who participated in an innovative program with those whose developmental education was more traditional - typically, a sequence of courses relying on lectures and drills to prepare students for college-level work in math, English, or reading. Guided by these standards for evidence, this review finds that the most promising strategies are those that work to improve students' skills within a compressed time frame or that link remediation to relevant vocational coursework.

As these programs are replicated, they should be evaluated rigorously to confirm the promising trends seen in the studies. But educators, policymakers, and researchers should not stop there. Even the most promising innovations described in this report led to only modest improvements in achievement, demonstrating that progress remains to be made in developing and evaluating more robust reforms. In particular, this review highlights technology-aided approaches, curricular redesign, and current efforts to align secondary school education with college readiness standards as areas with great potential but where research has been limited. It also suggests that community colleges should carefully consider the assessments that they use to place students in developmental education as well as the support that they provide to both full-time and adjunct faculty to teach well and participate in reforms.

The research demonstrates that minor modifications in developmental education programs are unlikely to produce dramatic improvements. Given that current programs succeed at moving less than half of their students into college-level courses, more substantive and transformative changes are needed.

Gordon L. Berlin

President 



\section{Acknowledgments}

In the preparation of this literature review, we are grateful for the support of the National Center for Postsecondary Research (NCPR), which was established by a grant from the Institute of Education Sciences in the U.S. Department of Education. NCPR is a partnership of the Community College Research Center at Columbia University's Teachers College, MDRC, the Curry School of Education at the University of Virginia, and faculty at Harvard University.

We are also thankful to the many people who read and reviewed this report. In particular, we are grateful to those individuals who gave us excellent guidance through written and oral feedback, including Robert Ivry, Thomas Brock, Thomas Bailey, John Hutchins, and Katherine Hughes. Finally, we thank the Publications staff at MDRC, including Robert Weber, who edited the report, and David Sobel and Stephanie Cowell, who prepared it for publication.

An earlier version of this review was prepared for the NCPR Developmental Education Conference "What Policies and Practices Work for Students?" (convened September 23-24, 2010, at Teachers College, Columbia University).

The Authors 



\section{Executive Summary}

Enrolling over one-third of all postsecondary education students, community colleges have become a centerpiece of America's efforts in recent years to improve the quality of its workforce and maintain its competitiveness in the global market. ${ }^{1}$ However, community colleges have often struggled to graduate their students, with just over three in ten community college students earning a degree or credential within six years of first enrolling. ${ }^{2}$ Over half of these students are academically underprepared for college-level work, and improving the success of these developmental, or remedial, students is one of the greatest challenges that community colleges face in the efforts to increase overall graduation rates - very few of these students end up completing their required sequence of developmental coursework needed to enroll in college-level courses, let alone graduating from college with a diploma or certificate. ${ }^{3}$

There is a strong and growing effort among educators and policymakers to address the needs of these students; however, the available research on effective practices is limited in its rigor and reliability. Emphasizing results from experimental and quasi-experimental studies, this literature review identifies the most promising approaches for revising the structure, curriculum, or delivery of developmental education: strategies that work to improve students' skills within a compressed time frame or that link remediation to relevant college-level work. These strategies tend to modify pedagogical approaches to fit the programs' nontraditional structures, and they provide clear opportunities for students to remain on a pathway to reaching their college goals rather than becoming mired in years of remedial work. Building on these findings, therefore, this literature review suggests areas for future growth in developmental education research and practice, identifies several untested reforms that merit further study, and flags two generic issues — placement assessments and faculty support - that will likely need to be addressed for community colleges to see large-scale changes in their developmental-level students' achievement.

\section{Promising Strategies for Improving Developmental Education Students' Success}

This review categorizes colleges' approaches to improving developmental education into four broad types of interventions:

\footnotetext{
${ }^{1}$ Provasnik and Planty (2008).

${ }^{2}$ Radford, Berkner, Wheeless, and Shepherd (2010).

${ }^{3}$ Adelman (2004); Attewell, Lavin, Domina, and Levey (2006); Jenkins, Jaggars, and Roksa (2009); Bailey, Jeong, and Cho (2010).
} 
1. Interventions aimed at helping students avoid developmental education by shoring up their skills before they enroll in college

2. Interventions designed to accelerate students' progress through developmental education by shortening the timing or content of their developmental education courses

3. Programs that provide contextualized basic skills together with occupational or college-content coursework

4. Programs that enhance the supports for developmental-level learners, such as advising or tutoring

Of these, acceleration and contextualization strategies appear to hold the most promise for improving developmental education students' success. In particular, programs that show the greatest benefits with relatively rigorous documentation either mainstream developmental students into college-level courses with additional supports, provide modularized or compressed courses to allow remedial students to more quickly complete their developmental work, or offer contextualized remedial education within occupational and vocational programs. These strategies should be prioritized by educators and policymakers and should continue to receive attention from researchers, as none of them have yet been evaluated using an experimental design.

\section{Defining Rigorous Research}

The review focused on studies that had large samples of students and included some type of comparison group research design to determine the effectiveness of a program over and above the regular services offered. The most rigorous studies use an experimental design, in which students are randomly assigned either to a program group that receives an intervention or to a control group that does not. Random assignment ensures that before enrollment in the intervention begins, students in both the program group and the control group are similar in measurable and unmeasurable characteristics such as motivation; hence, any subsequent differences that emerge in students' outcomes can be attributed with confidence to the intervention. Quasi-experimental research designs also take a rigorous approach to creating comparison groups; these studies use various methods to identify a similar group of students and then to control for any measurable (but not unmeasurable) differences in background characteristics between students who participate in the program and the comparison group. However, these results are generally not as reliable as the findings from experimental studies because such techniques cannot control for unmeasurable characteristics (and, thus, cannot fully account for the selection of students into an intervention). Experimental and quasi-experimental studies are fairly uncommon in higher education, and so the review also includes nonexperimental studies that use some other methodology to create a comparison group. While there is a range of 
nonexperimental approaches, most available studies in the field are simple comparisons that contrast outcomes for program participants with outcomes for a historical or current group of students at a similar level of developmental need, without controlling for differences in student characteristics. The results of such studies provide insights into the promise of many developmental education reforms and suggest directions for future evaluation.

\section{Avoidance Models}

Models that help students better prepare for college-level work before they enter postsecondary education have shown some promise for improving students' achievement. One type of program in this category alerts students to their academic weak points before they leave high school. Eleventh- or twelfth-graders take early college-readiness assessments, and those who are academically underprepared are given the opportunity to further develop their skills in high school or through bridge programs at the college, which offer students compressed developmental-level courses during the summer before their entry into college. Dual enrollment programs and early college high schools are another high school-based preparation program. These programs enroll students jointly in college and high school classes together during their final years of high school, with a specific focus on college preparatory coursework for students who are academically underprepared in a particular subject.

Research on interventions helping students avoid developmental education is promising, though relatively limited in rigor. Nonexperimental research on dual enrollment programs have shown positive increases in students' credit earning, ${ }^{4}$ while similar research on summer bridge programs has shown promising improvements in students' study skills and college readiness in math and reading. ${ }^{5}$ A more rigorous study of an early assessment program in California also revealed modest decreases in students' placement into developmental math and English when controlling for preexisting differences between participating and nonparticipating students. ${ }^{6}$ Further research is needed to confirm these promising trends with more rigorous evaluation designs, and researchers should pay special attention to how various program structures may benefit students with differing levels of need.

\section{Acceleration Models}

Acceleration models have also shown promise for increasing students' progress through developmental education. Several different models currently exist, including fast-track courses, which compress the developmental education course curriculum into several weeks or a half

\footnotetext{
${ }^{4}$ Kim and Barnett (2008); Jobs for the Future (2009).

${ }^{5}$ Texas Higher Education Coordinating Board (2009); Zuniga (2008).

${ }^{6}$ Howell, Kurlaender, and Grodsky (2010).
} 
semester; self-paced, or modularized, courses, which break apart semester-long developmental education classes into smaller, competency-based units; and mainstreamed courses, in which developmental education students are placed directly into college-level courses, often with additional supports such as tutoring or study skills courses.

Nonexperimental research on each program type has shown higher pass rates in developmental and subsequent college-level courses (both in math and in English), as well as higher rates of student persistence. ${ }^{7}$ One quasi-experimental study has also shown promising results for a mainstreaming program in developmental English at the Community College of Baltimore County. Students in the mainstreamed classes were much more likely to pass the college's introductory college-level English course within a year of taking the course than students not participating in the program. The program was also associated with improvements in the number of college-level courses that students attempted and with the percentage of students who passed the next level of college English. ${ }^{8}$

The positive results of these studies reveal that acceleration strategies are ripe for more rigorous evaluation. Because students who participate in these programs may have differences in motivation or prior academic achievement, further research is needed to establish a causal link between these programs and any observed increases in achievement. As these practices are replicated and evaluated more thoroughly, close attention should be paid to the policy environment; resistance to modifying developmental courses in this way has been seen at both the practitioner and the state levels, but flexible policies on course credit and prerequisites can also be central to easing implementation. ${ }^{9}$

\section{Contextualized Learning Models}

Contextualized instructional models seek to help academically underprepared students progress more quickly through their developmental skill building while engaging directly with their academic or vocational field of interest. ${ }^{10}$ In vocational programs, contextualized learning affords students the opportunity to gain professional or technical skills while still enrolled in their precollegiate programs. Contextualized learning may also be used in particular academic subjects to promote students' integration of course concepts with reading, writing, or math skills. Finally, learning communities, in which students co-enroll in developmental courses

${ }^{7}$ Zachry (2008); Adams (2003); Brancard, Baker, and Jensen (2006); Bragg (2009); Bassett (2009); Bragg and Barnett (2009); Epper and Baker (2009); Goen-Salter (2008); Adams, Miller, and Roberts (2009); Jenkins (2009).

${ }^{8}$ Jenkins et al. (2010).

${ }^{9}$ Moltz (2010); Jenkins (2009); Gleason (2000); Bassett (2009).

${ }^{10}$ Grubb and Kraskouskas (1992); Berns and Erickson (2001); Perin (2001); Badway and Grubb (1997). 
linked with college-level courses, can provide integrated environments to engage with both academic course content and basic skills learning.

While the evidence is still limited, rigorous research does exist about the success of contextualized learning programs. Nonexperimental evaluations of several vocationally focused programs that were developed as part of the Charles Stewart Mott Foundation's Breaking Through initiative revealed promising college outcomes, such as increased rates of college readiness and increased progress toward completing occupational certificates. ${ }^{11}$ A quasiexperimental study of Washington State's Integrated Basic Education and Skills Training (I-BEST) program — which offers basic English instruction, including discipline-specific vocabulary training and lessons on employer and employee communications, within the context of specific workforce training classes, such as commercial driving, nursing, and early childhood education - found that students in the I-BEST programs earned an average of 14 more college credits than non-I-BEST students and had a higher probability of persisting into the second year (17 percentage points) and of earning an occupational certificate (40 percentage points) ${ }^{12}$ Given the promising findings from I-BEST and Breaking Through, developmental education programs should consider how links with occupational courses might further improve their students' outcomes. Additionally, more rigorous research should be conducted to validate the promising results of programs following this model.

Positive, though more modest, findings have also been observed for learning communities. Qualitative and quasi-experimental analyses of learning communities throughout the country have shown that these programs have affective benefits for students, leading to high levels of engagement and a strong sense of belonging. ${ }^{13}$ Experimental studies have also found positive impacts on students' achievement and persistence in school; learning communities programs that link a developmental math or developmental English class with a college-level course have resulted in improvements in the number of credits earned and in students' progression through developmental education. ${ }^{14}$ However, these effects tended to diminish after the programs ended. These results should be considered a more definitive characterization of learning communities, given the strong research models used to document these effects.

\section{Student Supports}

Increasing the supports that developmental education students receive outside the classroom has been another way that many community colleges have attempted to improve academ-

\footnotetext{
${ }^{11}$ Bragg and Barnett (2009).

${ }^{12}$ Jenkins, Zeidenberg, and Kienzl (2009).

${ }^{13}$ Visher, Schneider, Wathington, and Collado (2010); Engstrom and Tinto (2008); Tinto (1997); Zhao and Kuh (2004).

${ }^{14}$ Scrivener et al. (2008); Weissman et al. (2011).
} 
ic achievement. Popular strategies include tutoring - which can be provided by faculty, staff, or student peers or through computer-assisted instruction with tutorial software packages - and supplemental instruction, a more structured tutoring model that is connected directly with a particular course. Intensive advising, which reduces advisers' caseloads, allowing them to meet more frequently with students and provide more personalized attention, is another oftenrecommended intervention, though it can be expensive to implement on a large scale. Student success courses, which teach students study skills and provide an introduction to college life, are also a popular strategy.

Rigorous research about these strategies is limited, and the available evidence reveals mixed results on student achievement. While some promising trends have been noted for tutoring programs - particularly for students who use learning assistance centers or who receive supplemental instruction - most studies were limited in what they could attribute to the influence of these programs versus other factors, such as student motivation. ${ }^{15}$ Rigorous research on advising models has also shown some positive results for students' retention and credit earning. However, the effects of these programs were relatively modest, dissipated over time, and generally did not affect other academic outcomes for these students, such as course pass rates or grade point averages (GPAs). ${ }^{16}$ Student success courses have seen more promising results, with experimental studies showing positive gains in credits earned and progression through developmental education, while quasi-experimental studies revealed other positive, long-term effects on degree earning and transfers, particularly for developmental-level students. ${ }^{17}$ These findings suggest that certain supplemental support services, such as student success courses, may produce important gains in students' achievement. More rigorous research is needed, however - particularly concerning tutoring and supplemental instruction programs - to determine whether these services have a measurable effect on students' achievement and progress into college-level work.

\section{Untested Innovations in Developmental Education Practice}

While most developmental education reforms have focused on modest tweaks to programs' curricula and practices, a few recent innovations have focused on changing the foundations of these programs in an effort to more quickly advance students into credit-bearing courses and the attainment of postsecondary credentials. Three reforms, in particular, that provide novel ways to

\footnotetext{
${ }^{15}$ Perin (2004); Roueche, Ely, and Roueche (2001); Xu, Hartman, Uribe, and Mencke (2001).

${ }^{16}$ Visher, Butcher, and Cerna (2010); Scrivener and Weiss (2009); Bettinger and Baker (2011).

${ }^{17}$ Zeidenberg, Jenkins, and Calcagno (2007); Scrivener et al. (2008); Scrivener, Sommo, and Collado (2009).
} 
improve developmental education students' success are worthy of further study as they are replicated at community colleges across the nation.

- Technology-aided approaches. Many colleges use technology to revise curricula or instruction in developmental courses, relying on computer tutorials — such as MyMathLab, Plato, or ALEKS - or other methods to supplement classroom instruction, to provide online developmental education, or to structure accelerated or modularized courses. ${ }^{18}$ Little research has been conducted on these strategies despite their popularity, and the research that exists shows mixed results.

- Improving alignment between secondary and postsecondary education. Numerous movements are currently under way to better align these systems, including the Common Core State Standards Initiative, which sets out careerand college-ready standards for high school curricula. ${ }^{19}$ Given the important influence that such alignment practices can have on developmental education students' success, researchers and policymakers should prioritize research to better understand how these policy efforts are making changes in students' educational experiences and achievement.

- Curricular redesign. Other recent efforts are radically reconsidering the curricula and practices in both developmental and college-level courses to focus on the key skills that students will need in their careers. One of the most promising of these innovations, the Statistics Pathway (or Statway), seeks to quickly advance academically underprepared students in nontechnical fields through a statistics-based (rather than an algebra- and calculusbased) math curriculum in one year. ${ }^{20}$ Though untested, programs such as Statway provide a unique answer to researchers' recent calls for more drastic changes in developmental education and provide a promising venue for exploring how more dramatic reforms may affect students' outcomes.

\section{Conclusion}

Developmental education remains an area ripe for further research and innovation. Given the alarmingly low success rates for developmental students, these programs can no longer afford

\footnotetext{
${ }^{18}$ Carpenter, Brown, and Hickman (2004); Zavarella and Ignash (2009); Creery (2001); McClenden and McArdle (2002); Weems (2002); Blackner (2000); Epper and Baker (2009).

${ }^{19}$ Achieve, Inc. (2010); American Youth Policy Forum (AYPF) (2009); National Governors Association (2010).

${ }^{20}$ Bryk and Treisman (2010).
} 
the status quo. The current research demonstrates that minor modifications in developmental education programs are insufficient for producing dramatic improvements in student achievement. Educators, policymakers, and researchers, however, have an opportunity to build on what has been learned about promising interventions in order to develop and rigorously evaluate more robust and innovative efforts aimed at transforming the educational experience of academically underprepared students. As the field advances, it will become increasingly important to replicate these early results using more rigorous and reliable methods whenever possible; if an experimental study is not feasible, another analytic strategy that minimizes the differences between comparison groups should be used.

In addition, to be successful on a wide scale, new reforms in developmental education need to address two institutional issues at the core of programming and practice:

- Placement assessments. On entering community college, most students are required to take an entrance exam that assesses their current math, reading, and writing skills and is used to place them into the appropriate developmental or college-level courses. While such assessments are designed to aid colleges' placement practices and are encouraged by earlier developmental education research, there is much debate as to their validity and their benefits for students. Given the important role of assessment and placement in defining students' college careers, researchers and policymakers should place a high priority on developing more nuanced placement methods and on understanding how they affect students' progress through college.

- Faculty support. The majority of developmental education classes are taught by adjunct, or part-time, faculty, who are often disconnected from departmental decision-making and the piloting of new programmatic strategies. Moreover, developmental education instructors - whether they teach full or part time - tend to have limited training in instructing basic skills students. The level of quality and effectiveness of instruction are undoubtedly among the most important factors influencing developmental-level students' academic performance; in recognizing this, educators, policymakers, and researchers should develop more integrated approaches to professional development that are designed to provide ongoing support to faculty as they implement new reforms and bring them to scale. Researchers should move beyond the cursory treatment of instructors' pedagogy and practice within the classroom and should rigorously document the relationship between instructional practices and student outcomes; a useful tool for this work would be more standardized measures for assessing the implementation of different practices. 
Improvements in these areas have the potential to enhance traditional developmental education programs, even as colleges pursue more dramatic reforms that may have an even larger impact on student achievement. By attacking the challenge of developmental education on each of these levels, educators, policymakers, and researchers will give academically disadvantaged students the opportunity to achieve the college and career dreams that they are so avidly pursuing.

\section{References for the Executive Summary}

Achieve, Inc. 2010. On the Road to Implementation: Achieving the Promising of the Common Core State Standards. Washington, DC: Achieve, Inc.

Adams, Peter S., Gerhart R. Miller, and A. Roberts. 2009. "The Accelerated Learning Program: Throwing Open the Gates." Journal of Basic Writing 28, 2: 50-69.

Adams, William W. 2003. Developmental Mathematics: A New Approach. Mathematical Association of America (MAA). Web site: http://www.maa.org/features/112103devmath.html.

Adelman, Clifford. 2004. Principal Indicators of Student Academic Histories in Postsecondary Education, 1972-2000. Washington, DC: Institute of Education Sciences, U.S. Department of Education.

American Youth Policy Forum (AYPF). 2009. "Linking Second and Postsecondary Systems Lessons from Indiana.” Issue Brief. Washington, DC: American Youth Policy Forum.

Attewell, Paul, David Lavin, Thurston Domina, and Tania Levey. 2006. "New Evidence on College Remediation." Journal of Higher Education 77, 5: 886-924.

Badway, Norena, and W. Norton Grubb. 1997. A Sourcebook for Reshaping the Community College: Curriculum Integration and the Multiple Domains of Career Preparation, Vols. I and II. Berkeley, CA: National Center for Research in Vocational Education.

Bailey, Thomas, Dong Wook Jeong, and Sung-Woo Cho. 2010. "Referral, Enrollment, and Completion in Developmental Education Sequences in Community Colleges." Economics of Education Review 29: 255-270.

Bassett, Mary Jane. 2009. Tennessee Board of Regents: Developmental Studies Redesign Initiative. "Jackson State Community College, Course Title: Basic Math, Elementary Algebra and Intermediate Algebra."

Web site: http://www.thencat.org/States/TN/Abstracts/JSCC\%20Algebra_Abstract.htm.

Berns, Robert G., and Patricia M. Erickson. 2001. "Contextual Teaching and Learning: Preparing Students for the New Economy.” The Highlight Zone: Research @ Work, No. 5. Columbus, OH: National Center for Career and Technical Education. 
Bettinger, Eric, and Rachel Baker. 2011. "The Effects of Student Coaching in College: An Evaluation of a Randomized Experiment in Student Mentoring." Paper presented at the Society for Research on Educational Effectiveness Conference, Washington, DC, March 3-5.

Blackner, D. B. 2000. "Prediction of Community College Students' Success in Developmental Math with Traditional Classroom, Computer-Based On-Campus and Computer-Based at a Distance Instruction Using Locus of Control, Math Anxiety and Learning Style." Doctoral dissertation. Available from ProQuest Dissertations and Theses database: UMI No. 3064379 .

Bragg, Debra D. 2009. Community College of Denver Breaking Through Outcomes Report. Denver, CO: Community College of Denver.

Bragg, Debra D., and Elisabeth Barnett. 2009. Lessons Learned from Breaking Through. In Brief. Champaign, IL: Office of Community College Research and Leadership.

Web site: http://occrl.ed.uiuc.edu.

Brancard, Ruth, Elaine DeLott Baker, and Laura Jensen. 2006. Accelerated Developmental Education Project: Research Report (Community College of Denver). Denver, CO: Community College of Denver.

Bryk, Anthony, and Uri Treisman. 2010. "Make Math a Gateway, Not a Gatekeeper." Chronicle of Higher Education (April 18).

Carpenter, Trudy G., William L. Brown, and Randall C. Hickman. 2004. "Influences of Online Delivery on Developmental Writing Outcomes." Journal of Developmental Education 28, 1: $14-18,35$.

Creery, Katherine W. 2001. "Comparison of Lecture, Self-Paced, and On-Line Courses." NADE Selected Conference Papers, Vol. 7. Louisville, KY: National Association of Developmental Education.

Engstrom, Cathy McHugh, and Vincent Tinto. 2008. "Learning Better Together: The Impact of Learning Communities on the Persistence of Low-Income Students." Opportunity Matters 1.

Epper, Rhonda M., and Elaine DeLott Baker. 2009. Technology Solutions for Developmental Math: An Overview of Current and Emerging Practices. Report funded by the William and Flora Hewlett Foundation and the Bill and Melinda Gates Foundation.

Gleason, Barbara. 2000. "Evaluating Writing Programs in Real Time: The Politics of Remediation." College Composition and Communication 51, 4: 560-588.

Goen-Salter, Sugie. 2008. "Critiquing the Need to Eliminate Remediation: Lessons from San Francisco State.” Basic Writing 27, 2: 81-105.

Grubb, W. Norton, and Eileen Kraskouskas. 1992. A Time to Every Purpose: Integrating Occupational and Academic Education in Community Colleges and Technical Institutes. Berkeley, CA: National Center for Research in Vocational Education. 
Howell, Jessica S., Michal Kurlaender, and Eric Grodsky. 2010. "Postsecondary Preparation and Remediation: Examing the Effect of the Early Assessment Program at California State University." Journal of Policy Analysis and Management 29, 4: 726-748.

Jenkins, Davis. 2009. "Educational Outcomes of the Digital Bridge Academy: Findings from a Multivariate Analysis." Presentation at the Conference of the League for Innovation in Community College, Reno, NV, March 16.

Jenkins, Davis, Shanna Smith Jaggars, and Josipa Roksa. 2009. Promoting Gatekeeper Course Success Among Community College Students Needing Remediation: Findings and Recommendations from a Virginia Study (Summary Report). New York: Community College Research Center, Teachers College, Columbia University.

Jenkins, Davis, Cecilia Speroni, Clive Belfield, Shanna Smith Jaggars, and Nikki Edgecombe. 2010. "A Model for Accelerating Academic Success of Community College Remedial English Students: Is the Accelerated Learning Program (ALP) Effective and Affordable?" CCRC Working Paper No. 21. New York: Community College Research Center, Teachers College, Columbia University.

Jenkins, Davis, Matthew Zeidenberg, and Gregory S. Kienzl. 2009. "Building Bridges to Postsecondary Training for Low-Skill Adults: Outcomes of Washington State's I-BEST Program." CCRC Brief No. 42. New York: Columbia University, Teachers College, Community College Research Center.

Jobs for the Future. 2009. Early College High School Initiative: A Portrait in Numbers. Boston: Jobs for the Future.

Kim, Jennifer E., and Elisabeth Barnett. 2008. "2007-08 MCNC Early College High School Students: College Coursework Participation and Performance." New York: National Center for Restructuring Education, Schools, and Teaching; Teachers College, Columbia University.

McClenden, Marie, and Michele McArdle. 2002. "Comparing Alternative Algebraic Modalities for Remedial Students." Paper presented at the Chair Academy Leadership Conference, Kansas City, MO, February 28 - March 2. ERIC ED 464568.

Moltz, David. 2010. “Competing Principles.” Inside Higher Education (June 28).

National Governors Association. 2010. "National Governors Association and State Education Chiefs Launch Common State Academic Standards." Press release. Washington, DC: National Governors Association.

Perin, Dolores. 2001. "Academic-Occupational Integration as a Reform Strategy for the Community College: Classroom Perspectives.” Teachers College Record 103: 303-335.

Perin, Dolores. 2004. "Remediation Beyond Developmental Education: The Use of Learning Assistance Centers to Increase Academic Preparedness in Community Colleges." Community College Journal of Research and Practice 28, 7: 559-582. 
Provasnik, Stephen, and Michael Planty. 2008. "Community Colleges: Special Supplement to The Condition of Education 2008 (Statistical Analysis Report)." NCES 2008-033. Washington, DC: National Center for Education Statistics, Institute of Education Sciences, U.S. Department of Education.

Radford, Alexandria Walton, Lutz Berkner, Sara C. Wheeless, and Bryan Shepherd. 2010. "Persistence and Attainment of 2003-04 Beginning Postsecondary Students: After 6 Years." NCES 2011-151. Washington, DC: National Center for Education Statistics, Institute of Education Sciences, U.S. Department of Education.

Roueche, John, Eileen Ely, and Suanne Roueche. 2001. In Pursuit of Excellence: The Community College of Denver. Washington, DC: Community College Press.

Scrivener, Susan, Dan Bloom, Allen LeBlanc, Christina Paxson, Cecilia Elena Rouse, and Colleen Sommo with Jenny Au, Jedediah J. Teres, and Susan Yeh. 2008. A Good Start: Two-Year Effects of a Freshmen Learning Community Program at Kingsborough Community College. New York: MDRC.

Scrivener, Susan, Colleen Sommo, and Herbert Collado. 2009. Getting Back on Track: Effects of a Community College Program for Probationary Students. New York: MDRC.

Scrivener, Susan, and Michael J. Weiss with Jedediah J. Teres. 2009. More Guidance, Better Results? Three-Year Effects of an Enhanced Student Services Program at Two Community Colleges. New York: MDRC.

Texas Higher Education Coordinating Board. 2009. Consolidated Annual Program Evaluation Report: THECB Funded Programs (Fiscal Year 2008). Austin: Texas Higher Education Coordinating Board.

Tinto, Vincent. 1997. "Classrooms as Communities: Exploring the Educational Character of Student Persistence." Journal of Higher Education 68, 6: 599-623.

Visher, Mary G., Kristin F. Butcher, and Oscar S. Cerna with Dan Cullinan and Emily Schneider. 2010. Guiding Developmental Math Students to Campus Services: An Impact Evaluation of the Beacon Program at South Texas College. New York: MDRC.

Visher, Mary G., Emily Schneider, Heather Wathington, and Herbert Collado. 2010. Scaling Up Learning Communities: The Experience of Six Community Colleges. New York: MDRC.

Weems, Gail H. 2002. "Comparison of Beginning Algebra Taught Onsite Versus Online." Journal of Developmental Education 26, 1: 10-18.

Weissman, Evan, Kristin F. Butcher, Emily Schneider, Jedediah Teres, Herbert Collado, and David Greenberg with Rashida Welbeck. 2011. Learning Communities for Students in Developmental Math: Impact Studies at Queensborough and Houston Community Colleges. New York: MDRC.

Xu, Yonghong, Stacey Hartman, Guillermo Uribe, and Reed Mencke. 2001. "The Effects of Peer Tutoring on Undergraduate Students' Final Scores in Mathematics." Journal of College Reading and Learning 32, 1: 22-31. 
Zachry, Elizabeth M., with Emily Schneider. 2008. Promising Instructional Reforms in Developmental Education: A Case Study of Three Achieving the Dream Colleges. New York: MDRC.

Zavarella, Carol A., and Jan M. Ignash. 2009. "Instructional Delivery in Developmental Mathematics: Impact on Retention.” Journal of Developmental Education 32, 3: 2-8.

Zeidenberg, Matthew, Davis Jenkins, and Juan Carlos Calcagno. 2007. "Do Student Success Courses Actually Help Community College Students Succeed?" CCRC Brief No. 36. Community College Research Center, Teachers College, Columbia University.

Zhao, Chun-Mei, and George D. Kuh. 2004. "Adding Value: Learning Communities and Student Engagement." Research in Higher Education 45, 2: 115-138.

Zuniga, Robin. 2008. Developmental Education Summer Bridge Program: Texas Higher Education Coordinating Board, Cross-Site Evaluation Final Report. Austin: Texas Higher Education Coordinating Board. 



\section{Chapter 1}

\section{Introduction}

In recent years, community colleges have become a centerpiece of America's efforts to improve the quality of its workforce and maintain its competitiveness in the global market. Enrolling over one-third of all postsecondary education students, community colleges play a critical role in helping educate the U.S. populace, often serving as the gateway for traditionally disadvantaged students to enter college. ${ }^{1}$ However, community colleges have often struggled to graduate their students, with just over three in ten community college students earning a degree or credential within six years of first enrolling. ${ }^{2}$ Faced with this dilemma, the federal and state governments, along with major national foundations such as the Bill and Melinda Gates Foundation and Lumina Foundation for Education, have begun to invest millions of dollars into improving community colleges' success rates. Along with these monies, these stakeholders have also called for a dramatic increase in community college graduation rates, with most seeking to double the number of graduates in the next 10 to 15 years. ${ }^{3}$

One of the greatest challenges that community colleges face in their efforts to increase graduation rates is improving the success of students in their developmental, or remedial, education programs. ${ }^{4}$ Recent research has revealed that, on entering college, over half of community college students are academically underprepared for college-level work and need to enroll in at least one developmental-level reading, writing, or math course; however, very few of these students end up completing their developmental education sequence, let alone graduating from college with a diploma or certificate. ${ }^{5}$ In fact, longitudinal studies have shown that the success rates of students with remedial needs have dropped over the past few decades, with fewer students earning a postsecondary degree regardless of the depth or subject of their remedial need. ${ }^{6}$

In addition to the difficulties inherent in serving this population, some of these challenges may reflect the lack of rigorous research documenting effective practices for improving

\footnotetext{
${ }^{1}$ Provasnik and Planty (2008).

${ }^{2}$ Radford, Berkner, Wheeless, and Shepherd (2010).

${ }^{3}$ Bill and Melinda Gates Foundation (2009); Lumina Foundation for Education (2009); Office of the Press Secretary (2009).

4"Developmental," "remedial," and "basic skills" are all terms commonly used to describe students who enter college with lower-level skills. These terms are used interchangeably throughout this report to discuss developmental education students and practices.

${ }^{5}$ Adelman (2004); Attewell, Lavin, Domina, and Levey (2006); Jenkins, Jaggars, and Roksa (2009); Bailey, Jeong, and Cho (2010).

${ }^{6}$ Adelman (2004).
} 
developmental education students' success. The field is slowly moving toward higher standards of evidence, however. While research on developmental education practices has abounded since the 1970s, few of these studies have provided hard evidence of how particular program components or interventions may have increased students' achievement, particularly compared with similar groups of students who did not receive such treatment. ${ }^{7}$ However, though the research base on developmental education practice is still thin, recent studies, based on more rigorous scientific methods, have noted some promising changes in students' achievement. Simultaneously, a number of institutions and agencies have begun developing more innovative approaches in an attempt to escalate developmental education students' achievement beyond its past limits.

This literature review seeks to examine the body of available research on developmental education strategies, in an effort to identify the most promising approaches for revising the structure and curriculum of developmental education, as well as to suggest areas for future growth in developmental education research and practice. The focus will be on investigating those strategies that have rigorous evidence documenting improvements in students' achievement, though the analysis will also touch on earlier studies documenting best practices in developmental education. The key research questions that this report seeks to answer are:

- Based on rigorous research, which practices show the greatest promise for increasing developmental education students' success?

- What are the more recent practices that show promise for increasing students' success in and progress through developmental education?

- Which of these practices should be highlighted for further study?

\section{Previous Research on Best Practices in Developmental Education}

Research into developmental education programs and practices is not a new field of study. Indeed, research articles have been discussing colleges' efforts to remediate students since the mid-nineteenth century. However, as enrollments in higher education increased in the latter half of the twentieth century and as numerous colleges implemented open admissions programs, additional emphasis has been placed on supporting those students who enter college needing to improve their basic skills. ${ }^{8}$ Starting in the 1970s, national organizations were formed to promote

\footnotetext{
${ }^{7}$ Boylan (1980); Boylan, Bliss, and Bonham (1997); Morante (1987); Roueche and Baker (1987); Roueche and Snow (1977); Boylan (1985); Maxwell (1979); Kulik, Kulik and Shwalb (1983).

${ }^{8}$ For a discussion of the history of developmental education, see Roueche and Roueche (1993), pp. 41-48.
} 
the discussion of remedial education, and many of them have published research on promising practices in the field. ${ }^{9}$

Since the 1970s, a wealth of studies have focused on identifying best practices for improving the instruction, support, and programming offered to developmental education students. ${ }^{10}$ In the past 20 years, a number of literature reviews and synthesis studies have used this research to develop overarching recommendations for the management, placement, and instructional practices in developmental education programs. ${ }^{11}$ Table 1.1 shows that many of these studies used surveys or case studies at "exemplary" institutions to analyze which program components were associated with increased student achievement. Often, the exemplary institutions were selected on the basis of receiving community college or developmental education awards or were identified as having strong programs by the researchers. Many of these studies also reviewed previous research on developmental education practices, often citing similar studies as evidence for their recommendations. As is common with synthesis reviews, most of these studies do not cite specific information on student outcomes, instead relying on the effects noted in previous research to support their recommendations.

Perhaps unsurprisingly, given the overlap in their research base, many of the synthesis studies of the past 20 years present relatively uniform recommendations for developmental education programs and practices. (See Table 1.2.) For instance, nearly all the reviews agree that mandatory assessment and placement of students into developmental education programs helps improve students' success. Additionally, many note the important role that particular program components - such as intensive advising or pedagogy supporting active learning can play in improving students' achievement. Many also suggest implementing specific management practices, such as creating centralized developmental education departments and conducting ongoing evaluations of programming and policies.

While this research lays a foundation for improving colleges' practices in developmental education, much of it suffers from several limitations. First, a large proportion of these

\footnotetext{
${ }^{9}$ Boylan (1985, 2002); Boylan, Bliss, and Bonham (1997); McCabe (2000); McCabe and Day (1998); Roueche and Roueche (1993, 1999); Starks (1994).

${ }^{10}$ Boylan, Bliss, and Bonham (1997); Boylan and Saxon (2002); Maxwell (1979); McCabe (2000); Morante (1987); Roueche and Baker (1987); Roueche and Roueche (1993, 1999); Roueche and Snow (1977); Cross (1976); Casazza and Silverman (1996).

${ }^{11}$ Boylan (2002); Boylan, Bliss, and Bonham (1997); Center for Student Success (2007); McCabe and Day (1998); Roueche and Roueche (1993); Sperling (2009); Schwartz and Jenkins (2007).
} 


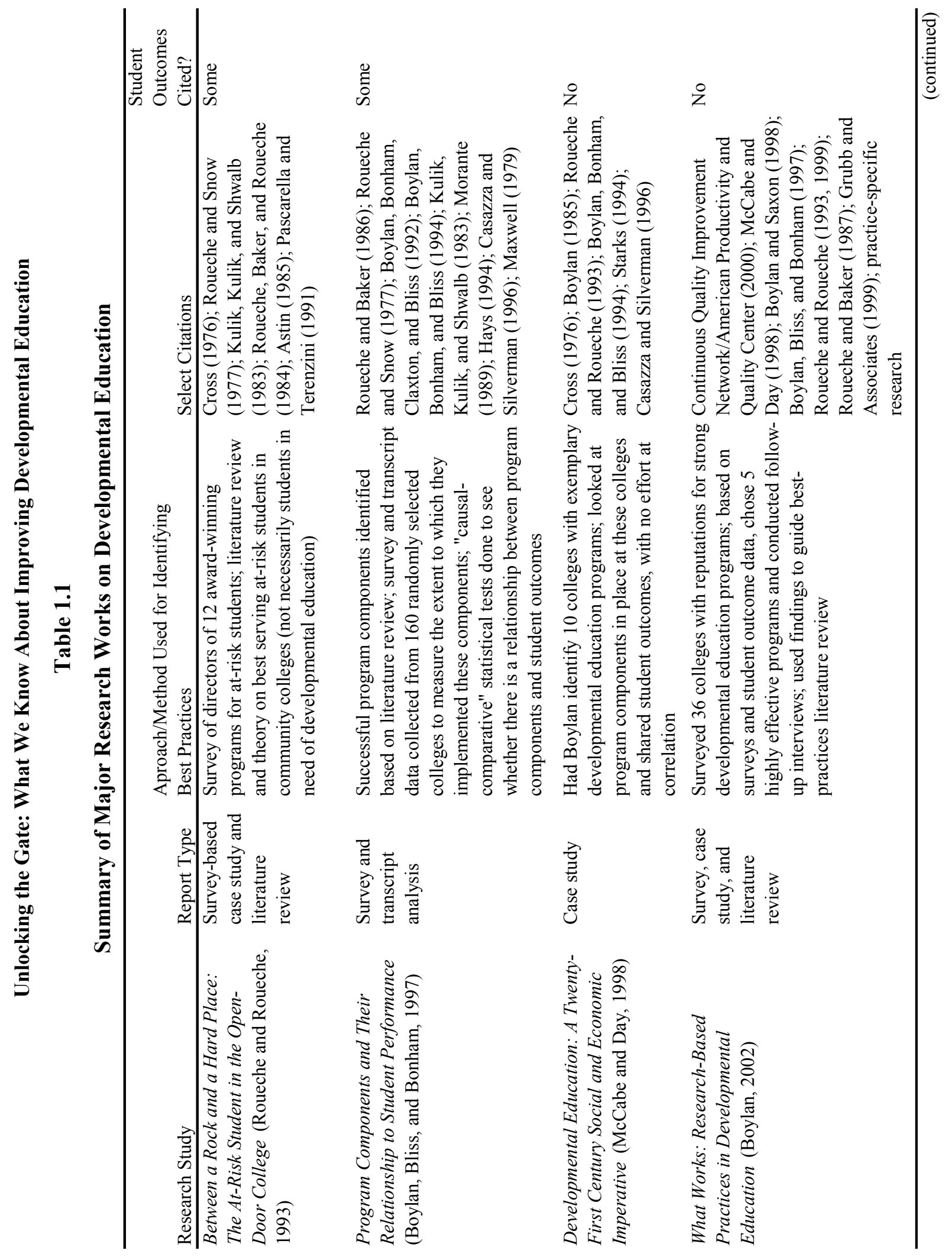




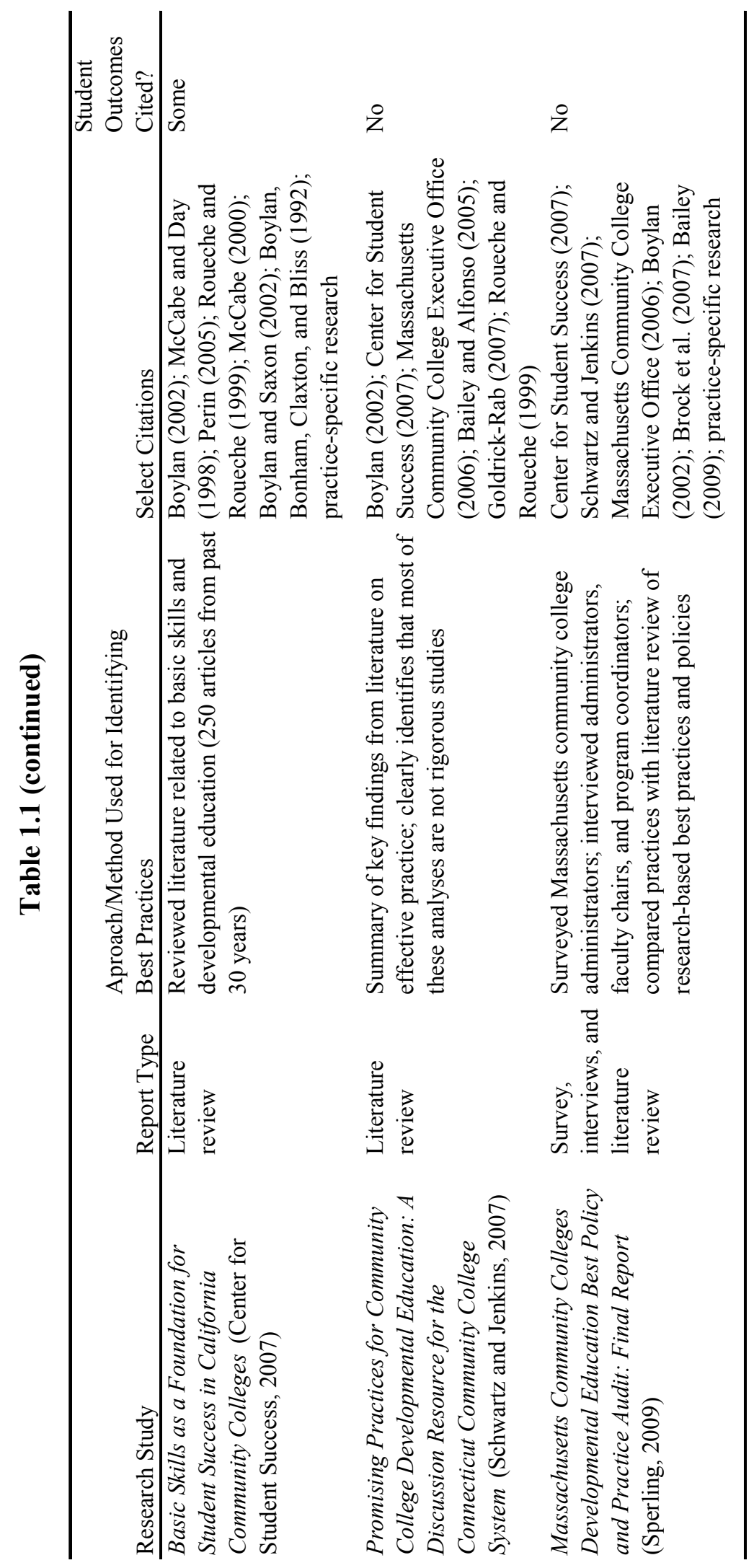




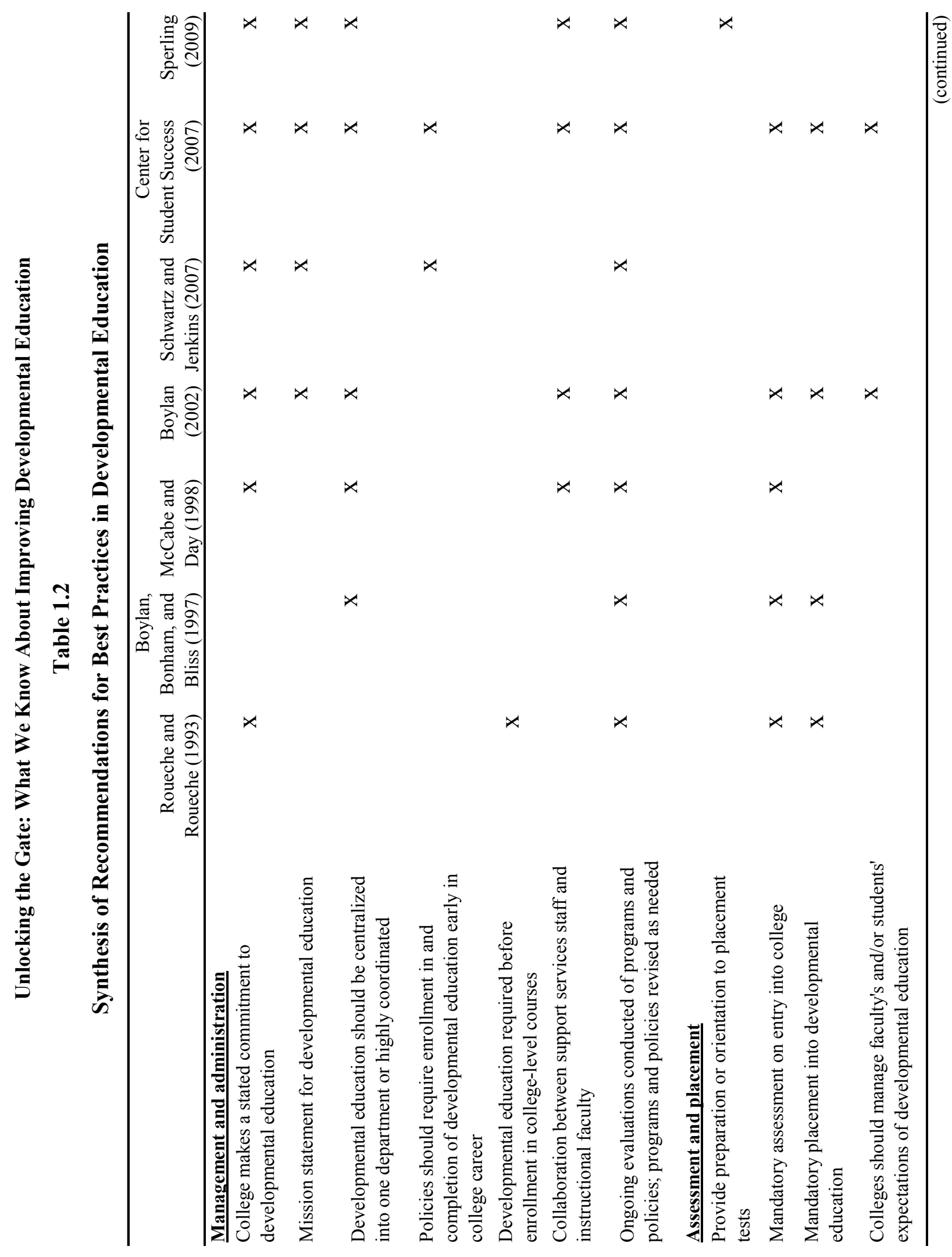




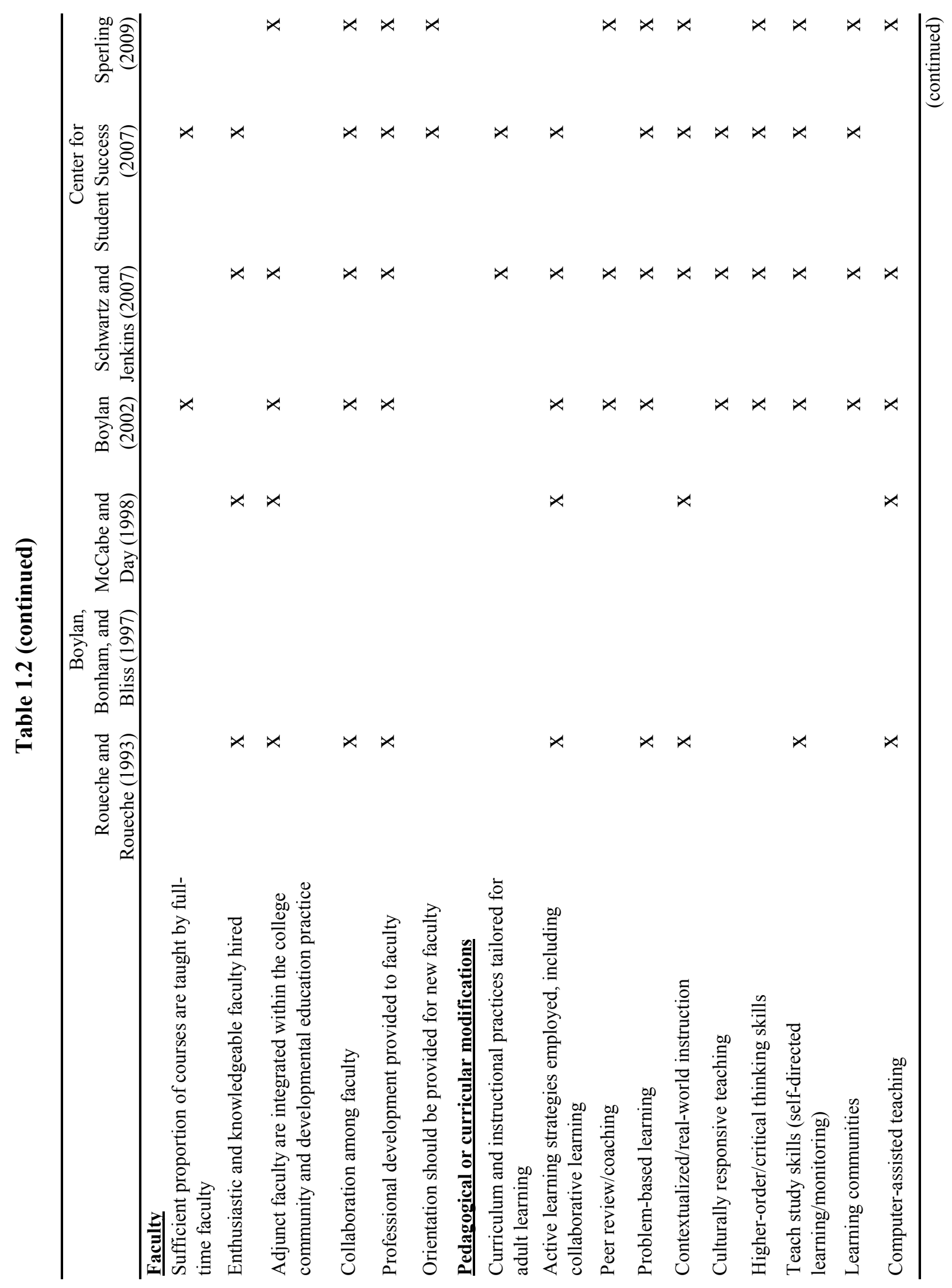




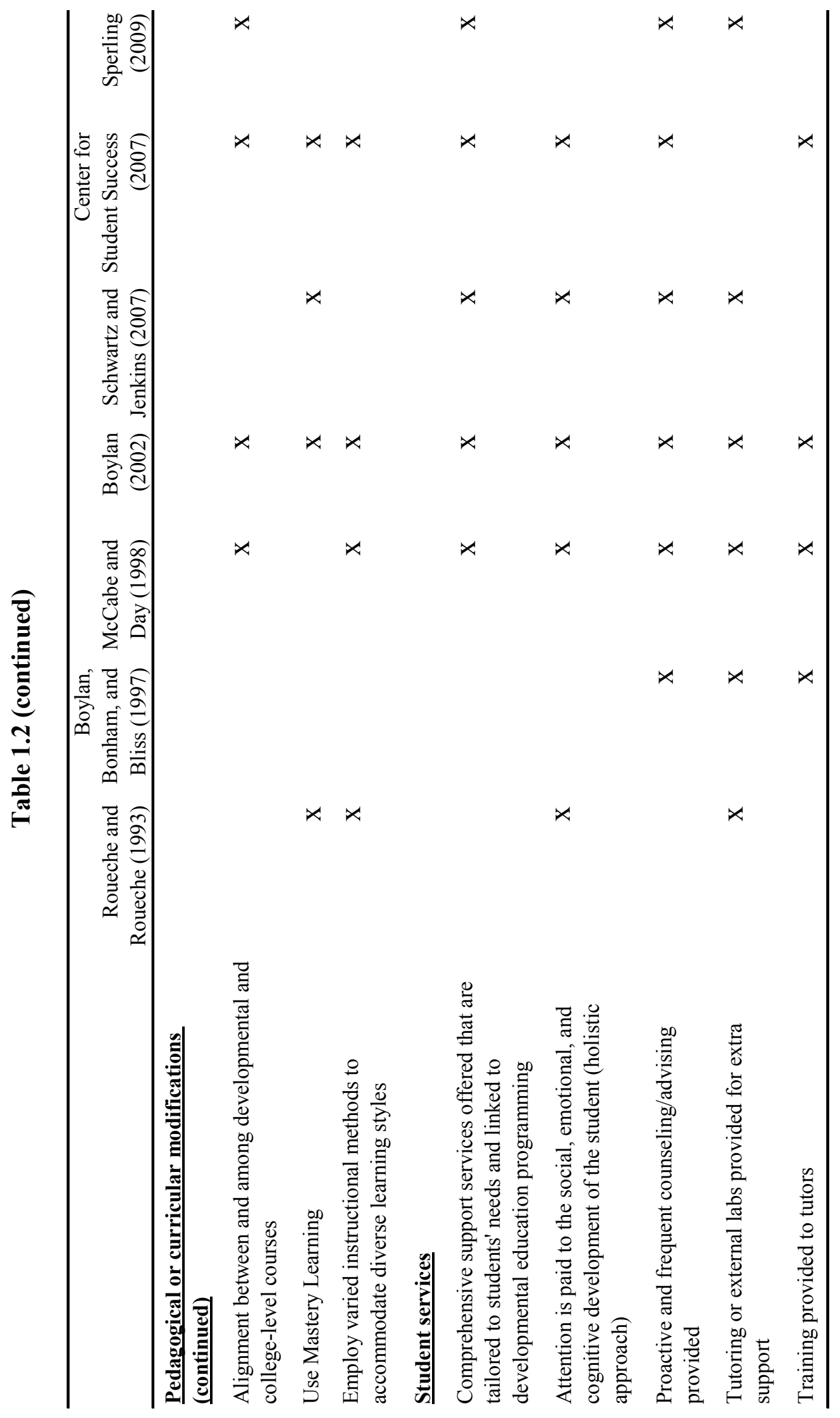


studies are based on descriptive statistics or correlation analyses, which document whether a specific program practice is correlated with higher student outcomes. Although such studies can suggest how particular services may be related to students' achievement, they do not provide definitive proof that such relationships exist. (See Table 1.3.) Indeed, the relationships identified may well be due to other factors in a students' experience that have not been unearthed, thus creating a misleading representation of the effects on student outcomes. This is true particularly when a number of different services are being analyzed together within one institution, as is often done in case study or survey research, making it difficult to disentangle which practice, if any, may be responsible for improved student achievement. As such, studies that use correlational analysis should be approached with caution, as they rarely provide a clear understanding of how particular program services may affect students' achievement.

Additionally, while some of these studies attempt to monitor the outcomes of students who received an intervention, often they share only descriptive statistics. The few comparative studies available employ only simple methods: before-and-after comparisons of outcomes among the same group of students or comparisons of outcomes for program participants and an observably similar group of students who did not receive the program. (See Table 1.3.) Beforeand-after studies can be useful for monitoring the trends in student achievement, while matched control analyses can provide some sense of how a program may have influenced achievement. However, these simple comparisons do not account for other, preexisting characteristics that may affect students' achievement; nor do they measure how any differences in these characteristics might influence different outcomes for the program and comparison groups. As such, they provide only a rough estimate of the trends in student achievement, rather than definitive proof of a strategy's success.

Furthermore, few of these studies provide specificity about the quality of a program's implementation, the content of particular program components, or the quantity that is needed to see improvements in students' success. For instance, a number of studies recommend instituting mandatory assessment and placement into developmental education on students' entry into college. However, they do not specify the type of assessment that should be used, how students should be divided across different developmental education levels, or at what point students should be considered college-ready. Generalizations like these are evident in much of the research on developmental education practices, making it difficult to ascertain how different permutations of particular practices may affect students' achievement or progress into creditbearing courses.

Finally, much of the research on best practices in developmental education tends to provide tacit acceptance of students' current performance and the practices that are generating their disheartening outcomes. For instance, many of the exemplary colleges profiled in earlier literature reviews did not report an overall profile of their students' achievement. However, 


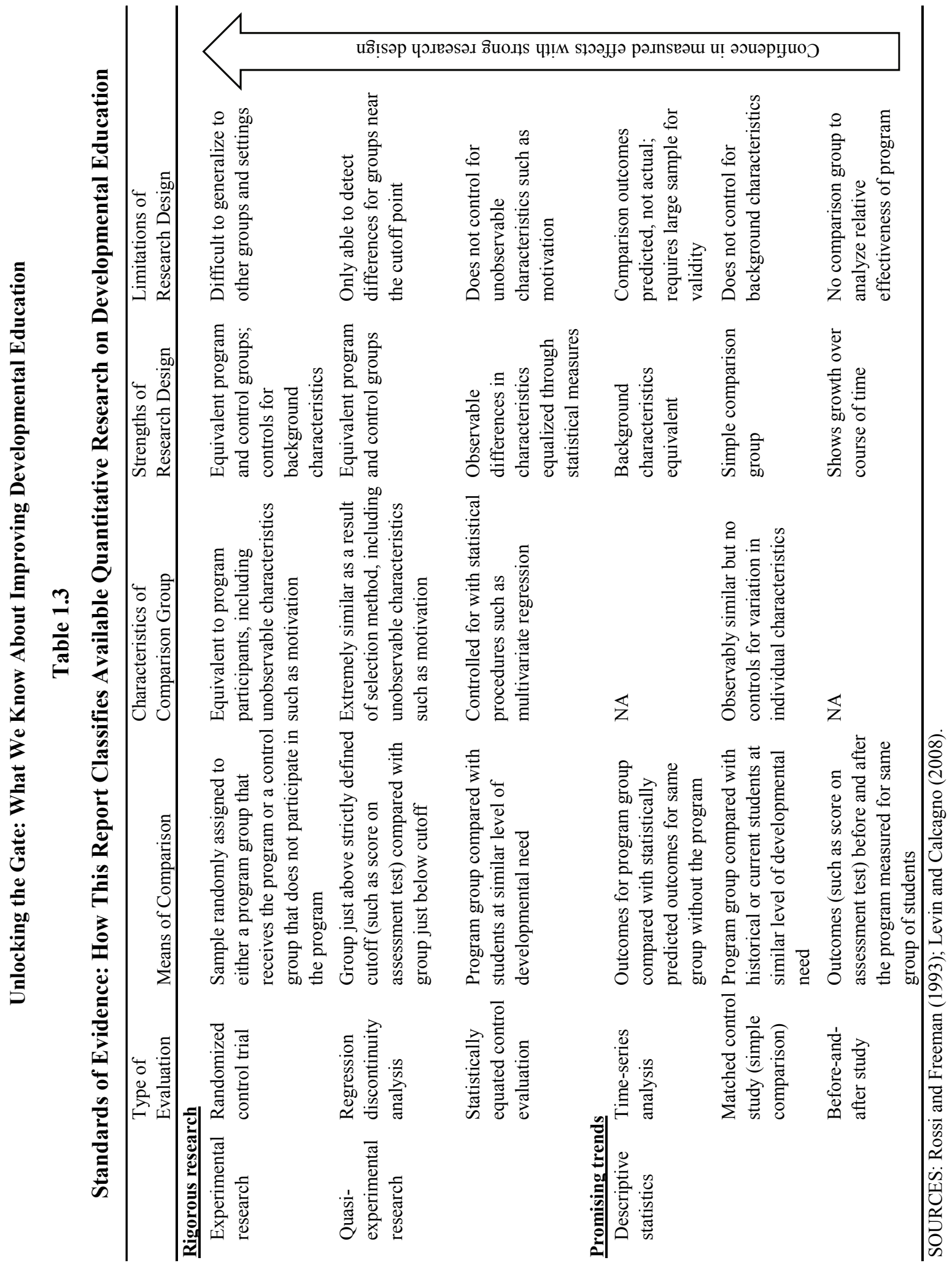


when this was reported, many schools had dissimilar student achievement levels, with large proportions of developmental education students still struggling to make it through their programs. ${ }^{12}$ Such challenges reveal that even institutions that had implemented a number of researchers' recommended practices still had difficulty helping students move into college-level courses and graduate. These challenges become even more apparent when looking at developmental education students' performance on a national scale, as multiple studies have noted that few students complete their developmental education sequence, move on to credit-bearing courses, or graduate with a degree or certificate. ${ }^{13}$ Such findings reveal that more radical changes may be needed to improve developmental education students' outcomes, with a much sharper focus on documenting the changes in their achievement over time.

\section{Rigorous Research in Developmental Education: The Next Step}

Over the past decade, new research has begun to take a more rigorous approach to analyzing developmental education programs and practices. ${ }^{14}$ Several key changes define these studies, as opposed to the descriptive statistics and correlational research of the past. First and foremost, these studies employ more rigorous methods of analysis that attempt to account for differences in baseline student characteristics and to minimize spurious correlations between potentially unrelated variables. (See Table 1.3.) These studies also attempt to directly measure the effects of particular programs, services, or developmental education programs as a whole on students' achievement and to clarify which factors, if any, may be associated with increases in achievement.

Additionally, students' progress tends to be measured by particular benchmarks, such as assessment scores, progress through specific levels of developmental education, course pass rates, persistence, and/or graduation rates. Often, these studies employ longitudinal designs whereby student outcomes can be tracked over a number of semesters or years, allowing changes in outcomes to be measured more definitively. Finally, this research tends to pay close attention to program scale, either by analyzing students' achievement using large state or national databases or by tracking the effects of large-scale programs that enroll many students.

\footnotetext{
${ }^{12}$ Boylan and Bonham (1992); Roueche and Roueche (1993); McCabe and Day (1998); Boylan (2002).

${ }^{13}$ Adelman (2004); Attewell, Lavin, Domina, and Levey (2006); Bailey (2009); Jenkins, Jaggars, and Roksa (2009).

${ }^{14}$ Adelman (2004); Attewell, Lavin, Domina, and Levey (2006); Jenkins, Jaggars, and Roksa (2009); Bahr (2010); Bailey, Jeong, and Cho (2010); Bailey and Alfonso (2005); Calcagno and Long (2008); Goldrick-Rab (2007); Bettinger and Long (2009); Grubb (2001a); Karp et al. (2008); Levin and Calcagno (2008); Martorell and McFarlin (2007); Scrivener et al. (2008); Visher, Butcher, and Cerna (2010); Weiss, Visher, and Wathington (2010); Weissman et al. (2011).
} 
Such attention to larger populations of students allows findings to be more readily generalized to whole populations of developmental education students.

Beyond the increasing reliability of their results, these more rigorous studies provide a number of benefits for analyzing developmental education programs and their students' achievement. First, they help provide a clearer picture of the overarching challenges in developmental education, as they are able to document the trends in student achievement at a larger scale. Additionally, many measure student achievement by recording students' performance before the intervention has occurred, thereby creating a more accurate basis for assessing progress or lack thereof after students' participation in a program. Finally, the analyses of particular program interventions often identify key program characteristics, allowing for a more concrete understanding of how differences in program components or implementation may affect students' achievement.

In order to provide a clearer picture of the link between programs and student outcomes, this review focuses primarily on these more rigorous analyses of developmental education programming and policies. In particular, given the challenges in promoting developmental education students' achievement, this review also seeks to document practices that focus on improving students' progress through developmental education and into credit-bearing courses. In cases where the research on these programs is limited, the key theoretical tenets of the programs and descriptive statistics are discussed, with an eye toward how future research may explore these trends more rigorously and develop more conclusive findings.

\section{Methods Used for This Literature Review}

In order to access articles on developmental education programming and policies, an in-depth computerized search of the literature was conducted using the Education Resources Information Center (ERIC) database of the Institute of Education Sciences. Additionally, numerous higher education and general education journals were analyzed for specific articles related to developmental education. (See Appendix A.) Key words used in the search include "developmental education," "remedial education," "basic skills," and "community college." In addition, several journals related to research in community colleges and developmental education were hand-searched, including the Community College Journal of Research and Practice, Journal of Developmental Education, and Research in Developmental Education. Finally, a thorough search was conducted of the Web sites and publications of organizations dedicated to research on community colleges and developmental education, including such organizations as the Community College Research Center, the National Association for Developmental Education, and MDRC. 
For each of the studies reviewed, the type of research conducted was noted, using six categories: (1) experimental, or random assignment, research; (2) quasi-experimental research; (3) descriptive statistics; (4) practitioner, or qualitative, research; (5) theory; and (6) literature review. As shown in Table 1.3, studies were considered rigorous if they employed an experimental or quasi-experimental design, both of which utilize methods to control for differences in students' background characteristics. Random assignment methodology is the most rigorous of these methods, as it uses a lottery system to assign study participants to either a treatment group that receives an intervention or a control group that does not. Because assignment to these groups is random, differences in students' motivation and background characteristics are minimized, thus allowing for a truer measure of a program's effects. While quasi-experimental research uses statistical controls for observable characteristics, such as educational background, these studies are not as widely generalizable as experimental studies.

Given the limited availability of rigorous research in developmental education, studies noting promising trends in students' achievement were also tracked, particularly for more recent, innovative designs that have not yet been rigorously evaluated. Studies documenting promising trends in student achievement often provide quantitative analyses of student outcomes for particular interventions or programs, sometimes with reference to a comparison group that did not receive the intervention. However, these studies generally lack a more rigorous design due to their selection and analysis of comparison groups; these tend to be convenience samples that do not necessarily provide the best reference point for changes in students' outcomes, and the researchers do not attempt to control for differences in students' prior achievement or characteristics. Many of the practitioner-led studies fall into this category.

General statistics describing the current or past state of developmental education were also noted, as well as theoretical work on promising practices or strategies in developmental education. The statistical studies were used to denote larger trends in developmental education or to describe the characteristics of particular student populations, such as the number of developmental students in community colleges. The theoretical studies, published by both researchers and practitioners, were reviewed in order to better understand the theoretical foundations of a particular practice and its intended outcomes.

\section{Identification of Promising Intervention Models}

Once selected for inclusion in this review, the research studies were grouped by the type of intervention discussed, using four broad categories:

1. Interventions aimed at helping students avoid developmental education. These strategies are designed to identify academically underprepared students before they enter college and to provide extra instructional supports to 
get them "up to speed" in order to bypass developmental education coursework. Common interventions include early assessment programs or summer bridge programs for recent high school graduates. (See Chapter 2.)

2. Interventions designed to accelerate students' progress through developmental education. These programs focus on compressing developmental education courses into shorter sequences in an effort to help students move as quickly as possible into college-level or professional-technical courses. Key acceleration strategies include the modularization of traditional developmental education courses, or "fast-track" courses, that provide instruction in compressed time periods. (See Chapter 3.)

3. Programs that provide contextualized learning opportunities. These models seek to provide a richer context for student learning by integrating a basic skills curriculum with vocational or college-content coursework. Typical models include integrated basic skills training in technical or professional programs or learning communities models that link developmental education courses with other college-level courses and seek to enhance students' social integration at the college. (See Chapter 4.)

4. Programs and services to further support developmental learners' educational advancement. Programs designed to enhance the supports for developmental-level learners include interventions such as tutoring, advising, and student success courses. These strategies tend to focus on enhancing a college's support resources or on increasing students' usage of existing resources, in an effort to help students overcome a multitude of barriers that may limit their academic progress. (See Chapter 5.)

Each of these types of models reflects a different entry point for improving students' progress through developmental education, transitioning into credit-bearing courses, and, ultimately, graduating with a degree or certificate. These types of interventions and the research evidence supporting their success are discussed in Chapters 2 through 5. Chapter 6 then provides a synthesis of these models and offers suggestions for further research. 


\section{Chapter 2}

\section{Interventions for Avoiding Developmental Education}

The goal of developmental education is simple: prepare students to engage in college-level work so that they can earn a credential in their field of choice and leave school qualified for a greater range of jobs and salaries. With this goal in mind, two- and four-year institutions have established a system for preparing academically underprepared students for collegelevel work by devising a sequence of semester-long courses aimed at improving their skills. Generally focused on improving students' reading, writing, and math abilities, most community colleges offer sequences of two to four levels of preparatory work in each of these subject areas. ${ }^{1}$ Students are placed into these classes based on their scores on a common placement test, which is designed to assess whether they have the skills to enter directly into college-level courses. ${ }^{2}$ Students must work upward from the level to which they are assigned, toward entry into college-level, credit-bearing courses. Additionally, they may be barred from college-level courses in their field of interest until their developmental prerequisites are completed.

While providing a noble opportunity for further preparation, the lengthy sequence of developmental education courses offered at most community colleges has also been criticized for creating an often-insurmountable barrier to students' progress through college. Recent large-scale studies have shown that a majority of students never enroll in or complete the recommended sequence of developmental education courses to which they are referred. ${ }^{3}$ This is particularly true of students with multiple developmental needs, as numerous studies have revealed that the number of developmental courses that a student places into is negatively associated with the student's likelihood of completing developmental education courses. ${ }^{4}$ Finally, there is mixed evidence on whether developmental education is beneficial for students who are placed into these courses. Some studies have revealed positive outcomes for students who are assigned to developmental education ${ }^{5}$ or who complete the developmental education sequence. ${ }^{6}$ However, other studies demonstrate that — at least for

\footnotetext{
${ }^{1}$ Bailey, Jeong, and Cho (2010); Parsad and Lewis (2003).

${ }^{2}$ Common placement tests include the ACCUPLACER (developed by the College Board) and COMPASS (developed by ACT, Inc.) However, each college (or district) chooses which test(s) to accept and where to set the cutoff scores for college-level coursework.

${ }^{3}$ Bailey, Jeong, and Cho (2010); Jenkins, Jaggars, and Roksa (2009).

${ }^{4}$ Bahr (2010); Bailey, Jeong, and Cho (2010); Jenkins, Jaggars, and Roksa (2009).

${ }^{5}$ Bettinger and Long (2009); Lesik (2006).

${ }^{6}$ Bahr (2010); Attewell, Lavin, Domina, and Levey (2006).
} 
students at the highest levels of academic preparation - participation in developmental education has little or no effect on subsequent academic performance. ${ }^{7}$

Given these challenges, a number of colleges have begun to focus on helping students better prepare for college-level work before they enter postsecondary education. Usually in collaboration with local high school districts, colleges have sought to identify students who are academically underprepared for college work and to provide them with extra instruction or supports to avoid placement into developmental education courses. The key goal of these programs is to improve students' skills before they enter college, thereby allowing them to bypass developmental education and enroll directly in college-level, credit-bearing courses. These programs may be provided by the high school itself and may take place while students are still enrolled in their junior or senior year. Other programs are offered by colleges and provide students with the opportunity to build their skills during the semester or summer before their entry into college. Often, high schools and colleges offer several of these types of programs, thereby providing a number of entry points for additional preparation.

\section{Models for Avoiding Developmental Education}

A number of common strategies exist for helping students avoid developmental education. Dual enrollment programs, which allow high school students to take college courses while still enrolled in high school, are relatively well-established strategies across U.S. community colleges and have recently been expanded beyond their traditional focus on high-achieving students to include students who have more basic skills needs. Another intervention focused on secondary institutions provides early assessments to high school enrollees. In these programs, high school students take the local college placement exam during their junior or senior year, and those who are deemed underprepared for college-level work are encouraged to follow a course of instruction to improve their college readiness before graduating from high school. Colleges have also developed similar types of early assessment programs for recent high school graduates; these programs are then used to recommend entering students to summer bridge programs. Summer bridge programs provide the final opportunity for entering students who have tested into developmental education courses to learn or relearn essential knowledge just before their college coursework begins. More information about each of these interventions and the related research is provided below.

\section{Dual Enrollment Programs}

As noted above, dual enrollment programs allow students to enroll in college courses and earn college credits while they are still enrolled in high school. Similar to Advanced Place-

\footnotetext{
${ }^{7}$ Calcagno and Long (2008); Martorell and McFarlin (2007).
} 
ment and International Baccalaureate programs, dual enrollment programs exist in most states and school districts across the country, though the policies around minimum academic requirements, tuition, and course options vary greatly. ${ }^{8}$ National data show that nearly every community college in the United States (along with three-quarters of public four-year colleges) offer opportunities for high school students to take courses for college credit within a dual enrollment program and that about 4 percent of high school students take advantage of these programs. ${ }^{9}$

\section{Examples of Dual Enrollment Programs}

While dual enrollment programs have long been a popular option for high-achieving students, they have only recently begun to target less academically prepared students. Although still limited, ${ }^{10}$ several models have been developed that create more structured opportunities for at-risk students, at no cost, to attempt courses that require the academic rigor and thinking expected in college-level courses. ${ }^{11}$ These programs include both high school and college-level courses, with a focus on college preparatory coursework for students who are academically underprepared in a particular subject. In addition, these programs aim to familiarize students with the college environment and, by doing so, to make the pursuit of a postsecondary degree an imaginable prospect. ${ }^{12}$

Two large-scale interventions - College Now and the Middle/Early College High School movement - provide good examples of well-established dual enrollment programs aimed at academically disadvantaged students. Though begun at Kingsborough Community College in Brooklyn, New York, College Now programs are offered at a number of institutions through the country. ${ }^{13}$ Generally, College Now courses are offered at the college campus and are taught by traditional college faculty, or they are delivered at the high school by specially trained high school faculty. Students often take a placement test or other standardized exam to become eligible for the program, and those who score below a mini-

\footnotetext{
${ }^{8}$ Bailey, Hughes, and Karp (2003).

${ }^{9}$ Kleiner and Lewis (2005).

${ }^{10}$ In the 2002-2003 school year, 110 institutions offered dual enrollment programs specifically targeting at-risk students; these programs served about 6,400 students (Kleiner and Lewis, 2005).

${ }^{11}$ American Institutes for Research and SRI International (2007); Jobs for the Future (2009); Karp et al. (2008).

${ }^{12}$ American Institutes for Research and SRI International (2007); Kleiman (2001). See also the Web sites for College Now in New York (http://collegenow.cuny.edu) and the Early College High School Initiative (www.earlycolleges.org).

${ }^{13}$ Kleiman (2001). Examples of other colleges with College Now programs include Lane Community College in Eugene, OR (http:/www.lanecc.edu/hsconnections/collegenow/index.html); Linn-Benton Community College in Albany, OR (http://www.linnbenton.edu/go/collegenow); Mt. Hood Community College in Gresham, OR (http://www.mhcc.edu/CollegeNow/); and Allan Hancock College in Santa Maria, CA (http://www.hancockcollege.edu/Default.asp?Page=740).
} 
mum threshold are eligible to take developmental-level education courses while still in high school. ${ }^{14}$ College Now thus also serves the important purpose of informing students about their readiness for college classes, while giving them an opportunity to improve their skills before enrolling in college.

The Middle/Early College High School movement is an all-encompassing version of dual enrollment. Such programs integrate high school enrollment with the first two years of college, so that students have the opportunity to accumulate credit toward an associate's degree, along with earning their high school diploma. Originally, schools that had these programs were designated "Middle College High Schools" and were located on college campuses. However, with a recent investment from the Bill and Melinda Gates Foundation, the model has expanded and been revamped as stand-alone small high schools, now termed "Early College High Schools." ${ }^{15}$ Like students in College Now programs, these students can take a mix of high school and college-level courses, based on their level of preparation and interest. ${ }^{16}$ On graduation, they can potentially earn both a high school diploma and an associate's degree.

\section{Research Evidence Supporting Dual Enrollment Programs}

Research on dual enrollment programs for academically needy students is relatively limited and is based primarily on studies of College Now programs at colleges in the City University of New York (CUNY) system, where the program was established, and on a developing national study of Early College High Schools. ${ }^{17}$ Additionally, most of the available studies tend to focus on the implementation of these interventions or undertake statistical analyses that do not employ rigorous methods, making it difficult to ascertain their true effects on student achievement. While some studies use comparison groups, most of them make simple comparisons that do not take into account such factors as preexisting differences in students' achievement levels.

Evidence about College Now's effectiveness is promising but partial, and none of the available studies specifically examine outcomes for academically underprepared students. (See Table 2.1.) However, early data showed that the college grade point averages (GPAs) of College Now students were comparable to those of a national sample of freshmen. ${ }^{18}$ More recently, comparison studies of CUNY's College Now program found that it had small but statistically significant benefits for students who matriculated at a CUNY

\footnotetext{
${ }^{14}$ Kleiman (2001).

${ }^{15}$ Golann and Hughes (2008).

${ }^{16} \mathrm{Kim}$ and Barnett (2008).

${ }^{17}$ Michalowski (2007); American Institutes for Research and SRI International (2007); Karp et al. (2008).

${ }^{18}$ Greenberg (1988).
} 


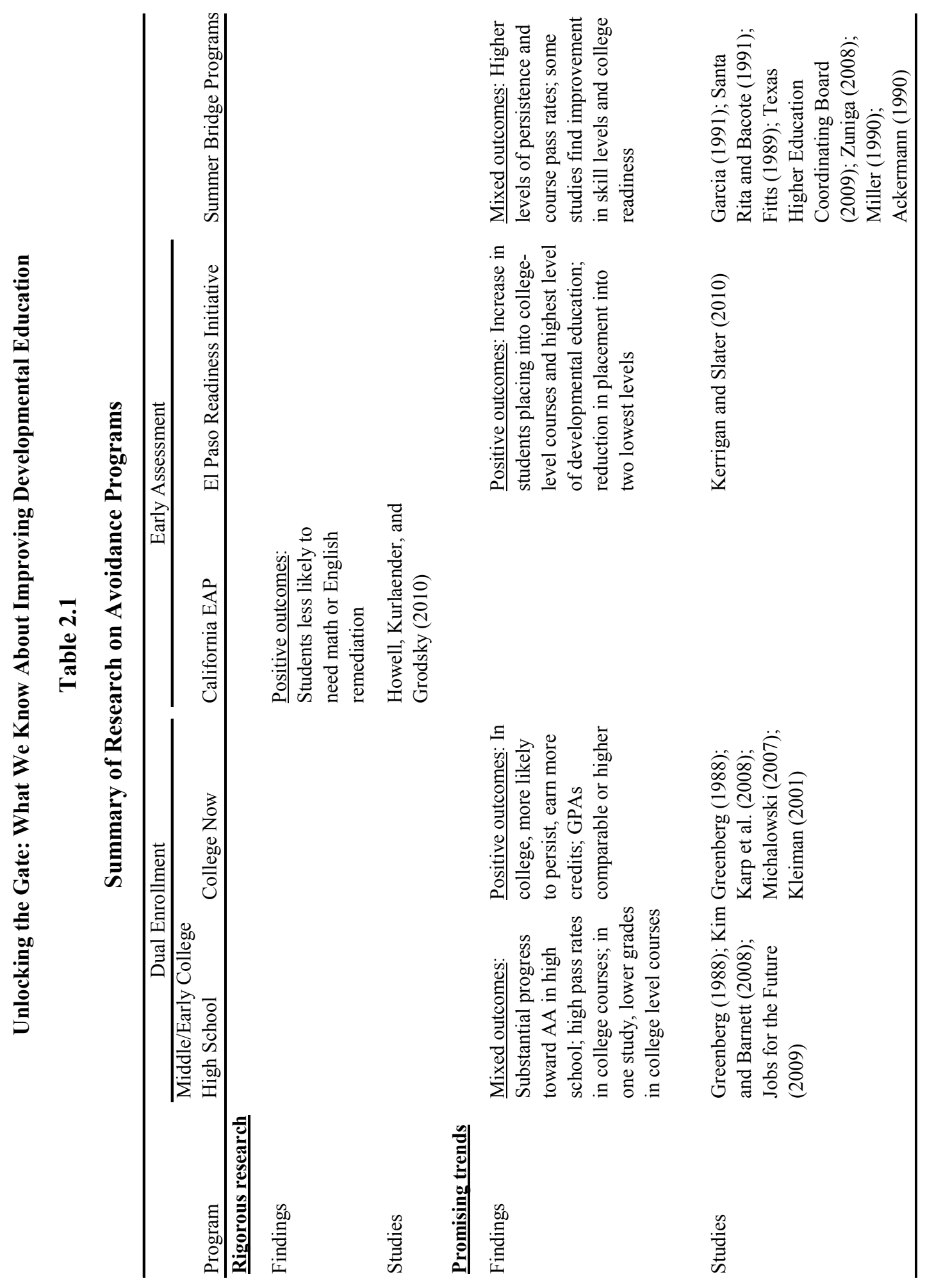


college, compared with a group of CUNY freshmen who did not enroll in College Now. Both studies found that College Now students earned more credits and were more likely to persist than students in the comparison group; one study also found a decrease in the likelihood of remediation, and the other found that, among students who were pursuing a bachelor's degree, College Now students also had slightly higher GPAs. ${ }^{19}$ Similarly, a largescale analysis of several College Now programs at vocational high schools and several CUNY campuses found that College Now students were more likely to pursue a bachelor's degree, to earn a higher first-semester GPA, and to earn more college credits after seven semesters of postsecondary enrollment. ${ }^{20}$

Evidence on Middle/Early College High Schools is limited and nonexperimental, though more rigorous analyses may be available in the future as a result of an evaluation of Gates Early College High Schools being conducted by the American Institutes for Research (AIR) and SRI International. ${ }^{21}$ Early trend data on Middle College High Schools revealed less positive results for academically disadvantaged students, as these students tended to receive worse grades in college than a national sample of freshmen. ${ }^{22}$ However, more recent nonexperimental studies have shown more positive results, with one sample of Early College High School students successfully making progress on postsecondary education goals, earning an average of 27 college credits by the end of high school and passing 90 percent of college courses after matriculation. ${ }^{23}$ National analyses have further confirmed these positive trends, with 75 percent of 2007 Early College High School graduates earning some college credit and 10 percent on top of those earning enough credits for an associate's degree. Additionally, over 60 percent were accepted to four-year colleges. ${ }^{24}$ However, as noted above, these findings should be approached with caution, as they do not account for preexisting differences in students' characteristics and academic achievement, and the only comparison employed is with national trend rates for an observably similar population.

\section{Early Assessment Programs}

One way to ensure that high school students are college ready is to test their skills with the same assessment instruments that are used to place them in developmental courses when

\footnotetext{
${ }^{19}$ Michalowski (2007); Kleiman (2001).

${ }^{20}$ Karp et al. (2008). Like the previously cited studies, this study employed some controls for background characteristics but did not use a quasi-experimental design; therefore, these results are categorized as promising trends.

${ }^{21}$ Much of this work to date has been about the implementation of the programs and students' experiences in the programs. For example, see American Institutes for Research and SRI International (2007) and other reports in this series.

${ }^{22}$ Greenberg (1988).

${ }^{23} \mathrm{Kim}$ and Barnett (2008).

${ }^{24}$ Jobs for the Future (2009).
} 
they enroll in college. In this way, students who are academically underprepared for college courses can be identified early and given extra time or tools to strengthen their skills before they arrive at college. As noted above, early assessment programs are generally developed collaboratively by colleges and high school districts.

\section{Examples of Early Assessment Programs}

While early assessment programs are a relatively new intervention, two promising, large-scale examples can be seen in the State of California's Early Assessment Program and in El Paso Community College's College Readiness Initiative in El Paso, Texas.

California's Early Assessment Program (EAP) is designed to inform high school juniors, along with their educators and family members, whether the California State University (CSU) system would consider them academically prepared to take college-level courses in English and math. Designed jointly by CSU and the state's Department of Education, the EAP adds optional questions to a mandatory statewide test for eleventh-graders to assess their college readiness, and it provides them with concrete steps to follow if they are deemed academically underprepared. While students who score above a certain threshold on these questions are exempted from the CSU placement exam and remedial coursework, students who score below the threshold can follow several pathways during their senior year to improve their skills, with the goal of being ready for college-level work when they matriculate at a CSU campus. These pathways include taking additional math, reading, or writing courses during their senior year or enrolling in an online math learning program designed by CSU. Ideally, these options will allow students to make an informed decision about enrolling in college and, potentially, will make it possible for them to avoid taking developmental education courses. ${ }^{25}$

A similar program on a smaller scale has been developed at El Paso Community College. The college has implemented an early assessment program — the College Readiness Initiative - in partnership with the University of Texas at El Paso and the local school districts. The College Readiness Initiative is predicated on a common concern about the validity of assessment test results: namely, the belief that some students do poorly on assessment tests when they enroll in college simply because they are unprepared to take the test, not because they are unprepared for college-level coursework itself. To address this, the community college and the university worked with local high schools to develop a protocol for graduating seniors to prepare for this exam. The protocol encourages students to (1) complete a joint application to both institutions; (2) attend an orientation about the college's placement test (ACCUPLACER), which includes an introduction to the high-stakes nature of the test and review materials for the exam; (3) take the placement exam; and (4) meet with

\footnotetext{
${ }^{25}$ Howell, Kurlaender, and Grodsky (2010).
} 
a counselor at the high school to review test scores and make decisions about the best way to move forward, given their level of academic preparation. Students qualifying for developmental courses can complete a refresher course in the subject(s) of their weakness or can enroll in a five-week summer bridge course with intensive work in reading, writing, and math. These students can then retake the ACCUPLACER for a final placement score, with the hope that they will be assessed into college-level courses or a more advanced developmental education course. ${ }^{26}$

\section{Research Evidence Supporting Early Assessment Programs}

Both California's Early Assessment Program and El Paso's College Readiness Initiative have seen positive improvements in students' achievement, with a more rigorous analysis of California's EAP program demonstrating key reductions in the number of students placed into developmental education. (See Table 2.1.) In a quasi-experimental analysis of the placement patterns at CSU's Sacramento State, students who participated in the EAP were less likely than similar students who did not participate to need developmental English and developmental math (reductions of 6.1 and 4.1 percentage points, respectively) ${ }^{27}$ While this study was unable to control for students' motivation levels, it did account for a number of other factors, including differences in students' characteristics and in their high schools.

El Paso Community College undertook a less rigorous, internal evaluation of its College Readiness Initiative and found promising trends in students' placement into developmental education. Over the course of three years, the findings revealed an increase in the number of students placing into college-level courses (ranging from an increase of 2 percentage points in math to 15 percentage points in writing) and who placed into the highest level of developmental education. (Most notably, the proportion of students placing into the highest level of developmental math increased by 13 percent.) These increases were paired with a reduction of 5 to 9 percentage points in the proportions of students placing into the two lowest levels of developmental courses in all subjects. ${ }^{28}$ While these trends cannot be causally linked to El Paso's program, they demonstrate that this type of program may be a promising method for reducing placements in developmental education courses.

\section{Summer Bridge Programs}

Summer bridge programs can provide a last-minute opportunity for students who qualify for developmental education courses to develop their skills before entry into college. These programs have been popular for a number of years at four-year institutions and have recently

\footnotetext{
${ }^{26}$ Kerrigan and Slater (2010).

${ }^{27}$ Howell, Kurlaender, and Grodsky (2010).

${ }^{28}$ Kerrigan and Slater (2010).
} 
become more widely implemented at community colleges. ${ }^{29}$ While not providing the residential component that is often associated with four-year colleges' programs, community college summer bridge programs also seek to foster a quick boost in students' skills in a relatively short time frame.

\section{Examples of Summer Bridge Programs}

Though they can take many forms, summer bridge programs generally require students to attend on-campus classes for several weeks during the summer before the fall semester begins. Courses take place during a compressed time period - usually three to five weeks - for students who have taken placement exams and tested into developmental education. Courses may focus on only one academic subject at a time or may touch on all developmental course areas and may range from a quick review of course concepts to more formal classes. Some summer bridge programs also incorporate a college-skills seminar that seeks to introduce students to college life and responsibilities. The goals of these programs vary from efforts to improve students' placement test scores to helping students complete one or more developmental courses before entry into college. Often summer bridge programs are offered free of charge to students as a quick, economical way to improve their academic skills. ${ }^{30}$

\section{Research Evidence Supporting Summer Bridge Programs}

Only nonexperimental research is currently available on summer bridge programs, and this research is sparse, though showing somewhat promising results on students' achievement. (See Table 2.1.) While summer programs at four-year institutions have shown some positive outcomes, ${ }^{31}$ research in community colleges has been more limited and has tended to focus on the implementation of programs rather than providing rigorous analyses of student outcomes. Older, simple comparison studies of summer bridge programs in New York and New Jersey showed mixed results; some studies revealed higher levels of persistence and subsequent course pass rates, while another found little change in students' skill levels or GPAs. ${ }^{32}$ More recently, internal analyses of student trends from several colleges conducting summer bridge programs in Texas have demonstrated promise, with descriptive statistics showing some improvements in students' study skills and in their readiness for college math and reading. ${ }^{33}$

\footnotetext{
${ }^{29}$ Ackermann (1990); Fitts (1989); Garcia (1991); Miller (1990); Santa Rita and Bacote (1991); Barnett (2009).

${ }^{30}$ Barnett (2009).

${ }^{31}$ Garcia (1991); Ackermann (1990).

${ }^{32}$ Santa Rita and Bacote (1991); Miller (1990); Fitts (1989).

${ }^{33}$ Texas Higher Education Coordinating Board (2009); Zuniga (2008).
} 
Building on these positive trends, a more rigorous analysis of summer bridge programs at eight Texas colleges is currently being conducted by the National Center for Postsecondary Research (NCPR). ${ }^{34}$ The evaluation uses a random assignment research design to compare the effects of four-week to six-week summer bridge programs on students' college enrollment, need for developmental education, GPAs, persistence, and credit accumulation. This research will help provide more definitive evidence with which to evaluate the effects of bridge programs on students' ability to avoid developmental education.

\section{Summary of Avoidance Models}

As can be seen above, very limited evidence is available supporting recent efforts to improve students' chances of avoiding remediation and placing directly into college-level, creditbearing courses. Rigorous evidence is currently limited to an evaluation of California's efforts to provide early assessment to high school students, which has shown positive results in decreasing the number of students placing into developmental education. While many studies have found promising trends related to dual enrollment and summer bridge programs, additional research is clearly needed to confirm what effects these programs have on reducing community college students' need for remediation. Given the promising trends noted with dual enrollment programs and early placement testing, these strategies appear to be the most promising for more rigorous analysis. Key to this research will be a clear demarcation of students' differing levels of need as well as documentation of how programs with differing structures and intensity affect placement into developmental and college-level courses. As the number of academically underprepared students leaving high school continues to rise, such studies will provide critical information about how to better prepare students for full entry into college-level courses and programs.

\footnotetext{
${ }^{34}$ Barnett (2009).
} 


\section{Chapter 3}

\section{Accelerating Students' Progress Through Developmental Education}

One of the key criticisms of developmental education is the lengthy amount of time that many students spend in remedial courses before reaching college-level work. As noted in Chapter 2, most community colleges provide multiple levels for each developmental education subject and require students to successfully complete each level before progressing to the next. Given that virtually all these courses are taught as semester-long classes, students who place at the lowest levels in a particular subject take multiple semesters - even years - to complete the course sequence in math, reading, or writing, in order to enroll in college-level courses. To make matters worse, most students do not receive standard college credits for the developmental education courses that they take, nor are these courses transferrable to four-year institutions. Yet students are required to pay for these courses, often using significant chunks of their limited financial aid packages to subsidize the costs. ${ }^{1}$

Recent research has pointed out the difficulties that can be engendered by this long course sequence. For instance, in an analysis of data from Achieving the Dream: Community Colleges Count - a large national initiative now encompassing over 10 percent of community colleges - less than 30 percent of students who place into the lowest levels of developmental math and reading ever complete their developmental education coursework. Often, these students fail to enroll in the first developmental education course to which they were referred, or they do not reenroll in the subsequent level after successfully completing the first recommended course. Additionally, around 10 percent of students who are directed to the lowest level of developmental math successfully complete a college-level math course, while fewer than 30 percent who are directed to the highest level completed these courses. ${ }^{2}$ Such findings reveal the enormous hurdles facing students who place into developmental education courses, particularly those with multiple remedial needs.

As a result, greater attention has been placed recently on helping students progress more quickly through the lengthy developmental education sequence. Most frequently, such programs have focused on modifying the timing of these courses, with an effort to condense the amount of time needed to complete a particular level. These reframed courses are generally designed to serve students with variable levels of need, creating alternative options for the pace

\footnotetext{
${ }^{1}$ Melguizo, Hagedorn, and Cypers (2008).

${ }^{2}$ Bailey, Jeong, and Cho (2010).
} 
of instruction, depending on students' skill levels in a particular area. For instance, some colleges offer compressed courses in which students may brush up on their skills, in preparation for direct entry into a college-level course. Other courses offer self-paced instruction, which allows individual students to determine the amount of time to spend on particular tasks or skills. In considering which option to recommend, colleges often refer to students' placement test scores; higher-scoring students are placed into faster-paced review courses, while lower-scoring students are referred to slower-paced instructional models.

\section{Models for Accelerating Students' Progress Through Developmental Education}

Several models exist for accelerating students' progress through developmental education. With a focus on providing instruction in a shorter time frame, some colleges have developed fasttrack courses that compress the developmental education curriculum into several weeks or a half semester, allowing students to pass through multiple levels in a single semester. Alternately, other models focus on offering self-paced instruction through modularized courses. This approach creates multiple mini-courses that focus on particular skill sets rather than offering the whole curriculum in one continuous course; it allows students to strengthen particular weaknesses that they may have in a subject area while bypassing instruction in their areas of strength. A third model relies on the assumption that students who are deemed developmental-level are capable of the work in college-level courses, given extra assistance or a different curricular approach. This approach of mainstreaming students directly into college-level courses offers supplemental supports, such as tutoring or study skills courses, for the group of students who have greater academic needs. Each of these acceleration models and its accompanying research evidence is discussed below, and Table 3.1 summarizes the research on these strategies.

\section{Fast-Track Courses}

As noted above, fast-track courses offer classes in a compressed time frame, usually in over several weeks during the summer or in half a semester during the regular school year. Generally, two levels of a particular developmental education subject are offered together and run back to back within the same semester, allowing students to complete both courses within one semester.

\section{Examples of Fast-Track Courses}

At Mountain Empire Community College in Big Stone Gap, Virginia, Fast-Track Math provides two levels of developmental math as half-semester courses designed to articulate with each other, with a focus on review and fast-paced instruction. This allows students to complete 


\section{Unlocking the Gate: What We Know About Improving Developmental Education}

Table 3.1

\section{Summary of Research on Acceleration Strategies}

\begin{tabular}{|c|c|c|c|}
\hline Program & Fast-Track Courses & Modularized Courses & $\begin{array}{l}\text { Mainstreaming into } \\
\text { College-Level Courses }\end{array}$ \\
\hline \multicolumn{4}{|c|}{ Rigorous research } \\
\hline Findings & & & $\begin{array}{l}\text { Positive outcomes: Higher } \\
\text { rates of attempting and } \\
\text { completing college-level } \\
\text { English and subsequent } \\
\text { courses } \\
\text { Jenkins et al. (2010) }\end{array}$ \\
\hline \multicolumn{4}{|c|}{ Promising trends } \\
\hline Findings & $\begin{array}{l}\text { Positive outcomes: Increased } \\
\text { progress through developmental } \\
\text { education; increased course pass } \\
\text { rates, grades, and rates of } \\
\text { persistence }\end{array}$ & $\begin{array}{l}\text { Positive outcomes: Higher } \\
\text { pass rate in college-level } \\
\text { courses; faster progress } \\
\text { through developmental } \\
\text { course sequence }\end{array}$ & $\begin{array}{l}\text { Positive outcomes: Higher } \\
\text { levels of persistence; } \\
\text { comparable or higher pass } \\
\text { rates in college-level course }\end{array}$ \\
\hline Studies & $\begin{array}{l}\text { Brown and Ternes (2009); Zachry } \\
\text { (2008); Adams (2003); Brancard, } \\
\text { Baker, and Jensen (2006); Bragg } \\
\text { (2009) }\end{array}$ & $\begin{array}{l}\text { Bassett (2009); Bragg and } \\
\text { Barnett (2009); Epper and } \\
\text { Baker (2009) }\end{array}$ & $\begin{array}{l}\text { Goen-Salter (2008); Adams, } \\
\text { Miller, and Roberts (2009); } \\
\text { Jenkins (2009) }\end{array}$ \\
\hline
\end{tabular}

two developmental course levels in one semester. ${ }^{3}$ Similarly, at University of Maryland College Park, students take an accelerated version of the developmental course in the first five weeks of the semester, and then they retake the placement exam. Those whose scores have increased to college-level spend the remainder of the semester in a compressed, intensive version of the college-level course. ${ }^{4}$

Fast-track courses are often designed for developmental education students who are better prepared, and many schools — including these two examples — implement a screening process to ensure that this criterion is met. While most colleges restrict entry to accelerated courses and allow only those students with higher assessment scores to enroll, such practices are not always a requirement. For instance, Community College of Denver's FastStart program

\footnotetext{
${ }^{3}$ Zachry (2008).

${ }^{4}$ Adams (2003).
} 
mandates that students meet with a counselor to ensure that they understand the course structure and speed, but the college does not have a placement score requirement for entry into these courses. ${ }^{5}$

In addition to compressed instruction, fast-track courses may modify their traditional requirements or pedagogy to better suit the revised structure. For instance, these courses may mandate attendance at every class or may require the cohort to enroll in a student success course (discussed in Chapter 5), which provides study skills training that is designed to support learning in the developmental-level courses. ${ }^{6}$ Additionally, fast-track courses often use computer-aided instruction to facilitate self-paced learning. For example, Community College of Denver's FastStart program utilizes computer tutorials in instruction, allowing faculty to monitor individual students' mastery of particular subjects. ${ }^{7}$

\section{Research Evidence Supporting Fast-Track Courses}

Like most developmental education interventions, little rigorous research exists documenting the success of fast-track courses. However, the simple comparisons used in all available studies demonstrate promising trends. For example, fast-track courses at two Ivy Tech Community College campuses in Evansville and Fort Wayne, Indiana, showed increases in students' course pass rates and fewer withdrawals from accelerated courses when compared with courses offered in the traditional semester-long format. ${ }^{8}$ Similarly, in internal evaluations employing simple comparisons between program and nonprogram students, Mountain Empire Community College found that Fast-Track Math students passed the math course and persisted at higher rates. ${ }^{9}$

Exploratory evaluations at University of Maryland College Park found that nearly all the accelerated students moved onto the college-level course, in which they performed at comparable levels to students who went directly into the course. The accelerated program structure also allowed students to pass out of developmental requirements more quickly than students taking the traditional developmental-level class. ${ }^{10}$ Likewise, in two nonexperimental evaluations of Community College of Denver's FastStart math program, students were more likely to pass developmental education math classes, gain more developmental education credits, pass college-level math courses, and stay enrolled in the college than students taking the

\footnotetext{
${ }^{5}$ Bragg (2009).

${ }^{6}$ Zachry (2008); Bragg (2009).

${ }^{7}$ Epper and Baker (2009).

${ }^{8}$ Brown and Ternes (2009), as cited in Edgecombe (2011).

${ }^{9}$ Zachry (2008).

${ }^{10}$ Adams (2003).
} 
semester-long courses. ${ }^{11}$ While these evaluations of FastStart used comparison groups, neither used more rigorous statistical methods to control for preexisting differences between the two groups of students, thereby limiting the reliability of this evidence. Building on these promising results, however, the Community College Research Center (CCRC) will be conducting a quasiexperimental analysis of this program's success as part of its efforts to test a number of promising interventions in developmental education.

\section{Modularized Courses}

Another model for accelerating students' progress through developmental education courses is to divide a traditional semester-long course into discrete learning units, or modules, that are designed to improve a particular competency or skill. This approach has become increasingly popular in the last decade, particularly in restructuring developmental math courses.

\section{Examples of Modularized Courses}

A number of colleges participating in high-profile developmental education reform movements - such as Achieving the Dream's Developmental Education Initiative and the Charles Stewart Mott Foundation's Breaking Through - have used modularized courses as a way to increase students' progress. ${ }^{12}$ While modularized courses can be implemented a number of ways, they generally allow students to prove mastery of particular skills by taking a series of short, focused assessments. After students demonstrate competency, they can move on to more advanced modules.

While some modularized courses are instructor-led, others implement a self-paced format, allowing students to complete particular segments of courses at their own pace. In selfpaced modularization programs, such tutorial software packages as MyMathLab, Plato, ALEKS, and Math Zone are often used to supplement in-class instruction or as the primary vehicle for teaching students new skills. These packages begin by identifying students' skill deficits and then allow them to work independently on building these skills through increasingly challenging content, built around frequent assessments of students' developing abilities. ${ }^{13}$

Math My Way at Foothill Community College in Los Altos Hills, California, and the SMART math program at Jackson State Community College in Tennessee provide two useful examples of modularized math courses. In both programs, the traditional math curriculum has

\footnotetext{
${ }^{11}$ Brancard, Baker, and Jensen (2006); Bragg (2009).

${ }^{12}$ See the Web sites of these initiatives for a list of project participants and the developmental education strategies that they use: Developmental Education Initiative (http://www.deionline.org/); Breaking Through (http://www.breakingthroughcc.org).

${ }^{13}$ Epper and Baker (2009).
} 
been broken down into a series of modules, with frequent assessments by which students demonstrate their mastery of key concepts. Math My Way splits math students into groups by skill level; each group meets with an instructor for two hours a day, five days a week, to learn and master key concepts through self-paced drills and games (both computer- and paperbased). ${ }^{14}$ Jackson State's SMART program is delivered through twelve online instructional modules with supplemental assistance from instructors in a math lab center, where students were required to work at least three hours each week. Students can pass quickly through modules by demonstrating competency in an online pretest at each level; if their skills fall below an 80 percent mastery level, they are required to complete a series of lessons and homework assignments and then pass a proctored posttest. Students can complete the modules at their own pace, and it is possible to complete all three levels of the developmental math sequence in a single semester. ${ }^{15}$

\section{Research Evidence Supporting Modularized Courses}

Evaluations of these modularized courses reveal promising trends in students' achievement, though the evidence is limited to simple comparisons between program and nonprogram students and, therefore, lacks the rigor needed to make causal inferences about these programs' effectiveness. The evaluations show some promising gains in students' pass rates of both developmental and college-level courses as well as gains in students' GPAs and their persistence into subsequent semesters. ${ }^{16}$ For instance, internal evaluations of Foothill's Math My Way program show that students who participated in it had a 20 percent higher pass rate in collegelevel math than nonparticipants, while Jackson State noted a 20 percentage point increase in students' progress through the developmental sequence, which the college attributed to its new modularized course format. ${ }^{17}$

\section{Mainstreaming into College-Level Courses}

Mainstreaming developmental education students into college-level courses is another approach to accelerating their progress that is being explored by a number of community colleges. While different versions of mainstreaming exist, common practices include offering a college-level course with a modified curriculum over a lengthier period of time (usually two semesters) or

\footnotetext{
${ }^{14}$ Epper and Baker (2009).

${ }^{15}$ Bassett (2009).

${ }^{16}$ Bassett (2009); Bragg and Barnett (2009); Epper and Baker (2009).

${ }^{17}$ Epper and Baker (2009); Bassett (2009). These positive results were also enabled by the flexible math requirements put in place by Jackson State as part of its redesign. Administrators used the modules to redefine the math competencies necessary for each program of study, which reduced the requirements for all but seven majors.
} 
providing supplemental supports, such as tutoring or additional class periods, for developmental students who are placed into a traditional college-level class. Both approaches rely on the assumption that students who have remedial needs are, with extra assistance, capable of mastering college-level work.

\section{Examples of Mainstreaming}

Yearlong, college-level courses for developmental students have been more popular in four-year colleges, driven by a political interest in minimizing remedial courses at these institutions. Such courses provide the opportunity to earn college credit immediately, and they contextualize skill acquisition with the applications that these competencies have in a collegelevel course. Additionally, because these courses offer the standard college-level curricula, they align with other college-level courses, effectively bridging the gap that can sometimes occur between the competencies taught in developmental-level courses and those expected in college-level courses. Many courses also emphasize student-centered instructional strategies and rely on a wide range of assessment practices, such as portfolio-based grades. For example, the yearlong Integrated Reading and Writing course at San Francisco State - which replaces semester-long courses in developmental reading, developmental writing, and college composition - reflects a holistic approach to reading and writing, incorporating self-reflective writing and activities to support metacognitive development. ${ }^{18}$ Programs at Arizona State University and at City University of New York (CUNY) use similar activities to support active learning and analytic thinking. ${ }^{19}$

At the community college level, mainstreaming has tended to focus on integrating developmental education students into a traditional semester-length, college-level course and on providing additional supports to enhance students' success. For example, in the Accelerated Learning Project (ALP) at Community College of Baltimore County, a limited number of developmental-level students are placed into a college-level English composition course along with students who tested directly into that course. While the standard college-level curriculum is followed, the developmental-level students also enroll in an additional hour-long companion section, in which the same instructor provides extra assistance and guidance. ${ }^{20}$ A similar type of immersion program has been run in Aptos, California, through Cabrillo College's Digital Bridge Academy (now the Academy for College Excellence), whereby developmental English students receive a two-week basic skills foundations course followed by enrollment in six

\footnotetext{
${ }^{18}$ Goen-Salter (2008).

${ }^{19} \mathrm{Glau}$ (2007); Gleason (2000). The CUNY program ended as a result of the institutional decision to relegate all developmental-level students to the system's community colleges, rather than providing remediation at the four-year colleges as well.

${ }^{20}$ Adams, Miller, and Roberts (2009).
} 
integrated courses, including the college-level English course. The program also features supplemental supports for students, including study groups, counseling, and other services. ${ }^{21}$

\section{Research Evidence Supporting Mainstreaming}

The most promising evidence for mainstreaming developmental-level students into college-level courses comes from the Community College Research Center's quasi-experimental evaluations of the Accelerated Learning Program (ALP) at Community College of Baltimore County. When comparing students with similar skill levels and controlling for preexisting characteristics, it was found that students who participated in ALP completed introductory college-level courses, enrolled in and completed additional college English requirements, and attempted college courses at higher rates than non-ALP students. ${ }^{22}$

Less rigorous studies have also shown promising trends. The yearlong college-level courses offered to remedial students at four-year colleges have shown promising increases in students' persistence and course pass rates as well as improved comprehension skills. For instance, an internal evaluation of San Francisco State's Integrated Reading and Writing program revealed increases in retention rates, English course pass rates, and the levels of reading comprehension and critical skills thinking for those who participated in the program. Additionally, these students were found to have similar achievement levels in other collegelevel courses as students who had no remedial needs. ${ }^{23}$ Similarly, nonexperimental internal evaluations of ALP found that students participating in the program passed college-level English course at just over 1.5 times the rate of students with similar academic needs who took the college's traditional developmental education sequence. ${ }^{24}$ Finally, an evaluation of the Digital Bridge Academy demonstrated that participating students passed college-level English and persisted at higher rates than a comparison group. ${ }^{25}$ While these trends cannot be used to establish a causal link between these programs and students' improved achievement, they do reveal that such mainstreaming programs may have an important influence on students' outcomes and should be tested more rigorously to see whether these promising trends hold.

\footnotetext{
${ }^{21}$ Jenkins (2009). The Digital Bridge Academy has since been restructured to replace the college-level English course with a reading lab and a literacy skills course, and so its current incarnation should not be considered a mainstreaming strategy. The restructuring decision was made in response to state policies about prerequisites for developmental-level students.

${ }^{22}$ Jenkins et al. (2010).

${ }^{23}$ Goen-Salter (2008).

${ }^{24}$ Adams, Miller, and Roberts (2009).

${ }^{25}$ Jenkins (2009).
} 


\section{Summary of Acceleration Models}

Acceleration strategies - fast-track courses, modularized courses, and mainstreaming — are ripe for more rigorous evaluation. These approaches show trends of relatively strong increases in students' achievement, but only mainstreaming has been tested with a relatively rigorous research design. (See Table 3.1.) Because students who participate in acceleration programs may have differences in motivation or prior academic achievement, further research is needed to establish a causal link between such programs and any increases observed in student success rates and advancement into college-level work. As these practices are replicated and evaluated more thoroughly, close attention should be paid to the policy environment; resistance to modifying developmental courses in this way has been seen at both the practitioner and the state level, but flexible policies on course credits and prerequisites can also be central to easing implementation. ${ }^{26}$ The potential role of technology should also be considered closely by practitioners and researchers, as self-paced instruction seems to enable acceleration programs. ${ }^{27}$

\footnotetext{
${ }^{26}$ Moltz (2010); Jenkins (2009); Gleason (2000); Bassett (2009).

${ }^{27}$ Epper and Baker (2009).
} 



\section{Chapter 4}

\section{Contextualized Instruction}

Throughout the literature on best practices in developmental education, there is a strong conviction that developmental-level skills and knowledge are best learned when applied to content that is relevant to students outside their developmental course curriculum. ${ }^{1}$ In many ways, this is a commonsense recommendation, designed to head off the classic question "Why do I have to learn this?" - which can be applied equally to lessons on arithmetic, grammar, or basic essay structures. Importantly, the recommendation is grounded in educational psychology and theories of learning. Research on knowledge transfer has shown that students are better able to apply skills to new situations when they understand the underlying principles and procedures as well as the facts. ${ }^{2}$ Additionally, active learning theory suggests that learning is deepest when students personally engage with and interpret material, generating meaning based on their own experiences and knowledge. ${ }^{3}$

Building on these theories, some practitioners have focused on developing instructional models that provide more contextualized learning experiences for students. Generally, contextualized instructional models focus on teaching basic skills in reading, writing, and math in conjunction with other course content, giving special attention to students' own personal experiences or learning goals. ${ }^{4}$ Contextualized instruction for remedial students may be used to reach two different goals. First, basic skills instruction may rely on a particular course subject, such as nursing or computer technology, to ground students' development of reading, writing, or math skills. In these cases, improvement of students' basic skills, rather than knowledge of content from the field, remains the primary objective. Alternately, contextualized instruction may focus more concretely on developing students' knowledge of an academic discipline or vocational field, with instruction in basic skills as a secondary objective toward better understanding this course content. ${ }^{5}$

Contextualized instructional models are thought to be particularly promising for helping academically underprepared students engage more quickly with their academic or vocational

\footnotetext{
${ }^{1}$ Center for Student Success (2007); Grubb and Associates (1999); McCabe and Day (1998); American Mathematical Association of Two-Year Colleges (AMATYC) (2006); Simpson, Stahl, and Francis (2004).

${ }^{2}$ Gillespie (2002); Berns and Erickson (2001).

${ }^{3}$ Center for Student Success (2007); Grubb and Associates (1999); De Corte (2007); Dirkx and Prenger (1997).

${ }^{4}$ Baker, Hope, and Karandjeff (2009).

${ }^{5}$ Perin (2011).
} 
field of interest. ${ }^{6}$ Unlike traditional developmental reading, writing, and math courses - which are offered as individualized courses disconnected from other course subjects - contextualized approaches offer more integrated learning environments for developing students' basic skills. By connecting with students' professional interests and providing real-world contexts for the application of basic skills, contextualized learning programs are expected to help developmental students attain skills more quickly.

\section{Models for Contextualized Learning with Developmental Education Students}

While contextualized learning has been used in a number of disciplines to promote deeper learning experiences, contextualized approaches for developmental education students have tended to focus on improving basic skills within the context of particular academic or vocational disciplines. In vocational programs, contextualized learning offers students the opportunity to gain professional or technical skills while still enrolled in their precollegiate programs. Contextualized learning may also be used in particular academic subjects to promote students' integration of course concepts with reading, writing, or math skills. Finally, learning communities, in which developmental courses are linked with other college-level courses, can provide integrated environments for students to engage with both academic course content and basic skills learning. Each of these contextualized instruction models and its accompanying research evidence is discussed below, and Table 4.1 summarizes the research on these strategies.

\section{Contextualized Learning in Vocational Programs}

A practice gaining much attention in the community college world is contextualized learning opportunities for basic skills students who are interested in vocational or technical fields, such as allied health or early childhood education. ${ }^{7}$ These programs may be geared either toward adult basic education students who have yet to earn a high school credential or toward developmental education students who are entering community college. In both cases, students have not yet developed the reading, writing, or math skills needed to earn the credential of interest, and they need additional preparation in these areas to master the course content. Therefore, occupational programs in these colleges have looked to develop integrated vocational and

\footnotetext{
${ }^{6}$ Grubb and Kraskouskas (1992); Berns and Erickson (2001); Perin (2001); Badway and Grubb (1997).

${ }^{7}$ Baker, Hope, and Karandjeff (2009); Berns and Erickson (2001); Jobs for the Future (2010).
} 


\section{Unlocking the Gate: What We Know About Improving Developmental Education}

Table 4.1

\section{Summary of Research on Contextualized Instruction Strategies}

\begin{tabular}{|c|c|c|c|}
\hline \multirow[b]{2}{*}{ Program } & \multicolumn{2}{|c|}{ Vocational Programs } & \multirow[b]{2}{*}{ Learning Communities } \\
\hline & I-BEST & Breaking Through & \\
\hline \multicolumn{4}{|c|}{ Rigorous research } \\
\hline Findings & $\begin{array}{l}\text { Positive outcomes: Increased progress } \\
\text { into credit-bearing courses; higher } \\
\text { persistence rates; earned more credits } \\
\text { that counted toward a credential; higher } \\
\text { rate of earning occupational } \\
\text { certificates; learning gains on basic } \\
\text { skills tests }\end{array}$ & & $\begin{array}{l}\text { Modestly positive outcomes: } \\
\text { Impacts on student engagement, } \\
\text { credits earned, and progression } \\
\text { through developmental course } \\
\text { sequence; positive effects } \\
\text { diminish over time }\end{array}$ \\
\hline Studies & Jenkins, Zeidenberg, and Kienzl (2009) & & $\begin{array}{l}\text { Scrivener et al. (2008); Weiss, } \\
\text { Visher, and Wathington (2010); } \\
\text { Weissman et al. (2010); Visher, } \\
\text { Schneider, Wathington, and } \\
\text { Collado (2010) }\end{array}$ \\
\hline \multicolumn{4}{|c|}{ Promising trends } \\
\hline Findings & $\begin{array}{l}\text { Positive outcomes: Increases in college } \\
\text { credits earned; improvements in access } \\
\text { and completion of workforce training; } \\
\text { some gains in English language skills }\end{array}$ & $\begin{array}{l}\text { Positive outcomes: } \\
\text { Increased rates of } \\
\text { college readiness; } \\
\text { improvements in } \\
\text { progress toward } \\
\text { completing } \\
\text { occupational } \\
\text { certificates }\end{array}$ & $\begin{array}{l}\text { Positive outcomes: Increased } \\
\text { student engagement and } \\
\text { persistence }\end{array}$ \\
\hline Studies & $\begin{array}{l}\text { Washington State Board for } \\
\text { Community and Technical Colleges }\end{array}$ & $\begin{array}{l}\text { Bragg and Barnett } \\
(2009)\end{array}$ & $\begin{array}{l}\text { Engstrom and Tinto (1998); } \\
\text { Tinto (1997); Zhao and Kuh }\end{array}$ \\
\hline
\end{tabular}

professional training along with substantial basic skills preparation. Many also provide opportunities for direct enrollment in degree or certificate programs, thus accelerating students' completion of these credentials. ${ }^{8}$

\section{Examples of Contextualized Learning in Vocational Programs}

One of the most promising contextualized learning models to date is Washington State's Integrated Basic Education and Skills Training (I-BEST) program, in which English as a Second Language (ESL) and adult basic education instructors work together with career-

\footnotetext{
${ }^{8}$ Jobs for the Future (2010); Washington State Board for Community and Technical Colleges (2005).
} 
technical faculty to jointly design and teach occupational courses. In the I-BEST program, basic English instruction is tailored to the language and communication skills needed for students' chosen occupation and are taught in the context of students' workforce training classes. Such comprehensive supports as tutoring, advising, and mentoring are often key program components for assisting students. The primary goal of I-BEST is to ensure that students receive at least one year of college training that culminates in the award of a certificate or degree. ${ }^{9}$

Another promising program that emphasizes contextualized learning models is the Charles Stewart Mott Foundation's Breaking Through initiative. Its pilot programs have been tested in a number of community colleges throughout the country, with many focusing on contextualized learning as a key gateway to college success. For instance, Central New Mexico Community College in Albuquerque has implemented the Construction Apprenticeship program, which offers for-credit contextualized courses in math and reading while integrating these skills into other college-level courses, such as carpentry. Similarly, Cuyahoga Community College in Cleveland, Ohio, has created a pre-state-tested Nursing Assistant program that allows individuals who have skills below the eighth-grade level to improve their academic abilities while learning about core concepts in health care and nursing. ${ }^{10}$ While many of these programs focus on students in adult basic education programs, several also target developmental education students who have already received a high school credential.

\section{Research Evidence Supporting Contextualized Learning in Vocational Programs}

The most promising evidence supporting contextualized learning for students with remedial needs comes from a recent evaluation of Washington State's I-BEST program by the Community College Research Center (CCRC). Building on encouraging results from the state's descriptive analysis, CCRC's evaluation used statewide data to compare I-BEST students with other similarly skilled adult basic education students. Using a multivariate logistic regression analysis and controlling for students' background characteristics, such as socioeconomic status and previous schooling, the analysis found positive effects across the board. Compared with nonparticipating students, those who were in the I-BEST program were significantly more likely to advance into credit-bearing courses, persist in college, earn credits that counted toward a credential, earn an occupational certificate, and make learning gains on basic skills tests. I-BEST students often showed large gains on many of these measures. ${ }^{11}$

\footnotetext{
${ }^{9}$ Washington State Board for Community and Technical Colleges (2005).

${ }^{10}$ Bragg and Barnett (2009).

${ }^{11}$ Jenkins, Zeidenberg, and Kienzl (2009).
} 
Promising evidence also exists documenting the success of several Breaking Through programs. Internal evaluations at some of the participating colleges have shown positive outcomes overall for students who are in the programs, such as increased rates of college readiness and progress toward completing occupational certificates. ${ }^{12}$ The findings from this research should be approached with caution, however, as the statistical analyses employed either do not use a comparison group or fail to control for such factors as earlier differences in achievement levels between students who are in the program and those who are not.

\section{Learning Communities}

Learning communities are another popular strategy employed by many community colleges to provide contextualized learning experiences for developmental-level students. While variations of this strategy are wide-ranging, the general principle behind learning communities is that students enroll in two or more courses together as a cohort. In the more developed versions of these programs, instructors of these linked courses collaborate to create an integrated curriculum that supports the development of multiple aspects of students' learning. As such, the linked courses generally employ overlapping syllabi and have joint assignments and projects. Additionally, because students proceed through the courses with the same cohort of classmates, learning communities are expected to promote social cohesion and the integration of students within the college campus. ${ }^{13}$

\section{Examples of Learning Communities for Developmental Education Students}

While learning communities are used with a number of different programs and courses at community colleges, those that involve academically underprepared students often link a developmental education course with a for-credit college-level course. At Queensborough Community College in Queens, New York, developmental math is linked with a variety of college-level courses, such as English, Sociology, and Business. ${ }^{14}$ Another popular strategy is to include a student success course, which generally emphasizes the development of study skills and college-going expectations, in order to provide additional advising and supports to students who are adapting to college life. Learning communities at Kingsborough Community College in Brooklyn, New York, use this program model, linking a developmental English course, a content-area college-level course, and a one-credit student success course. Kingsborough's

\footnotetext{
${ }^{12}$ Bragg and Barnett (2009).

${ }^{13}$ Tinto (1975, 1987); Visher, Schneider, Wathington, and Collado (2010).

${ }^{14}$ Weissman et al. (2011).
} 
program also includes additional supports, such as enhanced counseling and a voucher to purchase textbooks.

Although most learning communities do not engender the type of workforce or experiential skills that are addressed in other contextualized learning settings, such as vocational programs, the deliberate links that are made between the courses can give students the opportunity to practice in their college-level classes the skills that they are learning in their developmental courses. For instance, linking a developmental reading course with an introductory psychology course allows students the opportunity to use the psychology textbook as a resource for their reading development. Similarly, linking developmental math with an entry-level biology course allows students to apply their developing math knowledge to science problems. Additionally, learning communities that include college-level courses afford developmental students the opportunity to gain credits toward credentials while they are still working to improve their basic skills. Finally, learning communities' general promotion of active learning and student engagement is expected to enhance knowledge acquisition and encourage greater levels of commitment to the institution. ${ }^{15}$

\section{Research Evidence Supporting Learning Communities for Developmental Education Students}

Learning communities are one of the few strategies for which more rigorous evidence is available. In general, the findings related to learning communities have been positive, though modest, with some studies showing more mixed results. Quasi-experimental studies on the effects of learning communities for both college-level and developmental students at over a dozen institutions have found a significant relationship between students' participation in a learning community and their level of engagement with their classes, fellow students, and faculty. Additionally, students participating in learning communities were found to persist to the following year at significantly higher rates than comparison groups who did not participate, even when controlling for differences in students' background characteristics. ${ }^{16}$

More recent experimental studies testing developmental-level learning communities reinforce many of these positive findings, though showing more modest impacts on students' achievement and persistence in school. For instance, as noted above, Kingsborough developed a relatively comprehensive learning community model for developmental-level English students. This program resulted in improvements in educational outcomes, including the number of credits earned during the semester that students were enrolled in learning communities and students' progression through developmental education. Additionally, students in the learning

\footnotetext{
${ }^{15}$ Tinto (1997); Visher, Schneider, Wathington, and Collado (2010).

${ }^{16}$ Engstrom and Tinto (2008); Tinto (1997); Zhao and Kuh (2004).
} 
communities were significantly more likely to pass the standardized CUNY English assessment exams by the end of the second semester after the program, thereby qualifying them to pass out of developmental English and enroll in the college's for-credit introductory English course. ${ }^{17}$ Even so, the program had few long-term effects on students' achievement or persistence.

Currently, the National Center for Postsecondary Research (NCPR) is building on this work to conduct experimental evaluations of six different models of learning communities, five of which are geared toward developmental students. Qualitative analyses of learning communities in these colleges have shown that program participation clearly influences students affectively, leading to high levels of engagement and a strong sense of belonging. ${ }^{18}$ Emerging results about academic outcomes are mixed. At Hillsborough Community College in Tampa Bay, Florida, learning communities linked a developmental reading course with a student success course but did not integrate course curricula or offer comprehensive supports at the level achieved by Kingsborough's program. The Hillsborough program did not have a meaningful impact on students' academic success within the full sample, but there were some modest positive impacts on educational outcomes among the last group of students, who joined the sample after the program increased its faculty collaboration and curricular integration. ${ }^{19}$ However, learning communities for developmental math students at Queensborough Community College and at Houston Community College led to more positive results. Students attempted and passed the math course in the learning communities at significantly higher rates than students in comparison groups. After the program, learning communities students at both schools also progressed along the developmental course sequence more rapidly. ${ }^{20}$

Taken together, these findings suggest that more mature versions of learning communities - those that integrate training for faculty, institutional supports, and strong leadership may have a greater effect on students' achievement. However, even the effects of these programs have been relatively modest and tended to diminish over time, suggesting that learning communities will not dramatically increase students' success in and progress through developmental education.

\section{Summary of Contextualized Learning Models}

Based on the available evidence, developmental education models that offer contextualized learning opportunities hold great promise for helping students build basic skills and advance into college-level courses and beyond. (See Table 4.1.) Vocational and occupational contextual-

\footnotetext{
${ }^{17}$ Scrivener et al. (2008).

${ }^{18}$ Visher, Schneider, Wathington, and Collado (2010).

${ }^{19}$ Weiss, Visher, and Wathington (2010).

${ }^{20}$ Weissman et al. (2011).
} 
ized learning - at least, as implemented in Washington State's I-BEST program — appears to offer the most encouraging results, as such programs quickly move basic skills students into college-level courses and help them graduate in a compressed amount of time with a certificate or degree. It should be noted, however, that many of the vocational contextualized learning programs worked with adult basic education and ESL students, rather than with those entering college and placing into developmental education programs. Yet, given the promising findings from I-BEST and Breaking Through, developmental education programs should consider how links with occupational courses might further improve students' outcomes. Similarly, more rigorous research should be conducted to validate the promising results of programs based on this model.

Learning communities also provide some heartening news about the potential of contextualized learning for improving student outcomes, although the effects of these programs on long-term outcomes are much more limited. While strong learning community models show some positive effects while students are participating in the programs, less well-developed programs showed fewer effects. Additionally, evidence of academic improvement tended to diminish over time, after the learning communities program ended. This evidence and the strong research models used to document these effects reveal that learning communities may be a less effective method for dramatically changing the overall success of developmental education students. Given this, researchers, policymakers, and practitioners should look toward other methods, which may hold more promise for improving these students' achievement. 


\section{Chapter 5}

\section{Supplemental Supports to Advance Students' Achievement}

Most community colleges offer a wide array of services for students in order to support their persistence and advancement in college. The services range from academic counseling for students who are entering college to specialized programs for students with particular interests or backgrounds. Most colleges also offer academic supports - such as individualized tutoring, labs for math or English, and computer tutorials - which are designed to supplement classroom instruction. As such, student support services seek to facilitate academic achievement and remove the barriers that students may experience when seeking a postsecondary credential.

While many developmental education students may take advantage of such services, questions have been raised about whether these more general supports meet the challenges that academically underprepared students may face. Numerous studies have noted that students who place into developmental education arrive at school with more handicaps than the general population of students and are more likely to come from disadvantaged backgrounds that offer little exposure to college expectations. ${ }^{1}$ For such reasons, a number of colleges have looked to developing more extensive support services for students who have remedial needs, in an effort to better support their progress in college.

\section{Models for Supplemental Supports with Developmental Education Students}

As noted in Chapter 1, many studies of the best practices in developmental education encourage integrating multiple student supports into a comprehensive model to foster academic achievement. ${ }^{2}$ These services primarily include advising (both academic and career-focused) and academic assistance, such as tutoring or the creation of learning centers, but they can also include workshops or courses designed to teach study strategies and provide opportunities for students to access learning-assistance technology. ${ }^{3}$ Generally, recommendations for comprehensive student support services tend to state that the academic instruction and student support service divisions should

\footnotetext{
${ }^{1}$ Adelman (2004); Attewell, Lavin, Domina, and Levey (2006); Hagedorn et al. (1999); Goldrick-Rab (2007).

${ }^{2}$ Boylan (2002); McCabe and Day (1998); Center for Student Success (2007); Sperling (2009).

${ }^{3}$ American Mathematical Association of Two-Year Colleges (AMATYC) (2006); Boylan (2002).
} 
work collaboratively — on both an institutional and an individual level — to ensure that students are aware of support services and are accessing the ones that best meet their needs. ${ }^{4}$

Unfortunately, limited evidence is available to advance the recommendations for more comprehensive support services. However, several promising models that focus on select support services have shown some encouraging results. First, a number of colleges have looked to implementing more intensive tutoring services for developmental education students, particularly through supplemental instruction programs, which link tutoring directly with a particular course. Additionally, intensive advising models, whereby students meet regularly with a staff or faculty adviser to discuss their course plans and college experiences, have also proved popular among a number of schools as a way to advance students' achievement. Finally, student success courses, which provide students with an introduction to college life and study skills training, are another key intervention that colleges are using to improve developmental education students' achievement. Table 5.1 summarizes the available research on student support services.

\section{Tutoring and Supplemental Instruction}

Tutoring is a popular support that has been implemented by a number of colleges as a means to advance developmental education students' achievement. ${ }^{5}$ Like many other student support practices, tutoring can take diverse forms. Tutoring can be offered by faculty, staff, or student peers or through computer-assisted instruction with tutorial software packages. Students may receive individualized assistance or may work in small groups with a tutor outside the classroom. On college campuses, tutors may be housed in a stand-alone center or in learning assistance centers, which provide a number of other supports for students' learning. ${ }^{6}$ Finally, tutoring can be either more generalized and cover a number of academic subjects or more specialized and focus on a specific curriculum or content area.

One of the more focused models of tutoring that has recently become popular among developmental educators is supplemental instruction. Unlike the more generalized tutoring practices that are independent of students' courses, supplemental instruction is a structured tutoring model that is directly connected to a particular course. Generally, a trained tutor (the "SI leader") or the instructor conducts an additional course section that provides structured

\footnotetext{
${ }^{4}$ Center for Student Success (2007); Weissman et al. (2009).

${ }^{5}$ Brock et al. (2007).

${ }^{6}$ American Mathematical Association of Two-Year Colleges (AMATYC) (2006); Perin (2004); Maxwell (1990).
} 


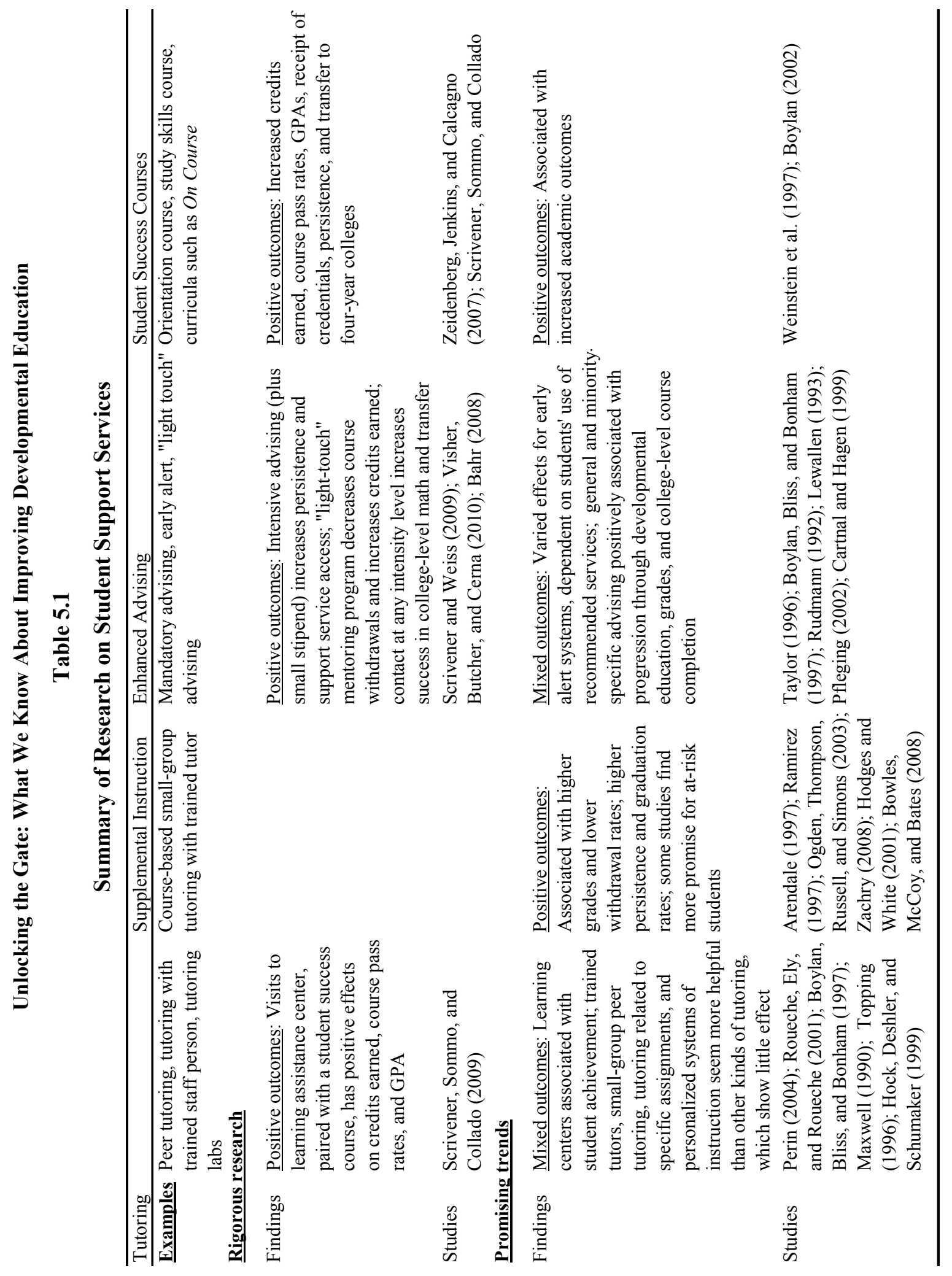


assistance to students about the course material or assignments. If someone other than the instructor is the SI leader, that person generally attends the core curriculum class to become familiar with the course material and the instructor's approach. SI leaders may be peer tutors who have already achieved success in the course or may be faculty or staff members who are well versed in the course content. Sessions are often led using active or collaborative learning techniques, which encourage students to more fully interact with the course material. The SI leaders work closely with the instructor leading the course, and they often receive guidance on the content of their sessions. ${ }^{7}$

\section{An Example of Supplemental Instruction for Developmental Students}

Supplemental instruction is used widely across the country in a variety of developmental and entry-level courses, all of which have historically high failure rates. One example of structured supplemental instruction is being offered by Mountain Empire Community College in Big Stone Gap, Virginia. Its program, called "Peer-Led Team Learning," provides an extra section of the college's developmental algebra course and meets weekly during an open block of time just before the class begins. The supplemental instruction section is led by a peer tutor, who successfully completed the course in an earlier semester and received training to lead the supplemental section. The peer tutor is also required to regularly attend the developmental algebra course and to work closely with the instructor, who reviews and may modify the tutor's lessons. Like many supplemental instruction programs, Peer-Led Team Learning also emphasizes active learning, with most lessons providing engaging exercises for students to interact with the course content. ${ }^{8}$

\section{Research Evidence Supporting Tutoring and Supplemental Instruction for Developmental Education Students}

Little rigorous evidence exists documenting the success of either generalized tutoring or supplemental instruction programs for developmental education students. Several challenges also limit the reliability of research demonstrating promising trends. First, student self-selection bias is particularly apparent with tutoring programs, as most studies have not accounted for the motivation of students who seek out tutoring services, which may be correlated with other characteristics that help these students succeed. ${ }^{9}$ Additionally, some research has indicated that students who use tutoring and learning assistance centers tend to be older and to have attended college for a longer period of time, making it difficult to generalize conclusions to a larger

\footnotetext{
${ }^{7}$ Arendale (1997).

${ }^{8}$ Zachry (2008).

${ }^{9} \mathrm{Xu}$, Hartman, Uribe, and Mencke (2001).
} 
student population. ${ }^{10}$ It can also be challenging to isolate the effects of tutoring from other forms of academic assistance — such as advising or revised pedagogical strategies — as developmental education students often receive multiple services. ${ }^{11}$ Finally, few studies focus specifically on developmental education students, making it difficult to disentangle the effects for these students from the effects for the general student population.

Overall, the available data on a variety of tutoring programs have shown mixed results. Some promising trends have been noted for students who utilize learning assistance centers. ${ }^{12}$ For instance, one experimental study of a program in which probationary students were required to go to a learning assistance center showed some positive effects on such academic outcomes as credits earned, course pass rates, and grade point averages (GPAs). However, the mandatory visits to the center were offered in conjunction with a required student success course, making it difficult to disentangle which service had the greater effect on students' achievement. ${ }^{13}$ Other, nonexperimental studies have found little evidence of improved achievement from tutoring, except when certain types of tutoring were implemented. Those programs with the most promising evidence include small-group tutoring led by a peer, programs designed to help students with specific assignments, and more personalized systems of instruction whereby students go through programmed learning material and a tutor is available for assistance. ${ }^{14}$ For a tutoring program to have benefits for students, research on best practices indicates that tutors must receive standardized training. ${ }^{15}$

While supplemental instruction is popular within developmental education, little research is available documenting the results of these programs in community college settings. Nonexperimental internal evaluations of Mountain Empire's Peer-Led Team Learning program revealed promising increases in students' course pass rates, persistence, and GPAs; however, the evaluation had relatively few students and employed only simple comparisons with students who were not enrolled in the program, thereby limiting any causal statements about the program's effects. ${ }^{16}$ Other nonexperimental studies conducted in four-year universities have shown positive effects for students who received supplemental instruction in historically difficult entrylevel courses. ${ }^{17}$ For instance, when using large data sets to compare students who received supplemental instruction and those who did not, the intervention was found to have resulted in higher grades, lower course withdrawal rates, higher GPAs, and higher rates of persistence and

\footnotetext{
${ }^{10}$ Bannier (2007).

${ }^{11} \mathrm{Xu}$, Hartman, Uribe, and Mencke (2001).

${ }^{12}$ Perin (2004); Roueche, Ely, and Roueche (2001).

${ }^{13}$ Scrivener, Sommo, and Collado (2009).

${ }^{14}$ Maxwell (1990); Topping (1996); Hock, Deshler, and Schumaker (1999).

${ }^{15}$ Boylan, Bliss, and Bonham (1997).

${ }^{16}$ Zachry (2008).

${ }^{17}$ Maxwell (1990); Hock, Deshler, and Schumaker (1999).
} 
graduation. ${ }^{18}$ Some studies have also noted positive effects of supplemental instruction with atrisk students, when compared with more traditional students. ${ }^{19}$ However, it is important to note that these studies did not effectively control for differences in students' motivation and were, at times, limited by the types of comparisons made between the research groups.

\section{Advising}

Developmental educators have also looked toward more intensive advising models to improve remedial students' success. At a minimum, advising in community colleges entails a staff or faculty member's helping students navigate their choice of classes or majors, although advisers in some schools also offer assistance in helping students access campus services or develop career goals or plans. Advising in community college settings tends to be somewhat limited, as advisers often have large caseloads of students - sometimes more than a thousand a semester - making it difficult to give students more personalized attention. High caseloads combined with the fact that at-risk students are far less likely to be proactive and seek out advising opportunities mean that developmental-level students tend to receive quite limited advising. ${ }^{20}$

In order to reverse this trend, some schools have looked to create more intensive advising experiences for students who have remedial needs. One of the most commonly recommended approaches is the reduction of advisers' caseloads, allowing them to meet more frequently with students and provide more personal attention, which can be coupled with mandatory advising for students. ${ }^{21}$ A more intensive version of this model has advisers serve as mentors to students, meeting regularly with them to monitor progress and inform them of college services that may assist them with their challenges. Other strategies have focused on implementing early-alert systems, in which faculty and student services staff collaborate to communicate with students who are at risk of failure. Such a system may also include meetings with an adviser to establish a corrective plan of action. ${ }^{22}$

\section{Examples of Enhanced Advising for Developmental Students}

Two examples of alternate advising models are found in Ohio and Texas. Lorain County Community College in Elyria, Ohio, and Owens Community College in Toledo offer an

\footnotetext{
${ }^{18}$ Arendale (1997); Bowles, McCoy, and Bates (2008); Hodges and White (2001); Ogden, Thompson, Russell, and Simons (2003); Ramirez (1997).

${ }^{19}$ Ogden, Thompson, Russell, and Simons (2003); Ramirez (1997).

${ }^{20} \mathrm{Grubb}$ (2001b).

${ }^{21}$ Sperling (2009).

${ }^{22}$ Pfleging (2002).
} 
enhanced advising program, and South Texas College, in McAllen, has the Beacon Mentoring program, which takes a "light touch" approach to advising.

In the enhanced advising program at Lorain County and Owens, low-income students - who were not all developmental-level - were assigned to a team of counselors with whom they were expected to meet at least twice per semester for two semesters, to discuss academic progress and resolve any issues that might affect their schooling. The caseloads of these counselors were reduced in order to facilitate more frequent, personalized contacts with students. $^{23}$

South Texas took a different approach in its Beacon Mentoring program, choosing to assign faculty or staff mentors to advise students in developmental and introductory math courses. These college employees made several short presentations within students' math classes to describe available resources on campus, and they worked with faculty to identify struggling students and offer them help early on. Some mentors also had more regular contact with their students through personalized meetings or e-mail. ${ }^{24}$

\section{Research Evidence Supporting Enhanced Advising}

A number of rigorous and nonrigorous studies of a variety of advising approaches have been conducted, and they tend to show fairly positive results on developmental education students' achievement. Less rigorous, large-scale studies have noted some positive trends from specialized advising services for developmental education students. ${ }^{25}$ Similarly, nonexperimental studies of advising models for minority developmental education students were found to positively influence students' progression through developmental coursework, their grades, and their rates of college-level course completion. ${ }^{26}$ Furthermore, some research on early-alert advising models using simple comparisons between program and nonprogram students revealed positive trends in achievement. However, the benefits associated with early-alert programs appeared only when students followed advisers' recommendations for corrective actions, such as attending tutoring. Most early-alert programs did not show meaningful improvements in students' academic achievement. ${ }^{27}$

Rigorous research on various advising models has shown fairly positive results. A large-scale longitudinal control analysis of first-year community college freshmen found that

\footnotetext{
${ }^{23}$ Scrivener and Weiss (2009).

${ }^{24}$ Visher, Butcher, and Cerna (2010).

${ }^{25}$ Boylan, Bliss, and Bonham (1997); Light (2001).

${ }^{26}$ Taylor (1996); the program (Puente, in California) also has a coursework component whereby students take English courses especially designed for Latino students.

${ }^{27}$ Lewallen (1993); Pfleging (2002); Cartnal and Hagen (1999); Rudmann (1992).
} 
participation in advising at any level of intensity is beneficial for developmental-level students' chances of success in college-level math and for their transfer to a four-year institution, and stronger effects were found for students with the weakest skills. ${ }^{28}$ Experimental study results from the Lorain County and Owens enhanced advising models paired with a small stipend reveal some positive outcomes; students who received more personalized attention from their advisers accessed advising services more often and had higher retention rates for the first two semesters following the program. However, the program did not have a positive impact on other academic outcomes, such as course pass rates, credit accumulation, or GPAs. ${ }^{29}$

A random assignment study of the South Texas Beacon Mentoring program provides more encouraging evidence about an advising service with relatively low intensity. While the program did not make a significant difference in the academic outcomes of the overall sample, students in developmental math classes who were visited by a Beacon Mentor withdrew from the course at lower rates and earned more credits at the end of the semester. The program also had some modest positive effects for students who attended part time, as they were found to be less likely to withdraw from and more likely to pass the math class, to earn more credits, and, in the developmental math classes, to score higher on the final exam. However, the effects of the program were relatively modest and did not affect other academic outcomes for these students, such as course pass rates, GPAs, or postprogram persistence. ${ }^{30}$

\section{Student Success Courses}

Student success courses have become one of the most popular support interventions among community colleges seeking to improve developmental-level students' achievement. Sometimes referred to as "study skills," "student development," or "new student orientation" courses, student success classes are generally offered as a stand-alone, credit-bearing course for developmental education students or newly entering students at the college. Usually one semester long, student success courses are used to introduce new students to college life, help them learn about the college's services, and give them tools to approach the decisions and responsibilities that they will face as college students. Several recent studies have associated these courses with promising increases in students' academic achievement and persistence in college, leading a number of states and schools to mandate them for newly entering students. ${ }^{31}$

\footnotetext{
${ }^{28} \mathrm{Bahr}$ (2008).

${ }^{29}$ Scrivener and Weiss (2009).

${ }^{30}$ Visher, Butcher, and Cerna (2010). Similarly positive effects were noted in a random assignment study of "light touch" mentoring for a more general college population (Bettinger and Baker, 2010).

${ }^{31}$ Scrivener, Sommo, and Collado (2009); Zeidenberg, Jenkins, and Calcagno (2007); Derby and Smith (2004).
} 


\section{Examples of Student Success Courses}

Student success courses have been linked to developmental math and reading in learning communities at Hillsborough Community College (Tampa Bay, Florida), Houston Community College, and Kingsborough Community College (Brooklyn, New York), providing extra support to students' academic and social integration into college life. ${ }^{32}$ Student success courses may also be targeted specifically to at-risk or developmental students; Chaffey College (Rancho Cucamonga, California) uses its student success courses for students who are on probation, and Guilford Technical Community College (Jamestown, North Carolina) targets the courses to students needing one or more developmental education class. ${ }^{33}$

Student success courses may be offered as less-intensive, one-credit classes (as was the case at Kingsborough) or as more structured, three-credit classes that provide more opportunities for student interaction (as in Guilford Tech's model). Regardless of the intensity of these programs, however, each of these models shares a focus on developing students' study skills and their knowledge of and expectations for college life.

\section{Research Evidence Supporting Student Success Courses}

Student success courses have long been promoted in the research on "best practices" as an important way to help developmental education students acquire better learning strategies, and some practitioner research has shown positive trends in student outcomes. ${ }^{34}$ Recently, more rigorous research has confirmed these promising trends. For instance, the Community College Research Center's quasi-experimental analysis of students who enrolled in student success courses in Florida revealed positive effects on students' persistence, degree earning, and transfers, particularly for developmental-level students. ${ }^{35}$

Experimental studies utilizing random assignment methodology have also shown promising effects. For instance, the experimental results of Kingsborough's learning communities model, which incorporated a one-credit student success course, found positive impacts on the number of credits that students earned and on students' progression through developmental education. ${ }^{36}$ Similarly, an analysis of Chaffey College's mandatory success course for probationary students - a particularly challenging population - found that students who enrolled in the success course earned more credits, passed more classes, and had higher GPAs than those who did not receive the course. The program also had large, positive effects on getting these

\footnotetext{
${ }^{32}$ Weiss, Visher, and Wathington (2010); Scrivener et al. (2008); Weissman et al. (2011).

${ }^{33}$ Scrivener, Sommo, and Collado (2009); Zachry and Orr (2009).

${ }^{34}$ Boylan (2002); Weinstein et al. (1997).

${ }^{35}$ Zeidenberg, Jenkins, and Calcagno (2007).

${ }^{36}$ Scrivener et al. (2008).
} 
students back into good academic standing; at the end of the two-semester follow-up period, there was nearly a 15 percentage point difference between students who received the course and the control group. ${ }^{37}$ However, because the success courses at both of these schools were linked to other support services, these results should be approached with caution, as it is difficult to know whether the findings are related to the success courses or to other services offered.

\section{Summary of Student Support Models}

Intensive advising, supplemental instruction, and student success courses have each shown some promising effects for increasing developmental-level students' achievement, though their effects appear to be limited. (See Table 5.1.) For instance, rigorous research on intensive advising and student success courses has documented some positive increases in the number of credits that developmental education students earned; in some cases, these supports have advanced students' progression through developmental education and their success in collegelevel work. Additionally, there is some suggestive evidence revealing that certain types of tutoring programs and supplemental instruction may produce positive gains in students' success in their courses and persistence in college.

While these findings are promising, none of the student support services described in this chapter have had dramatic effects on helping developmental education students advance more quickly to and through college-level courses. For example, none of the supports studied here provided striking changes in students' course pass rates, GPAs, or credits earned. Additionally, several of the positive findings that were noted during the time when these services were being offered diminished after the programs ended. These findings suggest that while student support services may produce modest gains in achievement, they are unlikely to have more dramatic effects on progress into college-level work and receipt of a credential. While more heartening information may come from the follow-up experimental studies on Chaffey College's student success course and Kingsborough's learning communities, the current evidence implies that reforming student support strategies may be a step in the right direction but is not sufficient, in isolation, to bring remarkable gains in developmental education students' achievement.

\footnotetext{
${ }^{37}$ Scrivener, Sommo, and Collado (2009). MDRC is conducting an additional random assignment study of Guilford Tech's student success course for developmental education students; results are due by the end of 2011.
} 


\section{Chapter 6}

\section{Conclusion}

The charge of developmental education is clear: to build up the skills of academically underprepared students so that they may be successful in college-level work and progress quickly to a credential that will advance their position in the marketplace. Unfortunately, as the system currently stands, this goal is rarely met. While around 60 percent of community college students begin their college career in developmental courses, less than half of them will make it through these courses successfully. ${ }^{1}$ Even more disturbing, from 60 percent to 70 percent of students who take a remedial course never earn a postsecondary degree or credential. ${ }^{2}$

Given these troubling achievement levels, many educators, policymakers, and foundations are reconsidering the most effective strategies for supporting developmental-level students. As noted in this report, a number of these strategies have exhibited promising trends in increasing the number of students who are ready for college-level work, and some strategies even appear to improve students' receipt of credentials. Generally, the strategies that hold the most promise focus on improving students' skills within a compressed time frame and on linking remediation to relevant college-level work. These include programs that mainstream developmental students into college-level courses with additional supports, programs that provide modularized or compressed courses to allow remedial students to more quickly complete the developmental course sequence, and programs that offer contextualized remedial education within occupational and vocational programs. These strategies tend to modify pedagogical approaches to fit within the programs' nontraditional structures, and they provide clear opportunities for students to remain on a pathway to reaching their college goals rather than becoming mired in multiple semesters or years of remedial work.

While these encouraging findings are a welcome relief for those hoping to advance remedial students' success in college, the relatively modest effects of these programs also need to be taken in context of the larger challenges facing developmental education students. Most of the promising programs cited in this report were conservative efforts to tweak the existing curriculum, and they improved students' academic achievement by only a few percentage points - a small change relative to the large numbers of students failing developmental education courses. Additionally, virtually all these programs are still in the pilot stages and have affected relatively few students, which makes it difficult to ascertain how they might impact the achievement of larger groups of students. Finally, and most importantly, rigorous research

\footnotetext{
${ }^{1}$ Adelman (2004); Attewell, Lavin, Domina, and Levey (2006); Bailey, Jeong, and Cho (2010).

${ }^{2}$ Adelman (2004).
} 
demonstrating a clear causal link between these programs and improved student achievement is limited, making it challenging to say with certainty how well these strategies have actually increased students' success.

Given these issues, a number of researchers, policymakers, and foundations have begun to suggest that developmental education in its current form is broken and are calling for a more radical reenvisioning of these programs. Noting that more conventional efforts to improve students' achievement have produced only modest results, some individuals have sought to restructure the core curricula of developmental education programs through innovative models to help students build skills for their education and the workforce. While still new and untested, these ideas offer a fresh perspective for advancing academically underprepared students' success, and they may hold promise for greater improvements in these students' achievement.

Finally, while educators are creating increasingly more novel ways to improve developmental education students' success, the institutional and organizational structures supporting developmental education also present clear challenges for any reform effort. For instance, most developmental education programs are structured around entrance exams, which assess students' skills on entering college and are used to place students into the appropriate developmental education or college-level courses. Given that assessment tests are part of the admissions process at most community colleges, any innovative approach must consider whether and how these tests will be used. Similarly, most community colleges rely heavily on adjunct, or parttime, faculty to teach developmental courses, meaning that large proportions of students are taught by instructors who are less connected to the campus community. Therefore, any reform effort that seeks to reach large groups of developmental education students must find ways to integrate these faculty into the effort - a goal that has proved difficult for many community colleges in the past.

Given these challenges, this concluding chapter outlines several promising paradigms for improving developmental education students' success while also detailing key factors to consider in efforts to reform developmental education. First, the chapter delineates a plan for increasing the availability of reliable evidence about the programs and strategies for developmental education students. It then develops an agenda for future innovation in developmental education, focusing both on the reform efforts for which reliable evidence exists as well as on new, more sweeping changes in developmental education curricula. Finally, the chapter discusses several mediating factors that affect the delivery of developmental education, which — with improvement - have the potential to enhance both traditional and innovative practices. 


\section{Improving the Quality of Evidence}

Currently, there is a dearth of reliable evidence for many of the avoidance, acceleration, contextualization, and support strategies discussed in Chapters 2 through 5 of this report. Only a few experimental and quasi-experimental studies exist that attempt to control for such factors as preexisting differences among students or their motivation levels. While a number of descriptive and correlational analyses exist, these studies rarely provide clear definitions of a program's implementation or characteristics, which limits the conclusions that can be drawn from their results and can also create challenges for replicating the program at other institutions.

Researchers and policymakers should prioritize expanding the field's knowledge about the causal link between new programs and students' achievement. Research designs should be as rigorous as possible, given the intervention and its context; if an experimental study is not feasible, another analytic strategy that minimizes the differences between comparison groups should be used. Such investigations might begin with quasi-experimental analyses, using clearly identified student-level data, which investigate the associations between a new program intervention and students' achievement. Whenever possible, analyses should note and control for such characteristics as preexisting differences in students' achievement levels and differing policies across institutions or states that might affect how students are placed or advanced through developmental education. Similarly, when available, analyses should provide detailed information about programs' implementation and components, to allow for a better understanding of how program structure might be related to outcomes.

While quasi-experimental research is a useful first step in such investigations, more rigorous experimental analyses should also be pursued, when feasible. Experimental analyses, utilizing random assignment methodology, would allow for a causal link to be established between new interventions and any resulting changes in students' achievement. Such experiments would also control for factors like students' motivation levels - a challenge that cannot be easily overcome through quasi-experimental research. Again, careful attention should be paid within this research to the structure, programming, and implementation of new strategies, in order to facilitate an understanding of what specific programmatic components may be linked with any improvements in students' achievement.

In considering a research agenda, researchers and policymakers should look to analyze the programs that appear to hold the most promise for rapidly increasing students' progress through developmental education, success in credit-bearing courses, and ultimate completion of a degree. Researchers should actively pursue more innovative programmatic strategies for accomplishing these goals; while tweaks to current developmental education practices may produce some modest results, the available research clearly demonstrates that such small changes are unlikely to produce dramatic improvements in students' achievement. Given that 
current programs succeed in promoting fewer than half of their students into college-level courses, more drastic changes are undoubtedly needed.

\section{Promising Strategies for Improving Developmental Students' Success}

\section{Interventions with Reliable Evidence}

As noted above, few developmental education reform efforts have been evaluated rigorously, thereby limiting the number of programs that can be causally linked to improved student achievement. Moreover, experimental evaluations of student support interventions and learning communities reveal that these strategies may have only modest effects on students' achievement. ${ }^{3}$ For instance, the most promising of these studies - a random assignment evaluation of Chaffey College's student success course linked with mandatory tutoring (discussed in Chapter 5) - did have large, positive effects on getting probationary students back into good academic standing. However, it only minimally increased these students' grade point averages (GPAs): 7 percent more program students earned a GPA of 2.0 or higher; minor increases in credit earning were primarily a result of enrollment in the success course itself. ${ }^{4}$ Similarly, an evaluation of Kingsborough's learning communities (Chapter 4) concluded that the program drove minor increases in developmental credits earned (by almost one credit) and in the proportion of students who attempted and passed skills tests that would allow them to move on to collegelevel English (a 6 percentage point increase) but that the program had few long-term effects. ${ }^{5}$ Finally, evaluations of advising and mentoring programs at South Texas College, Lorain County Community College, and Owens Community College (Chapter 5) revealed no sustained increases in the achievement of the overall population of students and increased the number of credits earned by less than a full credit. ${ }^{6}$

Interestingly, earlier quasi-experimental research on some of these programs - learning communities and student success courses — showed more promising results. ${ }^{7}$ The differing findings further underscore the need for more rigorous analyses of developmental education reforms, as they suggest that other characteristics, such as students' motivation and selfselection into these programs, may have accounted for the more positive results seen in the

\footnotetext{
${ }^{3}$ While programs at most of these colleges targeted both developmental and college-level students, the sample population in each of these studies included a large proportion of developmental education students.

${ }^{4}$ Scrivener, Sommo, and Collado (2009).

${ }^{5}$ Scrivener et al. (2008).

${ }^{6}$ Scrivener and Weiss (2009); Visher, Butcher, and Cerna (2010).

${ }^{7}$ Engstrom and Tinto (2008); Tinto (1997); Zhao and Kuh (2004); Zeidenberg, Jenkins, and Calcagno (2007).
} 
quasi-experimental studies. However, the positive experimental findings on learning communities and student support reforms, though at times modest, suggest that these relatively conservative reforms may help improve students' progress through developmental education. As such, colleges may wish to pursue such strategies while also looking for more innovative interventions that may have a larger impact on students' achievement.

Though more rigorous, experimental analysis is needed, quasi-experimental research on other approaches - such as several acceleration and avoidance strategies and contextualized instructional models - have shown great promise for increasing developmental education students' overall achievement, including their progress through developmental education and success in credit-bearing courses. The most promising of these models have focused on integrating developmental education students more quickly into mainstream college programs and providing clear opportunities for them to link their skill development with their field of interest. In particular, quasi-experimental research on Washington State's I-BEST program, which integrates basic skills instruction with vocational and professional training, has revealed substantial improvements in students' progress into credit-bearing courses, credits earned, and attainment of certificates. When controlling for differences in students' background characteristics, researchers found that students in the I-BEST programs earned an average of 14 more college credits than non-I-BEST students and had a higher probability of persisting into the second year (17 percentage points) and of earning an occupational certificate (40 percentage points). ${ }^{8}$ Furthermore, the short tracking period of this study (two years) reveals that substantial improvements in achievement among basic skills students may be possible within a relatively short period of time.

While the correlation between participation in I-BEST and better educational outcomes is striking, it is important to note that further research is needed to determine whether a causal link exists between this program and students' increased achievement. I-BEST students' improved success may have resulted from factors unrelated to this program, such as the way students were selected into the program or their relatively higher motivation levels when compared with students not participating in the program. Additionally, though I-BEST was able to increase the rate at which students received certificates, it did not affect students' receipt of an associate's degree. However, these findings do represent one of the most notable improvements in student achievement among the interventions analyzed in this report, demonstrating this program's potential for further replication and study.

Models that help students avoid developmental education before entering college as well as strategies to mainstream students into college-level courses have also demonstrated promise for improving students' achievement. As noted in Chapters 2 and 3, two quasi-

\footnotetext{
${ }^{8}$ Jenkins, Zeidenberg, and Kienzl (2009).
} 
experimental studies of avoidance and mainstreaming revealed modest improvements in developmental education students' success, when controlling for preexisting differences between participating and nonparticipating students. First, a study of California's Early Assessment Program, which gave college placement exams to eleventh-graders and allowed students with lower level skills to build on their abilities while still in high school, was associated with reductions in the number of students needing developmental math (4 percentage points) and English (6 percentage points). ${ }^{9}$ Second, Community College of Baltimore County's Accelerated Learning Program (ALP), which mainstreamed developmental English students into college-level English classes, was correlated with substantial improvements in students' pass rates in college-level English. When controlling for student characteristics, there was a 33 percentage point difference between the pass rates of ALP students (71 percent) and non-ALP students (38 percent) in the introductory college-level English course within a year of taking the course. The program was also associated with improvements in the number of college-level courses that ALP students attempted and in the percentage of ALP students who passed the next level of college English. ${ }^{10}$

As with evaluations of Washington State's I-BEST program, these results should be approached with caution, as the improvements cannot be causally linked to these programs, and other, nonintervention-related factors, such as student motivation, may explain some of the positive results noted in these reports. However, the fact that participation in these programs was associated with substantial increases in students' progress into credit-bearing courses, even when controlling for a number of student characteristics, suggests that these programs have important potential for helping decrease the lengthy amount of time that students spend in developmental courses while increasing their progress toward earning a degree or certificate.

When looking to expand or replicate these program models, practitioners and policymakers should pay careful attention to how students with lower-level skills or multiple developmental needs can be better assisted, as these students are the ones most at risk of failure. Washington State's I-BEST model, which worked with students who had skills below the eighth-grade level, provides a useful example of how students with low skill levels may be able to more quickly achieve credentials and degrees that will advance their status in the marketplace. Similarly, California's Early Assessment Program provides increased opportunities for students to understand their academic limitations and advance their basic skills before enrolling in college, which may be particularly beneficial to students who have multiple needs. Developmental education programs should take such findings to heart and consider how variations of these programs might improve the opportunities for their own struggling students.

\footnotetext{
${ }^{9}$ Howell, Kurlaender, and Grodsky (2010).

${ }^{10}$ Jenkins, Speroni, Belfield, Jaggars, and Edgecombe (2010).
} 


\section{Untested Innovations in Developmental Education Practice}

While most developmental education reforms have focused on modest tweaks to programs' curricula and practices, a few recent innovations have focused on changing the foundations of these programs in an effort to more quickly advance students into credit-bearing courses and the attainment of postsecondary credentials. For instance, some reformers have sought out technological approaches to instruction as a way to provide more individualized instruction to students. Additionally, policymakers and national leaders have recently made efforts to better align secondary and postsecondary curricula and mandate further preparation in high school in order to increase students' success in college. Finally, other programs have sought to redefine the curricula and practices in both developmental and college-level courses to focus on the key skills that students will need in their careers and to more quickly advance them through introductory college-level courses. While relatively untested, these recent innovations hold clear promise for advancing developmental education students' success and should be a critical part of the research agenda moving forward.

\section{Technology-Aided Approaches to Instruction}

Computer-aided instruction poses a number of new avenues for developmental education instruction. Many colleges have integrated technology into developmental courses that have traditional content and curriculum. Computer programs like MyMathLab, Plato, ALEKS, and Math Zone are used to supplement classroom instruction by means of learning assistance centers or individualized tutoring sessions. ${ }^{11}$ Similarly, many colleges are using technology to provide online courses, where all learning takes place remotely, via software. ${ }^{12}$ More recently, practitioners have used technology to structure accelerated or modularized courses, which aim to help students progress more quickly through developmental education. In these reforms, software tutorial packages are used to help students focus on particular areas of weakness while allowing them to advance more quickly through other areas of strength. Technological packages have an additional advantage in that they are generally adaptive to diverse circumstances or can be preset to create an individualized program of instruction for each student. ${ }^{13}$

While some efforts have been made to evaluate the use of technology in the classroom, little rigorous research exists documenting the effectiveness of these practices in improving developmental education students' outcomes. Given the utility that technology holds for creating more individualized methods of instruction, researchers, policymakers, and practitioners should seek to better understand how such systems may be used to help students more

\footnotetext{
${ }^{11}$ Epper and Baker (2009).

${ }^{12}$ Carpenter, Brown, and Hickman (2004); Zavarella and Ignash (2009); Creery (2001); McClenden and McArdle (2002); Weems (2002); Blackner (2000).

${ }^{13}$ Epper and Baker (2009).
} 
quickly build their skills. It should also be noted, however, that some nonexperimental studies suggest that technology-aided instruction may have its drawbacks; several simple analyses have revealed that instruction provided wholly through computers may increase the rates of course withdrawal and failure. ${ }^{14}$ However, students who remain in computerized courses often perform at similar or higher levels than students who take traditional courses, implying that appropriate assessment and advising might be a step toward ensuring that the students who will benefit from these courses are the ones who actually take them. Moreover, exploratory research into the use of technology in accelerated and modularized courses suggests that these instruments may be most efficacious in supporting innovative course structures, in which they seem to hold more promise for improving students' mastery of course content, course completion, and progress into college-level courses. ${ }^{15}$

\section{Improving the Alignment Between Secondary and Postsecondary Education}

As suggested by several of the programmatic interventions discussed in this report, critical challenges remain with regard to aligning the standards and curricula of secondary education with those of postsecondary education. While studies have noted that taking a college preparatory curriculum through the final years of high school may reduce the chances of students needing remediation, others have noted that a substantial proportion of these students still place into developmental coursework when entering college. ${ }^{16}$ Similarly, other research has noted a divide between the skills taught in developmental education courses and those required in college-level courses in the same subject. ${ }^{17}$

Given these challenges, a number of states and organizations have begun to focus on eliminating the gap between high school, developmental, and college-level courses. For instance, organizations such as Achieve, Inc., and the American Youth Policy Forum have driven a push for states to require college- and career-ready curricula in high schools; these organization are also working actively to disseminate best practices in states across the country. ${ }^{18}$ Building on these efforts, the National Governors Association and the Council of Chief State School Officers recently announced the Common Core State Standards Initiative, which sets out "clear and consistent goals for learning that will prepare America's children for success in college and work." ${ }^{\prime 19}$ Such efforts have the potential to take developmental education avoidance strategies — such as early placement testing and precollege preparation (Chapter 2) - to a

\footnotetext{
${ }^{14}$ Boylan (2002); Jaggars and Bailey (2010); Zavarella and Ignash (2009).

${ }^{15}$ Epper and Baker (2009).

${ }^{16}$ Attewell, Lavin, Domina, and Levey (2006); Fine, Duggan, and Braddy (2009); Hoyt and Sorenson (2001).

${ }^{17}$ Boylan (2002); Roueche and Roueche (1993).

${ }^{18}$ Achieve, Inc. (2010); American Youth Policy Forum (AYPF) (2009).

${ }^{19}$ National Governors Association (2010).
} 
national scale by integrating college expectations and standards into the secondary school curricula. Similarly, they could help reduce the number of students placing into developmental education as students are better able to develop the skills needed for college-level work while still in high school.

Better alignment of secondary, developmental, and college-level curricula is perhaps one of the most important frontiers for improving students' avoidance of developmental education and their progress through college. As demonstrated by the avoidance strategies discussed in Chapter 2, helping high school students develop a clear perspective on how their skills and abilities match expectations for college students and allowing them additional preparation time before entering college has real promise for helping students reach collegelevel coursework quickly. Given the important influence that such alignment can have on developmental education students' success, researchers and policymakers should prioritize research in this area and seek to better understand how these policy efforts are changing students' educational experiences and achievement.

\section{Transforming Developmental and College-Level Curricula and Practice}

While a number of efforts are being made to better align secondary and college curricula, even more innovative efforts are taking place within colleges in an attempt to better align developmental and college-level practices and to advance remedial students' progress to college-level work. One of the most transformative of these movements is the Statistics Pathway (also known as Statway), a collaborative project being launched by the Carnegie Foundation for the Advancement of Teaching and the Charles A. Dana Center at the University of Texas at Austin. Arguing that statistical reasoning and data analysis are key requirements for many of today's growing occupations, Statway seeks to realign colleges' math curricula to focus on statistics rather than the algebra and calculus content currently required. ${ }^{20}$ This transformed math curricula offered to entering college students in nontechnical fields, and it seeks to advance students who lack basic math skills through an introductory college-level statistics curricula in one year. Thus, the initiative seeks to better prepare students for the needs of the workforce while also helping basic skills students move more quickly through their math courses - a critical consideration, given that developmental math tends to present the highest hurdle to developmental education students. ${ }^{21}$

Such efforts to dramatically transform both developmental and college-level math curricula and to move students more quickly through basic skills work represent a distinct departure from past developmental education reforms, which have focused primarily on tweaking

\footnotetext{
${ }^{20}$ Bryk and Treisman (2010).

${ }^{21}$ Bailey, Jeong, and Cho (2010).
} 
particular aspects of instruction and less on changes in course content. Programs such as Statway provide a unique answer to researchers' recent calls for more drastic changes in developmental education and provide a promising venue for exploring how more dramatic reforms may affect students' outcomes. Given the limited impact that previous reforms have had on students' achievement, researchers and policymakers should prioritize investigations into these more innovative designs and should pay close attention to how these efforts affect students' progress through developmental education and into college-level courses.

\section{Acceleration Models}

As discussed in Chapter 3, a number of colleges are now experimenting with ways to accelerate students' progress through developmental education. While little rigorous research exists documenting the success of these programs, a number of internal and descriptive evaluations have shown that these programs hold great promise for increasing students' success. As noted above, Community College of Baltimore County's practice of mainstreaming developmental education students into college-level courses has helped students gain quicker access to and success in college-level courses. However, other approaches - such as modularizing developmental education courses into mini-classes focused on discrete skills or creating compressed courses by which students can quickly cover course material - have also shown promise for helping students move more quickly into credit-bearing courses. While limited evidence exists about these programs, practitioners and researchers should explore accelerated courses as an important avenue for moving students more quickly through remedial coursework and into college-level courses.

\section{Additional Considerations for Future Research and Practice}

While a number of promising innovations in developmental education are under development, most of these reform efforts will also need to consider how to tackle several institutional issues that are at the core of developmental education programming and practice. For instance, most developmental education programs rely on entrance exams or placement tests to funnel students into the appropriate course levels. The tests thus play a large role in determining the length of students' tenure in developmental education - an issue that most practitioners will need to face when developing new reforms. Educators should also consider which faculty members will be implementing classroom innovations and how these individuals will be trained in newly developed methodologies. The following sections outline some of the challenges that these issues pose for developmental education reform and make some recommendations about how practitioners, researchers, and policymakers might approach these difficulties. 


\section{Placement Assessments}

On entering community college, most students are required to take an entrance exam, which assesses their current math, reading, and writing skills and is used to place them into the appropriate developmental or college-level courses. While the tests are designed to aid colleges' placement practices and were encouraged within earlier developmental education research, much debate exists as to the validity of these assessments and their benefits for students. First, colleges across the country have established different cutoff scores for placement into developmental education, creating questions about how well these tests demarcate a true deficit in students' skills. ${ }^{22}$ Additionally, recent research reports, employing sophisticated statistical methods, have shown that students with skill levels denoted by some colleges as developmental performed successfully in college-level courses. ${ }^{23}$ Finally, these assessments are not diagnostic and provide little information about how instruction could improve students' skills, making their validity for classroom assignment questionable. ${ }^{24}$

Given the important role that assessment and placement play in defining students' college careers, researchers and policymakers should place a high priority on developing more nuanced placement methods and on understanding how they affect students' progress through college. Much as four-year colleges use a compendium of resources to assess students' skills, community colleges should seek to diversify their methods. In particular, assessments that are more diagnostic - which delineate particular skill weaknesses and strengths - would help practitioners better understand the level of students' deficiencies (or lack thereof) while also providing clearer guides for classroom practice and instruction. Such tests would be particularly useful for certain classroom reforms, such as fast-track or modularized courses, as they would help to place students into the appropriate class format.

While some developers of the current placement tests have began to provide more diagnostic tools to accompany their tests, ${ }^{25}$ other, more comprehensive assessments should be identified and researched in order to see whether more valid measures can be used for placing students into different levels of developmental education. Effective measures used in secondary schools for diagnosing reading, writing, and math deficiencies would be one place to begin, as these assessments have already been validated for classroom use. Other assessments, such as those designed to measure students' affective characteristics, could also be an option, as these

\footnotetext{
${ }^{22}$ Safran and Visher (2010); Attewell, Lavin, Domina, and Levey (2006).

${ }^{23}$ Bettinger and Long (2009).

${ }^{24}$ Safran and Visher (2010).

${ }^{25}$ For instance, the College Board has developed a diagnostic tool for the ACCUPLACER tests, which many community colleges use for assessment and placement (Hughes and Scott-Clayton, 2010).
} 
tests might be useful in considering other supports that might help improve students' success, such as more intensive advising or mentoring. ${ }^{26}$

\section{Adjunct Faculty}

Studies have clearly demonstrated that a large majority of developmental education classes are taught by adjunct, or part-time, faculty. While consistent estimates are difficult to find, national surveys have found that up to three-quarters of developmental courses in community colleges are taught by adjuncts. ${ }^{27}$ While adjunct faculty make invaluable contributions to the nation's higher education system, they can also suffer several major disadvantages as a result of their employment status. For instance, adjunct faculty are generally paid only for their time teaching in the classroom, which can limit their involvement in other activities at the college, such as departmental decision-making and piloting new programmatic strategies. Additionally, adjuncts tend to work multiple jobs, which usually makes them less accessible to students or other faculty. Finally, adjunct faculty are rarely paid for professional development, thus restricting their chances of being trained to fully implement programs seeking to transform developmental education practice. ${ }^{28}$

Given that adjunct faculty have the greatest access to developmental education students, educators and policymakers need to pay close attention to integrating them into interventions, particularly when considering how to scale new strategies to reach larger populations of students. While a number of community college initiatives and developmental educators recommend such integration, few structures currently exist in the community college environment to make such practices a reality, and so very few adjuncts become deeply involved in colleges' work. ${ }^{29}$ Indeed, numerous colleges have cited budget limitations as the key reason why adjunct faculty are employed at such high numbers, thus revealing the substantial challenges that colleges face in providing additional support to these faculty. ${ }^{30}$

These issues suggest that more fundamental changes in community college programming and practices may be needed in order to bring larger proportions of adjunct faculty into colleges' implementation of new reforms. For instance, higher-level policies, allowing for additional resources to be funneled to the preparation of adjunct faculty, might help colleges overcome some of the limitations that they face in readying personnel to lead new instructional interventions. Similarly, finding ways to standardize practices across full-time and adjunct

\footnotetext{
${ }^{26}$ Hughes and Scott-Clayton (2010); Boylan (2009).

${ }^{27}$ Boylan, Bonham, Jackson, and Saxon (1994); Gerstein (2009); Shults (2000).

${ }^{28}$ Gerstein (2009); Schuetz (2002).

${ }^{29}$ Boylan (2002); Zachry (2008); Rutschow et al. (2011); Center for Student Success (2007).

${ }^{30}$ Rutschow et al. (2011).
} 
faculty will require deeper investment in a college's ongoing professional development activities (which is itself an important field for future research, as discussed below).

\section{Classroom Instructional Practice}

Several studies have demonstrated that the level of quality and effectiveness of instruction are among the most important factors influencing developmental students' academic performance and that classroom experiences are an important predictor of commitment to the institution for students at all levels. ${ }^{31}$ Researchers, however, have given only cursory treatment to instructors' pedagogy and practice within the classroom, and currently no rigorous studies have attempted to document how different instructional practices affect student outcomes. ${ }^{32}$ Theoretical and best-practices research have hypothesized that certain pedagogical techniques - such as active, or "constructivist," learning, in which students play a critical role in facilitating and evaluating their own learning — provide promising methods for classroom instruction. ${ }^{33}$ However, although some researchers have attempted to document the variation in developmental education instruction and have found correlational evidence that active learning is beneficial to developmental-level students, currently no standardized techniques exist for assessing the effectiveness of various pedagogical practices. ${ }^{34}$

Given the important role that pedagogy and instruction play in student learning, practitioners, policymakers, and researchers should pay close attention to the variations in instruction and should develop more standardized measures for assessing the effectiveness of different practices. In order to undertake this work, these individuals might identify particular instructors who have high levels of success and then determine what practices make their instruction effective. Similarly, researchers might look to develop a standardized classroom observation instrument, which would allow for a more consistent method of assessing instruction across different classrooms and schools. Finally, rigorous evaluations of new reforms and innovations should be accompanied by more intensive observations of actual classroom instruction. This would allow researchers to evaluate the continuity of implementation across classrooms, and it would help policymakers and practitioners to better understand what practices and pedagogies facilitate student achievement.

\footnotetext{
${ }^{31}$ Boylan (2002); Strauss and Volkwein (2004); Tinto (1975).

${ }^{32}$ Grubb and Associates (1999).

${ }^{33}$ Boylan (2002); Grubb and Associates (1999); Simpson, Stahl, and Francis (2004); Center for Student Success (2007). These recommendations do not entirely discount lectures but suggest that students are more likely to succeed if they are exposed to a variety of pedagogical techniques that encourage active rather than passive learning.

${ }^{34}$ Grubb and Associates (1999); Schwartz and Jenkins (2007); Braxton, Milem, and Sullivan (2000); Weinstein et al. (1997); Kuh, Pace, and Vesper (1997); DePree (1998); Chaffee (1992).
} 


\section{Professional Development}

Professional development is also a critical consideration in developmental education practice and reform. As might be expected, classroom instructors and other support staff play a key role in implementing reforms to improve students' success and, as such, may require substantial training to learn the methodology behind the new practices. Professional development is particularly important for developmental education instructors, as these individuals tend to have limited previous training for teaching basic skills students. ${ }^{35}$ Unfortunately, studies have found that most community colleges provide only episodic staff development activities, which tend to take the form of one-day workshops or seminars led by outside experts, or else informal and isolated conversations among colleagues or departmental meetings that focus on logistics or content knowledge rather than pedagogy. ${ }^{36}$ Sadly, studies have revealed that such isolated professional development does little to change individuals' everyday practice, as they become subsumed in normal routines and have little support for integrating new learning into their practice. ${ }^{37}$ Moreover, little research has been done within community colleges to determine whether and how a particular professional development activity may have influenced faculty practice or student outcomes. ${ }^{38}$

While research in middle and high schools has shown that professional development reforms alone do not necessarily lead to improved student achievement, ${ }^{39}$ a more systematic approach to professional development activities can be a vital tool in colleges' efforts to implement large-scale reforms aimed at increasing developmental education students' success. As such, policymakers and reformers should place a high priority on developing more integrated approaches to professional development that are designed to provide ongoing support to faculty and staff implementing new reforms and to assist them in bringing this new learning into their actual classroom practice. Promising methods have been developed at a few colleges, including the efforts of several California community colleges to create Faculty Inquiry Groups, which provide opportunities for regular collaboration and reflection on specific goals for student success. ${ }^{40}$ Patrick Henry Community College in Martinsville, Virginia, has developed a training center - the Southern Center on Active Learning Excellence - to support the institutionalization of pedagogical practices that encourage active and collaborative learning. This center

\footnotetext{
${ }^{35}$ Shults (2000).

${ }^{36}$ Grubb and Associates (1999); Murray (2002); Gerstein (2009).

${ }^{37}$ Troen and Boles (2003).

${ }^{38}$ Chism and Szabo (1997).

${ }^{39}$ Some studies, which have focused on the effects of increased professional development on student outcomes, have had disappointing results (Corrin et al., 2008; Garet et al., 2010). However, systematic professional development and training remain key in other K-12 efforts that have seen some success in increasing students' academic and workforce outcomes (Darling-Hammond et al., 2009).

${ }^{40}$ Carnegie Foundation for the Advancement of Teaching (2008).
} 
provides a number of ongoing opportunities for faculty and staff training, including free courses to learn different pedagogical approaches, coaching and mentoring in implementing these practices, examples of classroom lessons, surveys for students, and training institutes for other colleges to learn about collaborative learning. ${ }^{41}$ Innovations like these represent promising steps toward a more integrated approach for faculty and staff training, which, in turn, may create a more systematic approach to implementation of reforms while supporting their wide-scale adoption.

Similarly, given the dearth of rigorous research on the effects of professional development in community colleges, researchers should seek to develop new inquiries into this field. One useful approach would be to create a more holistic research process for observing program implementation, which would provide on-the-ground time to assess instructors' training and the consistency with which they implement new methodologies within their actual practice. As with research into instructional practices, developing more standardized techniques for evaluating the effectiveness of colleges' training practices would allow for more concrete comparisons across different institutions. These instruments might seek to document such factors as the depth and intensity of colleges' training programs, their institution of research-based principles and practices, the ongoing supports provided for classroom implementation, and the actual integration of the new knowledge and methods into classroom instruction.

\section{Conclusion}

Developmental education remains a field ripe for further research and innovation. With multiple studies revealing alarmingly low success rates for developmental students, these programs can no longer afford to focus on the status quo. Research to date clearly demonstrates that minor modifications in developmental education programs are insufficient for producing dramatic improvements in student achievement. Given this, educators, policymakers, and researchers should continue to question the traditional developmental course sequence and should turn to more innovative efforts aimed at transforming the educational experience of academically underprepared students. Creating ever more novel ways to improve students' achievement and providing rigorous, reliable evidence for the successes of these new innovations are two actionable steps that educators, policymakers, and researchers can take to allow academically disadvantaged students the opportunity to achieve the college and career dreams that they are so avidly pursuing.

\footnotetext{
${ }^{41}$ Rutschow et al. (2011); Zachry (2008).
} 

Appendix A

List of Journals Reviewed 

The journals listed below were searched by keywords that include "basic skills," "community college," "developmental education," and "remedial education."

American Educational Research Journal

Community College Journal of Research and Practice

Education and Information Technologies

Education Technology Research and Development

Educational Assessment, Evaluation and Accountability

Educational Evaluation and Policy Analysis

Educational Research for Policy and Practice

Educational Studies in Mathematics

Higher Education: The International Journal of Higher Education and Educational Planning

Industry and Higher Education

Innovative Education

Journal of College Student Development

Journal of Developmental Education

Journal of Higher Education

New Directions for Community Colleges

New Directions for Higher Education

New Directions for Teaching and Learning New Directions in Adult and Continuing

Education

New England Journal of Higher Education

Opportunity Matters

Research in Developmental Education

Research in Higher Education

Review of Research in Education

Review of Higher Education 



\section{References}

Achieve, Inc. 2010. On the Road to Implementation: Achieving the Promising of the Common Core State Standards. Washington, DC: Achieve, Inc.

Ackermann, S. P. 1990. "The Benefits of Summer Bridge Programs for Underrepresented and Low-Income Students." Paper presented at the Annual Meeting of the American Educational Research Association, Boston, April 16-20.

Adams, Peter S., Gerhart R. Miller, and A. Roberts. 2009. "The Accelerated Learning Program: Throwing Open the Gates." Journal of Basic Writing 28, 2: 50-69.

Adams, William W. 2003. Developmental Mathematics: A New Approach. Mathematical Association of America (MAA).

Web site: http://www.maa.org/features/112103devmath.html.

Adelman, Clifford. 2004. Principal Indicators of Student Academic Histories in Postsecondary Education, 1972-2000. Washington, DC: Institute of Education Sciences, U.S. Department of Education.

American Institutes for Research and SRI International. 2007. Evaluation of the Early College High School Initiative: Select Topics on Implementation. Report prepared for the Bill and Melinda Gates Foundation. Washington, DC: American Institutes for Research and SRI International.

American Mathematical Association of Two-Year Colleges (AMATYC). 2006. Beyond Crossroads: Implementing Mathematics Standards in the First Two Years of College. Memphis, TN: American Mathematical Association of Two-Year Colleges.

American Youth Policy Forum (AYPF). 2009. "Linking Second and Postsecondary Systems Lessons from Indiana.” Issue Brief. Washington, DC: American Youth Policy Forum.

Arendale, David. 1997. "Supplemental Instruction (SI): Review of Research Concerning the Effectiveness of SI from the University of Missouri-Kansas City and Other Institutions from Across the United States." Proceedings of the 17th and 18th Annual Institutes for Learning Assistance Professionals, Tucson: University Learning Center, University of Arizona.

Astin, Alexander W. 1985. Achieving Educational Excellence. San Francisco: Jossey-Bass.

Attewell, Paul, David Lavin, Thurston Domina, and Tania Levey. 2006. "New Evidence on College Remediation." Journal of Higher Education 77, 5: 886-924.

Badway, Norena, and W. Norton Grubb. 1997. A Sourcebook for Reshaping the Community College: Curriculum Integration and the Multiple Domains of Career Preparation, Vols. I and II. Berkeley, CA: National Center for Research in Vocational Education. 
Bahr, Peter Riley. 2008. "Cooling Out in the Community College: What Is the Effect of Academic Advising on Students' Chances of Success?" Research in Higher Education 49: 704-732.

Bahr, Peter Riley. 2010. "Revising the Efficacy of Postsecondary Remediation: The Moderating Effects of Depth/Breadth of Deficiency." Review of Higher Education 33, 2: 177-205.

Bailey, Thomas. 2009. "Challenge and Opportunity: Rethinking the Role and Function of Developmental Education in Community College." New Directions for Community Colleges 145: 11-30.

Bailey, Thomas R., and Mariana Alfonso. 2005. Paths to Persistence. New Agenda Series 6, 1. Indianapolis: Lumina Foundation for Education.

Bailey, Thomas, Katherine L. Hughes, and Melinda Mechur Karp. 2003. "Dual Enrollment Programs: Easing Transitions from High School to College." CCRC Brief No. 17. New York: Community College Research Center, Teachers College, Columbia University.

Bailey, Thomas, Dong Wook Jeong, and Sung-Woo Cho. 2010. "Referral, Enrollment, and Completion in Developmental Education Sequences in Community Colleges." Economics of Education Review 29: 255-270.

Baker, Elaine DeLott, Laura Hope, and Kelley Karandjeff. 2009. Contextualized Teaching and Learning: A Faculty Primer (A Review of Literature and Faculty Practices with Implications for California Community College Practitioners). Sacramento: Center for Student Success/RP Group and the Academic Senate for California Community Colleges.

Bannier, Betsy. 2007. "Predicting Mathematics Learning Center Visits: An Examination of Correlating Variables." Learning Assistance Review 12, 1: 7-16.

Barnett, Elisabeth. 2009. "Developmental Summer Bridges: Young Texans on the Road to College." Presentation at the Annual Conference of the League for Innovation in the Community College, Reno, NV, March 17.

Bassett, Mary Jane. 2009. Tennessee Board of Regents: Developmental Studies Redesign Initiative. "Jackson State Community College, Course Title: Basic Math, Elementary Algebra and Intermediate Algebra."

Web site: http://www.thencat.org/States/TN/Abstracts/JSCC\%20Algebra_Abstract.htm.

Berns, Robert G., and Patricia M. Erickson. 2001. "Contextual Teaching and Learning: Preparing Students for the New Economy.” The Highlight Zone: Research @ Work, No. 5. Columbus, OH: National Center for Career and Technical Education.

Bettinger, Eric, and Rachel Baker. 2011. "The Effects of Student Coaching in College: An Evaluation of a Randomized Experiment in Student Mentoring." Paper presented at the Society for Research on Educational Effectiveness Conference, Washington, DC, March 3-5.

Bettinger, Eric P., and Bridget Terry Long. 2009. "Addressing the Needs of Underprepared Students in Higher Education: Does College Remediation Work?" Journal of Human Resources 44, 3: 736-771. 
Bill and Melinda Gates Foundation. 2009. Postsecondary Success. Seattle, WA: Bill and Melinda Gates Foundation.

Blackner, D. B. 2000. "Prediction of Community College Students' Success in Developmental Math with Traditional Classroom, Computer-Based On-Campus and Computer-Based at a Distance Instruction Using Locus of Control, Math Anxiety and Learning Style." Doctoral dissertation. Available from ProQuest Dissertations and Theses database: UMI No. 3064379 .

Bowles, Tyler J., Adam C. McCoy, and Scott Bates. 2008. "The Effect of Supplemental Instruction on Timely Graduation." College Student Journal 42, 3: 853-859.

Boylan, Hunter R. 1980. "Academic Intervention in Developmental Education." Journal of Developmental and Remedial Education 3, 3: 10-11.

Boylan, Hunter R. 1985. "The Effectiveness of Developmental Education Programs." Journal of Developmental Education 2, 2.

Boylan, Hunter R. 2002. What Works: Research-Based Practices in Developmental Education. Boone, NC: Continuous Quality Improvement Network and the National Center for Developmental Education, Appalachian State University.

Boylan, Hunter R. 2009. "Targeted Intervention for Developmental Education Students (T.I.D.E.S.)." Journal of Developmental Education 32, 3: 14-23.

Boylan, Hunter R., Leonard B. Bliss, and Barbara S. Bonham. 1997. "Program Components and Their Relationship to Student Performance." Journal of Developmental Education 20, 3: 2-8.

Boylan, Hunter R. and Barbara S. Bonham. 1992. "The Impact of Developmental Education Programs." Research in Developmental Education 9, 5: 1-3.

Boylan, Hunter R., Barbara S. Bonham, and Leonard B. Bliss. 1994. "Characteristic Components of Developmental Education Programs." Research in Developmental Education 11, 1: 1-4.

Boylan, Hunter R., Barbara S. Bonham, C. Claxton, and Leonard B. Bliss. 1992. "The State of the Art in Developmental Education." Paper presented at the First National Conference on Research in Developmental Education, Charlotte, NC.

Boylan, Hunter R., Barbara S. Bonham, James Jackson, and D. Patrick Saxon. 1994. "Staffing Patterns in Developmental Education Programs: Full-Time/Part-Time, Credentials, and Program Placement." Research in Developmental Education 11, 5.

Boylan, Hunter R., and D. Patrick Saxon. 1998. An Evaluation of Developmental Education in Texas Public Colleges and Universities. Austin: Texas Higher Education Coordinating Board.

Boylan, Hunter R., and D. Patrick Saxon. 2002. "What Works in Remediation: Lessons from 30 Years of Research." Presentation prepared for the League for Innovation in the Community College, Phoenix, AZ. 
Bragg, Debra D. 2009. Community College of Denver Breaking Through Outcomes Report. Denver, CO: Community College of Denver.

Bragg, Debra D., and Elisabeth Barnett. 2009. Lessons Learned from Breaking Through. In Brief. Champaign, IL: Office of Community College Research and Leadership. Web site: http://occrl.ed.uiuc.edu.

Brancard, Ruth, Elaine DeLott Baker, and Laura Jensen. 2006. Accelerated Developmental Education Project: Research Report (Community College of Denver). Denver, CO: Community College of Denver.

Braxton, John M., Jeffrey F. Milem, and Anna Shaw Sullivan. 2000. "The Influence of Active Learning on the College Student Departure Process: Toward a Revision of Tinto's Theory." Journal of Higher Education 71, 5.

Brock, Thomas, Davis Jenkins, Todd Ellwein, Jennifer Miller, Susan Gooden, Kasey Martin, Casey MacGregor, and Michael Pih. 2007. Building a Culture of Evidence for Community College Student Success: Early Progress in the Achieving the Dream Initiative. New York: MDRC.

Brown, R., and R. Ternes. 2009. Final Report to the Lilly Endowment Grant: Grant for Targeted and Accelerated Remediation. Unpublished. Indianapolis: Ivy Tech.

Bryk, Anthony, and Uri Treisman. 2010. "Make Math a Gateway, Not a Gatekeeper." Chronicle of Higher Education (April 18).

Calcagno, Juan Carlos, and Bridget Terry Long. 2008. The Impact of Postsecondary Remediation Using a Regression Discontinuity Approach: Addressing Endogenous Sorting and Noncompliance. NCPR Working Paper. New York: National Center for Postsecondary Research.

Carnegie Foundation for the Advancement of Teaching. 2008. "Strengthening Pre-Collegiate Education in Community Colleges: Project Summary and Recommendations." Stanford, CA: Carnegie Foundation for the Advancement of Teaching.

Carpenter, Trudy G., William L. Brown, and Randall C. Hickman. 2004. "Influences of Online Delivery on Developmental Writing Outcomes." Journal of Developmental Education 28, 1: $14-18,35$.

Cartnal, Ryan, and Peter F. Hagen. 1999. Evaluation of the Early Alert Program, Spring 1999 (Cuesta College, California). ERIC ED 441541.

Casazza, Martha E., and Sharon L. Silverman. 1996. Learning Assistance and Developmental Education: A Guide for Effective Practice. San Francisco: Jossey-Bass.

Center for Student Success. 2007. Basic Skills as a Foundation for Student Success in California Community Colleges. Sacramento: Research and Planning Group for California Community Colleges. 
Chaffee, John. 1992. "Critical Thinking Skills: The Cornerstone of Developmental Education." Journal of Developmental Education 15, 3: 2-4.

Chism, Nancy Van Note, and Borbala Szabo. 1997. "How Faculty Development Programs Evaluate Their Services." Journal of Staff, Program, and Organizational Development 15, 2 .

Continuous Quality Improvement Network (CQIN) and American Productivity and Quality Center (APQC). 2000. Benchmarking Best Practices in Developmental Education. Houston: American Productivity and Quality Center.

Corrin, William, Marie-Andrée Somers, James J. Kemple, Elizabeth Nelson, and Susan Sepanik with Terry Salinger and Courtney Tanenbaum. 2008. The Enhanced Reading Opportunities Study: Findings from the Second Year of Implementation. New York: MDRC.

Creery, Katherine W. 2001. "Comparison of Lecture, Self-Paced, and On-Line Courses." NADE Selected Conference Papers, Vol. 7. Louisville, KY: National Association of Developmental Education.

Cross, K. Patricia. 1976. Accent on Learning. San Francisco: Jossey-Bass.

Darling-Hammond, Linda, Ruth Chung Wei, Alethea Andree, Nikole Richardson, and Stelios Orphanos. 2009. Professional Learning in the Learning Profession: A Status Report on Teacher Development in the United States and Abroad. Sanford, CA: National Staff Development Council and the School Redesign Network.

De Corte, Erik. 2007. "Learning from Instruction: The Case of Mathematics." Learning Inquiry 1: 19-30.

DePree, J. 1998. "Small-Group Instruction: Impact on Basic Algebra Students." Journal of Developmental Education 22, 1: 2-5.

Derby, D. C., and T. Smith. 2004. "An Orientation Course and Community College Retention." Community College Journal of Research and Practice 28, 9: 763-773.

Dirkx, John M., and Suzanne M. Prenger. 1997. A Guide to Planning and Implementing Instruction for Adults: A Theme-Based Approach. San Francisco: Jossey-Bass.

Edgecombe, Nikki. 2011. "Accelerating the Academic Achievement of Students Referred to Developmental Education." CCRC Working Paper No. 30, Assessment of Evidence Series. New York: Community College Research Center, Teachers College, Columbia University.

Engstrom, Cathy McHugh, and Vincent Tinto. 2008. "Learning Better Together: The Impact of Learning Communities on the Persistence of Low-Income Students." Opportunity Matters 1.

Epper, Rhonda M., and Elaine DeLott Baker. 2009. Technology Solutions for Developmental Math: An Overview of Current and Emerging Practices. Report funded by the William and Flora Hewlett Foundation and the Bill and Melinda Gates Foundation. 
Fine, Anne, Mickle Duggan, and Linda Braddy. 2009. "Removing Remediation Requirements: Effectiveness of Intervention Programs." PRIMUS 19, 5: 433-446.

Fitts, J. D. 1989. "A Comparison of Locus of Control and Achievement Among Remedial Summer Bridge and Nonbridge Students in Community Colleges in New Jersey." Paper presented at the Annual Meeting of the American Educational Research Association, San Francisco, March 27-31.

Garcia, Phillip. 1991. "Summer Bridge: Improving Retention Rates for Underprepared Students." Journal of the Freshman Year Experience 3, 2: 91-105.

Garet, Michael S., Andrew J. Wayne, Fran Stancavage, James Taylor, Kirk Walters, Mengli Song, Seth Brown, Steven Hurlburt, Pei Zhu, Susan Sepanik, and Fred Doolittle. 2010. Middle School Mathematics Professional Development Impact Study: After the First Year of Implementation. Washington, DC: Institute of Education Sciences, U.S. Department of Education.

Gerstein, Amy. 2009. Community College Faculty and Developmental Education: An Opportunity for Growth and Investment. Stanford, CA: Carnegie Foundation for the Advancement of Teaching.

Gillespie, Marilyn K. 2002. EFF Research Priniciple: A Contextualized Approach to Curriculum and Instruction. Washington, DC: National Institute for Literacy.

Glau, Gregory. 2007. "Stretch at 10: A Progress Report on Arizona State University's Stretch Program." Journal of Basic Writing 26, 2: 30-48.

Gleason, Barbara. 2000. "Evaluating Writing Programs in Real Time: The Politics of Remediation." College Composition and Communication 51, 4: 560-588.

Goen-Salter, Sugie. 2008. "Critiquing the Need to Eliminate Remediation: Lessons from San Francisco State.” Basic Writing 27, 2: 81-105.

Golann, Joanne Wang, and Katherine L. Hughes. 2008. Dual Enrollment Policies and Practices: Earning College Credit in California High Schools. San Francisco: James Irvine Foundation.

Goldrick-Rab, Sara. 2007. "Promoting Academic Momentum at Community Colleges: Challenges and Opportunities." CCRC Working Paper No. 5. New York: Community College Research Center, Teachers College, Columbia University.

Greenberg, Arthur Richard. 1988. "High School Students in College Courses: Three Programs." New Directions for Community Colleges 63: 69-84.

Grubb, W. Norton. 2001a. From Black Box to Pandora's Box: Evaluating Remedial/Developmental Education. Community College Research Center, Teachers College, Columbia University. ERIC ED 453893.

Grubb, W. Norton. 2001b. "Getting into the World”: Guidance and Counseling in Community Colleges. New York: Community College Research Center, Teachers College, Columbia University. 
Grubb, W. Norton, and Associates. 1999. Honored but Invisible: An Inside Look at Teaching in Community Colleges. New York: Routledge.

Grubb, W. Norton, and Eileen Kraskouskas. 1992. A Time to Every Purpose: Integrating Occupational and Academic Education in Community Colleges and Technical Institutes. Berkeley, CA: National Center for Research in Vocational Education.

Hagedorn, Linda Serra, M. Vali Siadet, Shereen F. Fogel, Amaury Nora, and Ernest T. Pascarella. 1999. "Success in College Mathematics: Comparisons Between Remedial and Nonremedial First-Year College Students." Research in Higher Education 40, 3: 261-284.

Hays, K. 1994. "Student Assessment in the Community College and the Use of Technology in Testing." Pages 474-484 in G. Baker (ed.), A Handbook on the Community College in America. Westport, CT: Greenwood Press.

Hock, Michael F., Donald D. Deshler, and Jean B. Schumaker. 1999. "Tutoring Programs for Academically Underprepared College Students: A Review of the Literature." Journal of College Reading and Learning 29: 101-122.

Hodges, Russ, and William G. White, Jr. 2001. "Encouraging High-Risk Student Participation in Tutoring and Supplemental Instruction." Journal of Developmental Education 24, 3: 210.

Howell, Jessica S., Michal Kurlaender, and Eric Grodsky. 2010. "Postsecondary Preparation and Remediation: Examing the Effect of the Early Assessment Program at California State University." Journal of Policy Analysis and Management 29, 4: 726-748.

Hoyt, Jeff E., and Colleen T. Sorenson. 2001. "High School Preparation, Placement Testing, and College Remediation." Journal of Developmental Education 25, 2: 26-34.

Hughes, Katherine, and Judith Scott-Clayton. 2010. "Assessing Developmental Assessment in Community Colleges: A Review of the Literature." CCRC Working Paper No. 19. Presented at the NCPR Developmental Education Conference: What Policies and Practices Work for Students? New York, September 23-24.

Jaggars, Shanna Smith, and Thomas Bailey. 2010. Effectiveness of Fully Online Courses for College Students: Response to a Department of Education Meta-Analysis. New York: Community College Research Center, Teachers College, Columbia University.

Jenkins, Davis. 2009. "Educational Outcomes of the Digital Bridge Academy: Findings from a Multivariate Analysis." Presentation at the Conference of the League for Innovation in Community College, Reno, NV, March 16.

Jenkins, Davis, Shanna Smith Jaggars, and Josipa Roksa. 2009. Promoting Gatekeeper Course Success Among Community College Students Needing Remediation: Findings and Recommendations from a Virginia Study (Summary Report). New York: Community College Research Center, Teachers College, Columbia University.

Jenkins, Davis, Cecilia Speroni, Clive Belfield, Shanna Smith Jaggars, and Nikki Edgecombe. 2010. "A Model for Accelerating Academic Success of Community College Remedial 
English Students: Is the Accelerated Learning Program (ALP) Effective and Affordable?" CCRC Working Paper No. 21. New York: Community College Research Center, Teachers College, Columbia University.

Jenkins, Davis, Matthew Zeidenberg, and Gregory S. Kienzl. 2009. "Building Bridges to Postsecondary Training for Low-Skill Adults: Outcomes of Washington State's I-BEST Program." CCRC Brief No. 42. New York: Columbia University, Teachers College, Community College Research Center.

Jobs for the Future. 2009. Early College High School Initiative: A Portrait in Numbers. Boston: Jobs for the Future.

Jobs for the Future. 2010. Contextualization Toolkit: A Tool for Helping Low-Skilled Adults Gain Postsecondary Certificates and Degrees. Boston: Jobs for the Future.

Karp, Melinda Mechur, Juan Carlos Calcagno, Katherine L. Hughes, Dong Wook Jeong, and Thomas Bailey. 2008. "Dual Enrollment Students in Florida and New York City: Postsecondary Outcomes." CCRC Brief No. 37. New York: Community College Research Center, Teachers College, Columbia University.

Kerrigan, Monica Reid, and Doug Slater. 2010. Collaborating to Create Change: How El Paso Community College Improved the Readiness of Its Incoming Students Through Achieving the Dream. Report No. 4 in the Achieving the Dream Culture of Evidence Series. New York: Community College Research Center and MDRC.

Kim, Jennifer E., and Elisabeth Barnett. 2008. "2007-08 MCNC Early College High School Students: College Coursework Participation and Performance." New York: National Center for Restructuring Education, Schools, and Teaching; Teachers College, Columbia University.

Kleiman, Neil Scott. 2001. "Building a Highway to Higher Ed: How Collaborative Efforts Are Changing Education in America." New York: Center for an Urban Future. ERIC ED 453 738.

Kleiner, Brian, and Laurie Lewis. 2005. "Dual Enrollment of High School Students at Postsecondary Institutions: 2002-03.” NCES 2005-008. Washington, DC: National Center for Education Statistics, Institute of Education Sciences, U.S. Department of Education.

Kuh, George D., C. Robert Pace, and Nick Vesper. 1997. "The Development of Process Indicators to Estimate Student Gains Associated with Good Practices in Undergraduate Education." Research in Higher Education 38, 4: 435-454.

Kulik, Chen-Lin C., James A. Kulik, and Barbara J. Shwalb. 1983. "College Programs for HighRisk and Disadvantaged Students: A Meta-Analysis of the Findings." Review of Educational Research 53, 3: 397-414.

Lewallen, Willard Clark. 1993. Early Alert: A Report on Two Pilot Projects at Antelope Valley College. ERIC ED 369452. 
Lesik, Sally Andrea. 2006. "Applying the Regression-Discontinuity Design to Infer Causality with Non-Random Assignment." Review of Higher Education 30, 1: 1-19.

Levin, Henry M., and Juan Carlos Calcagno. 2008. "Remediation in the Community College: An Evaluator's Perspective." Community College Review 35, 3: 181-207.

Light, Richard J. 2001. Making the Most of College: Students Speak Their Minds. Cambridge, MA: Harvard University Press.

Lumina Foundation for Education. 2009. Lumina Foundation's Strategic Plan: Goal 2025. Indianapolis: Lumina Foundation for Education.

Martorell, Paco, and Isaac McFarlin. 2007. "Help or Hindrance? The Effects of College Remediation on Academic and Labor Market Outcomes." Unpublished manuscript.

Massachusetts Community College Executive Office. 2006. 100\% Math Initiative: Building a Foundation for Student Success in Developmental Mathematics. Boston: Massachusetts Community College Executive Office.

Maxwell, Martha. 1979. Improving Student Learning Skills. San Francisco: Jossey-Bass.

Maxwell, Martha. 1990. "Does Tutoring Help? A Look at the Literature." Review of Research in Developmental Education 7, 4: 1-5.

McCabe, Robert H. 2000. No One to Waste: A Report to Public Decision-Makers and Community College Leaders. Alexandria, VA: Community College Press.

McCabe, Robert H., and Philip R. Day (eds.). 1998. Developmental Education: A Twenty-First Century Social and Economic Imperative. Laguna Hills, CA: League for Innvoation in the Community College.

McClenden, Marie, and Michele McArdle. 2002. "Comparing Alternative Algebraic Modalities for Remedial Students." Paper presented at the Chair Academy Leadership Conference, Kansas City, MO, February 28 - March 2. ERIC ED 464568.

Melguizo, Tatiana, Linda Serra Hagedorn, and Scott Cypers. 2008. "Remedial/Developmental Education and the Cost of Community College Transfer: A Los Angeles County Sample." Review of Higher Education 31, 4: 401-431.

Michalowski, Sam. 2007. Positive Effects Associated with College Now Participation. New York: Collaborative Programs Research and Evaluation, City University of New York.

Miller, M. F. 1990. 1990 Pre-Freshman Summer Program: Post-Program Self-Study Report. ERIC ED 337213.

Moltz, David. 2010. “Competing Principles.” Inside Higher Education (June 28).

Morante, Edward A. 1987. "A Primer on Placement Testing." New Directions for Community Colleges 59: 55-63. 
Murray, John P. 2002. "The Current State of Faculty Development in Two-Year Colleges." New Directions for Community Colleges 2002, 18: 89-98.

National Governors Association. 2010. "National Governors Association and State Education Chiefs Launch Common State Academic Standards." Press release. Washington, DC: National Governors Association.

Office of the Press Secretary. 2009. "Excerpts of the President's Remarks in Warren, Michigan and Fact Sheet on the American Graduation Initiative" (July 14). Washington, DC: White House.

Ogden, Peggy, Dennis Thompson, Art Russell, and Carol Simons. 2003. "Supplemental Instruction: Short- and Long-Term Impact." Journal of Developmental Education 26, 3: 28.

Parsad, Basmat, and Laurie Lewis. 2003. "Remedial Education at Degree-Granting Postsecondary Institutions in Fall 2000." NCES 2004-010. Washington, DC: National Center for Education Statistics, Institute of Education Sciences, U.S. Department of Education.

Pascarella, Ernest T., and P. T. Terenzini. 1991. How College Affects Students. San Francisco: Jossey-Bass.

Perin, Dolores. 2001. "Academic-Occupational Integration as a Reform Strategy for the Community College: Classroom Perspectives." Teachers College Record 103: 303-335.

Perin, Dolores. 2004. "Remediation Beyond Developmental Education: The Use of Learning Assistance Centers to Increase Academic Preparedness in Community Colleges." Community College Journal of Research and Practice 28, 7: 559-582.

Perin, Dolores. 2005. "Institutional Decision Making for Increasing Academic Preparedness in Community Colleges." New Directions for Community Colleges 129: 27-38.

Perin, Dolores. 2011. "Facilitating Student Achievement Through Contextualization" CCRC Working Paper No. 29, Assessment of Evidence Series. New York: Community College Research Center, Teachers College, Columbia University.

Pfleging, Elizabeth. 2002. "An Evaluation of the Early Alert Program at Columbia College." Unpublished doctoral dissertation. ERIC ED 478596.

Provasnik, Stephen, and Michael Planty. 2008. "Community Colleges: Special Supplement to The Condition of Education 2008 (Statistical Analysis Report)." NCES 2008-033. Washington, DC: National Center for Education Statistics, Institute of Education Sciences, U.S. Department of Education.

Radford, Alexandria Walton, Lutz Berkner, Sara C. Wheeless, and Bryan Shepherd. 2010. "Persistence and Attainment of 2003-04 Beginning Postsecondary Students: After 6 Years." NCES 2011-151. Washington, DC: National Center for Education Statistics, Institute of Education Sciences, U.S. Department of Education. 
Ramirez, Gen M. 1997. "Supplemental Instruction: The Long-Term Impact." Journal of Developmental Education 21, 1.

Rossi, Peter H., and Howard E. Freeman. 1993. Evaluation: A Systematic Approach. Newbury Park, CA: Sage Publications.

Roueche, John, and George Baker. 1987. Access and Excellence: The Open-Door College. Alexandria, VA: Community College Press.

Roueche, John, George Baker, and Suanne Roueche. 1984. College Responses to LowAchieving Students: A National Study. Orlando, FL: HBJ Media Systems.

Roueche, John, Eileen Ely, and Suanne Roueche. 2001. In Pursuit of Excellence: The Community College of Denver. Washington, DC: Community College Press.

Roueche, John, and Suanne Roueche. 1993. Between a Rock and a Hard Place: The At-Risk Student in the Open Door College. Washington, DC: Community College Press.

Roueche, John, and Suanne Roueche. 1999. High Stakes, High Performance: Making Remedial Education Work. Washington, DC: American Assocation of Community Colleges.

Roueche, John, and Jerry Snow. 1977. Overcoming Learning Problems. San Francisco: JosseyBass.

Rudmann, Jerry. 1992. An Evaluation of Several Early Alert Strategies for Helping First Semester Freshmen at the Community College and a Description of the Newly Developed Early Alert Retention System (EARS) Software. Irvine, CA: Irvine Valley College.

Rutschow, Elizabeth Zachry, Lashawn Richburg-Hayes, Thomas Brock, Genevieve Orr, Oscar Cerna, Dan Cullinan, Monica Reid Kerrigan, Davis Jenkins, Susan Gooden, and Kasey Martin. 2011. Turning the Tide: Five Years of Achieving the Dream in Community Colleges. New York: MDRC.

Safran, Stephanie, and Mary G. Visher. 2010. "Case Studies of Three Community Colleges: The Policy and Practice of Assessing and Placing Students in Developmental Education Courses.” NCPR Working Paper. New York: MDRC.

Santa Rita, E., and J. B. Bacote. 1991. "The College Discovery Summer Program: Its Effects on Persistence and Academic Performance." New York: Bronx Community College. ERIC ED 338290.

Schuetz, Pam. 2002. "Instructional Practices of Part-Time and Full-Time Faculty." New Directions for Community Colleges 2002, 118: 39-46.

Schwartz, Wendy, and Davis Jenkins. 2007. Promising Practices for Community College Developmental Education: A Discussion Resource for the Connecticut Community College System. New York: Community College Research Center, Teachers College, Columbia University. 
Scrivener, Susan, Dan Bloom, Allen LeBlanc, Christina Paxson, Cecilia Elena Rouse, and Colleen Sommo with Jenny Au, Jedediah J. Teres, and Susan Yeh. 2008. A Good Start: Two-Year Effects of a Freshmen Learning Community Program at Kingsborough Community College. New York: MDRC.

Scrivener, Susan, Colleen Sommo, and Herbert Collado. 2009. Getting Back on Track: Effects of a Community College Program for Probationary Students. New York: MDRC.

Scrivener, Susan, and Michael J. Weiss with Jedediah J. Teres. 2009. More Guidance, Better Results? Three-Year Effects of an Enhanced Student Services Program at Two Community Colleges. New York: MDRC.

Shults, Christopher. 2000. Remedial Education: Practices and Policies in Community Colleges. Washington, DC: American Association of Community Colleges.

Simpson, Michele L., Norman A. Stahl, and Michelle Anderson Francis. 2004. "Reading and Learning Strategies: Recommendations for the 21st Century." Journal of Developmental Education 28, 2.

Sperling, Charmian B. 2009. "Massachusetts Community Colleges Developmental Education Best Policy and Practice Audit: Final Report." Boston: Massachusetts Community College Executive Office and Jobs for the Future.

Starks, G. 1994. "Retention and Developmental Education: What the Research Has to Say." Pages 19-27 in M. Maxwell (ed.), From Access to Success. Clearwater, FL: H\&H Publishing.

Strauss, Linda C., and J. Fredericks Volkwein. 2004. "Predictors of Student Commitment at Two-Year and Four-Year Institutions." Journal of Higher Education 75, 2: 203-227.

Taylor, A. 1996. "The Puente Program: Latino Student Outcomes in English 96 and 1A, $1993-$ 1995." San Francisco: City College of San Francisco, Office of Research, Planning and Grants . Web site: http://www.ccsf.edu/Offices/Research_Planning/planning/puente.htm.

Texas Higher Education Coordinating Board. 2009. Consolidated Annual Program Evaluation Report: THECB Funded Programs (Fiscal Year 2008). Austin: Texas Higher Education Coordinating Board.

Tinto, Vincent. 1975. "Dropout from Higher Educaction: A Theoretical Synthesis of Recent Research." Review of Education Research 45: 89-125.

Tinto, Vincent. 1987. Leaving College: Rethinking the Causes and Cures of Student Attrition. Chicago: University of Chicago Press.

Tinto, Vincent. 1997. "Classrooms as Communities: Exploring the Educational Character of Student Persistence." Journal of Higher Education 68, 6: 599-623.

Topping, K. J. 1996. "The Effectiveness of Peer Tutoring in Further and Higher Education: A Typology and Review of the Literature." Higher Education: The International Journal of Higher Education and Educational Planning 32: 321-345. 
Troen, Vivian, and Katherine C. Boles. 2003. Who's Teaching Your Children? Why The Teacher Crisis Is Worse than You Think and What Can Be Done About It. New Haven: Yale University Press.

Visher, Mary G., Kristin F. Butcher, and Oscar S. Cerna with Dan Cullinan and Emily Schneider. 2010. Guiding Developmental Math Students to Campus Services: An Impact Evaluation of the Beacon Program at South Texas College. New York: MDRC.

Visher, Mary G., Emily Schneider, Heather Wathington, and Herbert Collado. 2010. Scaling Up Learning Communities: The Experience of Six Community Colleges. New York: MDRC.

Washington State Board for Community and Technical Colleges. 2005. I-BEST: A Program Integrating Adult Basic Education and Workforce Training. Research Report No. 05-2. Olympia: Washington State Board for Community and Technical Colleges.

Weems, Gail H. 2002. "Comparison of Beginning Algebra Taught Onsite Versus Online." Journal of Developmental Education 26, 1: 10-18.

Weinstein, Claire Ellen, Gary Hanson, Lorrie Powdrill, Linda Roska, Doug Dierking, Jenefer Husman, and Erin McCann. 1997. "The Design and Evaluation of a Course in Strategic Learning." Web site: www.nade.net/documents/SCP97/SCP97.20.pdf.

Weiss, Michael J., Mary G. Visher, and Heather Wathington with Jedediah J. Teres and Emily Schneider. 2010. Learning Communities for Students in Developmental English: An Impact Study at Hillsborough Community College. New York: MDRC.

Weissman, Evan, Kristin F. Butcher, Emily Schneider, Jedediah Teres, Herbert Collado, and David Greenberg with Rashida Welbeck. 2011. Learning Communities for Students in Developmental Math: Impact Studies at Queensborough and Houston Community Colleges. New York: MDRC.

Weissman, Evan, Oscar Cerna, Christian Geckeler, Emily Schneider, Derek V. Price, and Tom J. Smith. 2009. Promoting Partnerships for Student Success: Lessons from the SSPIRE Initiative. New York: MDRC.

Xu, Yonghong, Stacey Hartman, Guillermo Uribe, and Reed Mencke. 2001. "The Effects of Peer Tutoring on Undergraduate Students' Final Scores in Mathematics." Journal of College Reading and Learning 32, 1: 22-31.

Zachry, Elizabeth M. with Emily Schneider. 2008. Promising Instructional Reforms in Developmental Education: A Case Study of Three Achieving the Dream Colleges. New York: MDRC.

Zachry, Elizabeth, and Genevieve Orr. 2009. Building Student Success from the Ground Up: A Case Study of an Achieving the Dream College. New York: MDRC.

Zavarella, Carol A., and Jan M. Ignash. 2009. "Instructional Delivery in Developmental Mathematics: Impact on Retention.” Journal of Developmental Education 32, 3: 2-8. 
Zeidenberg, Matthew, Davis Jenkins, and Juan Carlos Calcagno. 2007. "Do Student Success Courses Actually Help Community College Students Succeed?" CCRC Brief No. 36. Community College Research Center, Teachers College, Columbia University.

Zhao, Chun-Mei, and George D. Kuh. 2004. "Adding Value: Learning Communities and Student Engagement." Research in Higher Education 45, 2: 115-138.

Zuniga, Robin. 2008. Developmental Education Summer Bridge Program: Texas Higher Education Coordinating Board, Cross-Site Evaluation Final Report. Austin: Texas Higher Education Coordinating Board. 


\section{About MDRC}

MDRC is a nonprofit, nonpartisan social policy research organization dedicated to learning what works to improve the well-being of low-income people. Through its research and the active communication of its findings, MDRC seeks to enhance the effectiveness of social and education policies and programs.

Founded in 1974 and located in New York City and Oakland, California, MDRC is best known for mounting rigorous, large-scale, real-world tests of new and existing policies and programs. Its projects are a mix of demonstrations (field tests of promising new program approaches) and evaluations of ongoing government and community initiatives. MDRC's staff bring an unusual combination of research and organizational experience to their work, providing expertise on the latest in qualitative and quantitative methods and on program design, development, implementation, and management. MDRC seeks to learn not just whether a program is effective but also how and why the program's effects occur. In addition, it tries to place each project's findings in the broader context of related research - in order to build knowledge about what works across the social and education policy fields. MDRC's findings, lessons, and best practices are proactively shared with a broad audience in the policy and practitioner community as well as with the general public and the media.

Over the years, MDRC has brought its unique approach to an ever-growing range of policy areas and target populations. Once known primarily for evaluations of state welfare-to-work programs, today MDRC is also studying public school reforms, employment programs for exoffenders and people with disabilities, and programs to help low-income students succeed in college. MDRC's projects are organized into five areas:

- Promoting Family Well-Being and Child Development

- Improving Public Education

- Promoting Successful Transitions to Adulthood

- Supporting Low-Wage Workers and Communities

- Overcoming Barriers to Employment

Working in almost every state, all of the nation's largest cities, and Canada and the United Kingdom, MDRC conducts its projects in partnership with national, state, and local governments, public school systems, community organizations, and numerous private philanthropies. 
